Hileia dos Santos Barroso

Hidrocarbonetos policíclicos aromáticos (HPAs) em organismos marinhos da Baía do Almirantado,

\title{
Península Antártica
}

Tese apresentada ao Instituto
Oceanográfico da Universidade de São
Paulo como parte dos requisitos para
obtenção do título de Doutor em Ciências,
área de Oceanografia Química e Geológica

Orientadora: Prof $\stackrel{a}{\text {. Dra }}$. Márcia Caruso Bícego

São Paulo

2010 
Universidade de São Paulo Instituto Oceanográfico

\section{Hidrocarbonetos policíclicos aromáticos (HPAs) em organismos marinhos da Baía do Almirantado, Península Antártica}

\section{Hileia dos Santos Barroso}

Tese apresentada ao Instituto Oceanográfico da Universidade de São Paulo como parte dos requisitos para obtenção do título de Doutor em Ciências, área de Oceanografia Química e Geológica

Julgada em

Prof.(a). Dr.(a).:

Prof.(a). Dr.(a).:

Prof.(a). Dr.(a).:

Prof.(a). Dr.(a).:

Prof.(a).Dr.(a).: 
Dedico este trabalho aos meus filhos Emerson, Guilherme e Rose "filha de coração", aos meus pais e ao meu maravilhoso maridão Fernando. 
"Bom mesmo é ir à luta com determinação, abraçar a vida e viver com paixão, perder a classe e vencer com ousadia, porque o mundo pertence a quem se atreve e a vida é muito maravilhosa para ser insignificante"

(Charles Chaplin) 


\section{SUMÁRIO}

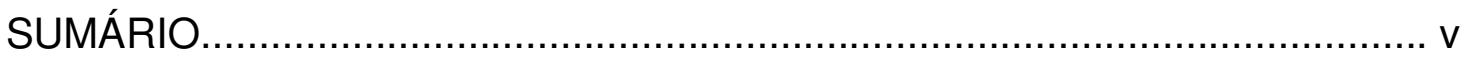

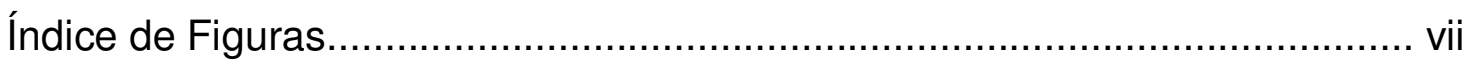

Índice de Tabelas......................................................................... xi

Índice de Abreviaturas.................................................................... XV

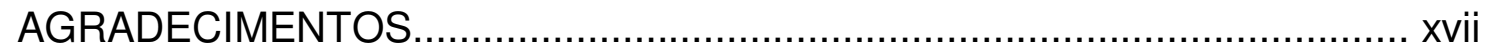

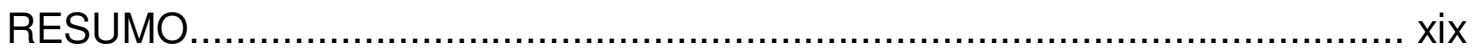

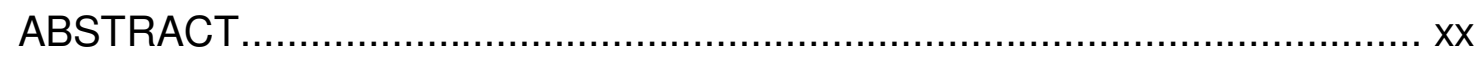

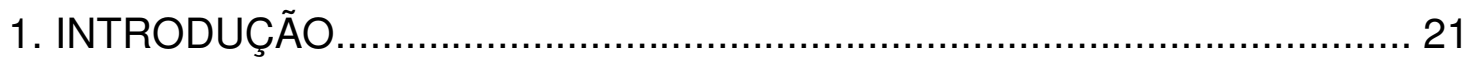

1.1. Contaminação por HPAs no ambiente marinho antártico..................... 22

1.2. Hidrocarbonetos policíclicos aromáticos............................................. 25

1.2.1. HPAs no ambiente marinho......................................... 31

1.2.2 HPAs na fauna marinha............................................. 34

1.3. HPAs na fauna marinha Antártica...............................................38

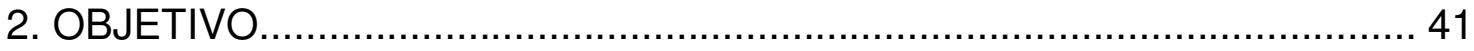

2.1 Objetivos específicos....................................................................... 41

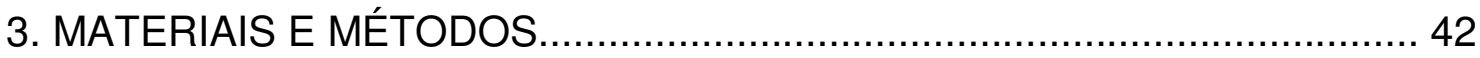

3.1. Caracterização da área de estudo.............................................. 42

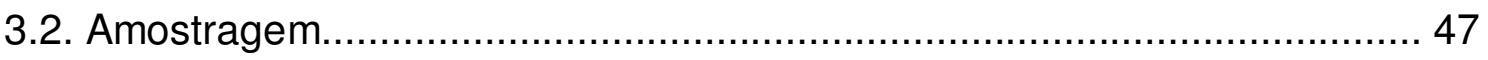

3.3. Caracterização das espécies estudadas...................................... 52

3.3.1 Espécies de invertebrados estudados........................................... 52

3.3.2 Espécies de vertebrados estudados................................................ 59

3.4. Procedimento metodológico das análises de HPAs..............................65

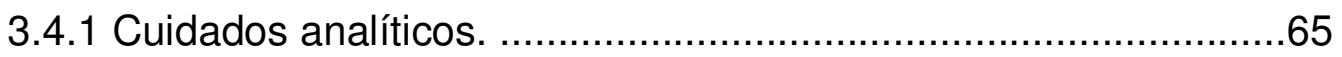


3.4.2 Reagente e soluções...........................................................66

3.4.3 Preparação das Amostras e extração.....................................67

3.4.4 Estimativa do peso lipídico.....................................................68

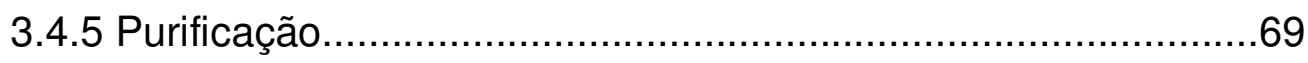

3.4.6 Análise cromatográfica.........................................................71

3.4.7 Controle de Qualidade Analítica...............................................71

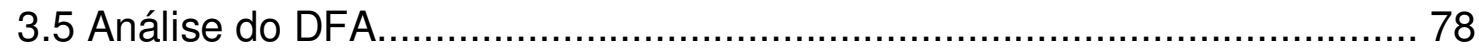

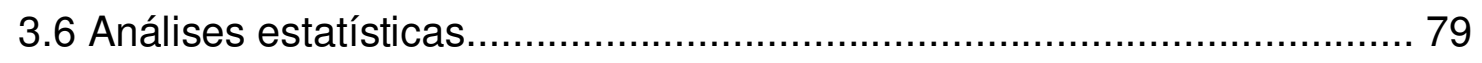

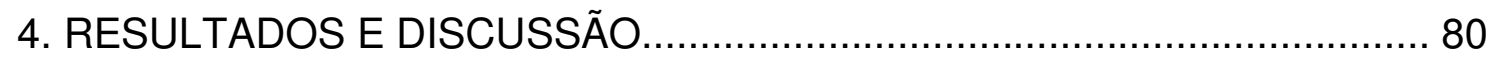

4.1. Hidrocarbonetos policíclicos aromáticos em invertebrados....................... 80

4.1.1 Hidrocarbonetos policíclicos aromáticos em moluscos.............. 80

4.1.2 Hidrocarbonetos policíclicos aromáticos em equinodermos...... 95

4.1.3 Hidrocarbonetos policíclicos aromáticos em crustáceos............107

4.1.4. Comparações entre as espécies de invertebrados................. 117

4.2. Hidrocarbonetos policíclicos aromáticos em vertebrados....................... 121

4.2.1 Hidrocarbonetos policíclicos aromáticos em peixes (Notothenia

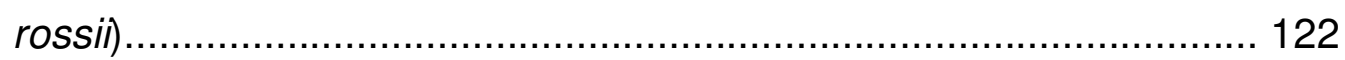

4.2.2 Hidrocarbonetos policíclicos aromáticos em aves................... 129

4.3. Comparação entre invertebrados, peixes e aves................................... 136

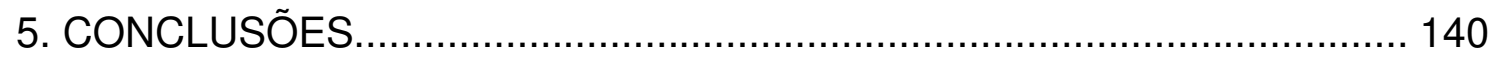

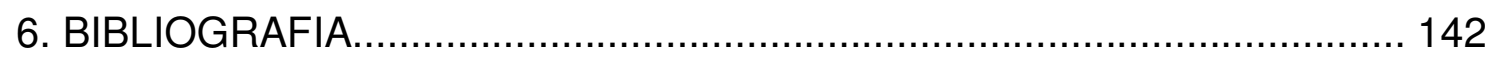




\section{LISTA DE FIGURAS}

Figura 1. Introdução e distribuição de contaminantes químicos nos sistemas aquáticos, enfatizando o acúmulo em peixes. 32

Figura 2. Biodegradação do naftaleno por Cunninghamella elagans. (adaptado de Rochkind et al. 1986.) 33

Figura 3. Estrutura do benzo(a)pireno mostrando a região de baía .36

Figura 4. Mecanismo metabólico do benzo[a]pireno. (1) benzo(a)pireno; (2) benzo(a)pireno-7,8-oxido areno; (3) benzo(a)pireno-7,8-diol; (4) benzo(a)pireno -7,8-diol-9,10-epóxido; (5) estrutura ligada ao DNA. (apud Locatelli, 2006; Yu, 2002) 36

Figura 5. Esquema das relações tróficas na zona costeira rasa da enseada Martel (Corbisier et al., 2004). 39

Figura 6. Localização da llha Rei George, Arquipélago Shetlands do Sul na Península Antártica. Fonte: Relatório Rede 2 (2006). .42

Figura 7. Localização da Baía do Almirantado, Ilha Rei George, Antártica e a Área Antártica Especialmente Gerenciada. (Fonte: Neto, 2001) .44

Figura 8. Localização das instalações científicas na Baía do Almirantado, llha Rei George dentro da AAEG. (Fonte: Neto, 2001) .46

Figura 9. Pontos de coleta das amostras de organismos na Baía do Almirantado.(1) EACF, (2) Refúgio I, (3) Ponta Plaza, (4) Ponta Yellow, (5) Ponta Ullmann, (6) Enseada Martel, (7) Ponta Hennequin, (8) Arctowisk, (9) Copacabana, (10) Ponta Demay, (11) Blue Dick, (12) Ilha Shag, (13) Chabrier Rocks. 
Figura 10. $P$. antarcticus são encontrados na Antártica e nas ilhas da América do Sul 61

Figura11. Distribuição circumpolar de $P$. adeliae no continente antártico, dentro dos limites da plataforma de gelo

Figura12. Distribuição circumpolar nas águas sub Antárticas e antárticas, evita gelo e costas continentais (exceto perto da península Antártica) 63

Figura 13. Fluxograma das etapas do método analítico utilizado para determinação dos compostos .70

Figura 14. Concentrações de HPAs totais, em $\mathrm{ng} \mathrm{g}^{-1}$ peso seco, obtidos em $Y$. eightsi, N. concinna e L. elliptica. 84

Figura 15. Composição dos parâmetros da $\Sigma$ HPAs (2-3 anéis) e $\Sigma$ HPAs (2-3 anéis) (\%) obtidos em Y. eightsi, N. concinna e L. elliptica. .86

Figura 16. Composição dos parâmetros da $\Sigma$ HPAs alquilados e $\Sigma$ HPAs não alquilados (\%) obtidos em Y. eightsi, N. concinna e L. elliptica. 86

Figura 17. Concentrações de HPAs individuais, em ng g ${ }^{-1}$ peso seco, obtidos em Y.eightsi, N. concinna e L. elliptica. .87

Figura 18. Concentrações obtidas no Diesel Fuel Arctic - DFA. 87

Figura 19. Valores de HPAs totais, em $\mathrm{ng} \mathrm{g}^{-1}$ peso seco, obtidos em $N$. concinna.

Figura 20. Cromatogramas obtidos nas análises do DFA e de uma amostra de N. concinna. 90

Figura 21. Concentrações de HPAs individuais, em ng g-1 peso seco, obtidos em N. concinna. 91

Figura 22. Concentrações de HPAs individuais, em $\mathrm{ng} \mathrm{g}^{-1}$ peso seco, obtidos em N. concinna e L. elliptica coletadas próximo a EACF .93 
Figura 23. Concentrações de HPAs individuais, em $\mathrm{ng} \mathrm{g}^{-1}$ peso seco, obtidos em N. concinna e Y. eightsi, coletadas em P. Ullmann. .95

Figura 24. Concentrações de HPAs totais, $\mathrm{ng} \mathrm{g}^{-1} \mathrm{ps}$, obtidos em $O$. victoria, $O$. validus e $S$. neumayeri. 98

Figura 25. Composição dos parâmetros da $\Sigma$ HPAs (2-3 anéis) e $\Sigma$ HPAs (2-3 anéis) (\%) detectados em $O$. victoria, $O$. validus e S. neumayeri. 99

Figura 26. Composição dos parâmetros da $\Sigma$ HPAs alquilados e $\Sigma H P A s$ não alquilados (\%) detectados em $O$. victoria, $O$. validus e $S$. neumayeri. 99

Figura 27. Concentrações de HPAs individuais, em $\mathrm{ng} \mathrm{g}^{-1}$ peso seco, obtidos em O. victoria, O. validus e $S$. neumayeri. 100

Figura 28. Concentrações de HPAs totais, $n g g^{-1} p s$, obtido em $S$. neumayeri. 101

Figura 29. Concentrações de HPAs individuais, $\mathrm{ng} \mathrm{g}^{-1} \mathrm{ps}$, obtido em $S$. neumayeri...... 102

Figura 30. Concentrações de HPAs individuais, $\mathrm{ng} \mathrm{g}^{-1} \mathrm{ps}$, obtido em $O$. validus. 103

Figura 31. Cromatograma obtido das análises de uma amostra de $O$. validus e do Diesel Fuel Arctic - DFA 104

Figura 32. Concentrações de HPAs individuais, $\mathrm{ng} \mathrm{g}^{-1} \mathrm{ps}$, obtido em $S$. neumayeri e Ophionotus victoriae, coletadas na EACF próximo ao heliponto. 106

Figura 33. Concentrações de HPAs individuais, $\mathrm{ng} \mathrm{g}^{-1} \mathrm{ps}$, obtido em $S$. neumayerie Odontaster validus, coletadas na EACF próximo ao heliponto...106 Figura 34. Concentrações de HPAs totais, em $\mathrm{ng} \mathrm{g}^{-1}$ peso seco, obtidas em $G$. antarcticus, S. polita, B. gigantea e E. superba. 


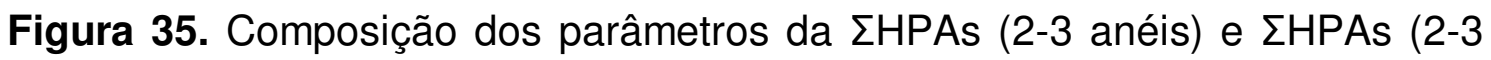
anéis) (\%) obtidos em G. antarcticus, S. polita, B. gigantes e E. superba......111 Figura 36. Composição dos parâmetros da $\Sigma$ HPAs alquilado e $\Sigma$ HPAs não alquilados (\%) obtidos em G. antarcticus, S. polita, B. gigantes e $E$. superba. 112

Figura 37. Concentrações de HPAs individuais, em $\mathrm{ng} \mathrm{g}^{-1}$ peso seco, obtidas em G. antarcticus, E. superba, B. gigantea e S. polita. 113

Figura 38. HPAs individuais detectados em $S$. polita. Concentrações em ng g ${ }^{-1}$ peso seco. 114

Figura 39. HPAs individuais detectados em E. superba. Concentrações em ng $\mathrm{g}^{-1}$ peso seco 115

Figura 40. HPAs individuais detectados em B. gigantea coletada na EACF. Concentrações em ng g ${ }^{-1}$ peso seco.

Figura 41. Concentrações de HPAs individuais em pinguins adélia, papua e antártico 135

Figura 42. Médias das concentrações de HPAs em skua, petrel gigante, pomba do cabo e gaivotão. .136 


\section{LISTA DE TABELAS}

Tabela 1. Nome (IUPAC) e a estrutura de alguns HPAs analisados nesse estudo. .26

Tabela 2. Propriedades físico-químicas de alguns HPAs (adaptado de Latimer \& Zheng, 2003) .28

Tabela 3. Carcinogenicidade, genotoxicidade e mutagenicidade de alguns HPA (Bouchez et al., 1996' a partir de dados do IARC, 1986) .29

Tabela 4. Classe/ordem, espécie, número de amostras e local de coleta das amostras de invertebrados. .50

Tabela 5. Espécie, nome comum, local, ano da coleta e o número de indivíduos (n) de peixes analisados .51

Tabela 6. Espécie, nome comum, local, mês e ano da coleta e número de indivíduos $(\mathrm{N})$ de aves analisadas .51

Tabela 7. Espécie, classe ou ordem, filo, habito alimentar e classificação ecológica dos invertebrados analisados neste estudo. .52

Tabela 8. Classificação taxonômica das aves analisadas neste estudo (Schreiber \& Burger, 2002) 60

Tabela 9. HPAs analisados neste trabalho e seu respectivo íon molecular. .67

Tabela 10. Recuperação dos surrogates e analitos padrões analisados do branco fortificado e a amostra fortificada no controle de qualidade. .74

Tabela 11. Resultados obtidos na análise do material de referência certificado SRM 2978 77

Tabela 12. O limite de detecção do método (LDM) para os compostos analisados. Dados apresentados em $\mathrm{ng} \mathrm{g}^{-1}$ 79 
Tabela 13. Concentrações de HPAs em moluscos obtidas por outros autores em diferentes locais da região Antártica

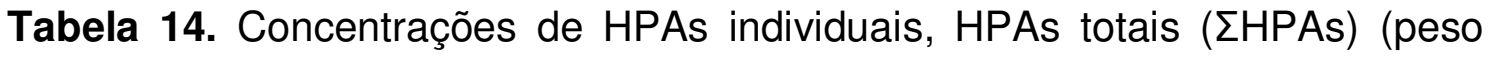
seco e peso úmido) soma de HPAs com 2 e 3 anéis aromáticos (LHPAs 2-3), soma de HPAs com 4 a 6 anéis aromáticos (इHPAs 4-6), soma de HPAs alquilados ( $\Sigma$ HPAs-alquil) em $\mathrm{ng} \mathrm{g}^{-1}$ peso seco, porcentagem de lipídios (\%) e porcentagem de umidade (\%) obtidos em moluscos. Os valores abaixo do Limite de detecção do método (LDM) estão indicados como "n.d.". .83

Tabela 15. Concentrações de HPAs em equinodermos analisados por outros autores em diferentes regiões na Antártica. .96

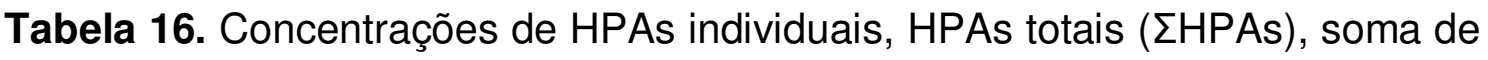
HPAs com 2 e 3 anéis aromáticos (EHPAs 2-3), soma de HPAs com 4 a 6

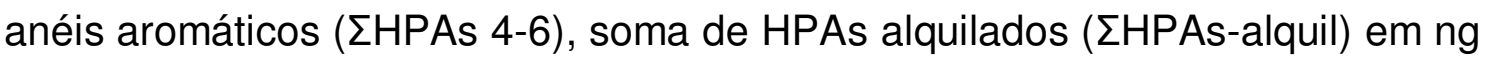
$\mathrm{g}^{-1}$ peso seco; porcentagem de lipídios (\%); porcentagem de umidade (\%); HPAs totais $\mathrm{ng} \mathrm{g}^{-1}$ peso úmido, obtidos em equinodermos. Os valores abaixo do limite de detecção do método (LDM) estão indicados como "n.d." 97

Tabela 17. Concentrações de HPAs em crustáceos analisados em diferentes regiões na Antártica 108

Tabela 18. Concentrações de HPAs individuais, HPAs totais (EHPAs) (peso seco e peso úmido), soma de HPAs com 2 e 3 anéis aromáticos (LHPAs 2-3), soma de HPAs com 4 a 6 anéis aromáticos (LHPAs 4-6), soma de HPAs alquilados ( $\Sigma$ HPAs-alquil) em $\mathrm{ng} \mathrm{g}^{-1}$ peso seco, porcentagem de lipídios (\%) e porcentagem de umidade (\%) obtidas em crustáceos. Os valores abaixo do limite de detecção do método (LDM) estão indicados como "n.d.". 110 
Tabela 19. Concentrações de HPAs totais ( $\Sigma$ HPAs) em $\mathrm{ng} \mathrm{g}^{-1}$ peso seco e peso úmido obtidos em invertebrados.

Tabela 20. Concentrações ( $\mu \mathrm{g} \mathrm{kg}^{-1}$ peso úmido) de HPAs em peixes provenientes de diferentes regiões da Antártica.

Tabela 21. Concentrações ( $\mathrm{ng} \mathrm{g}^{-1}$ peso seco) de HPAs em peixes provenientes de diferentes regiões da Antártica .123

Tabela 22. Concentrações de HPAs individuais, HPAs totais (EHPAs), soma de HPAs com 2 e 3 anéis aromáticos (LHPAs 2-3), soma de HPAs com 4 a 6

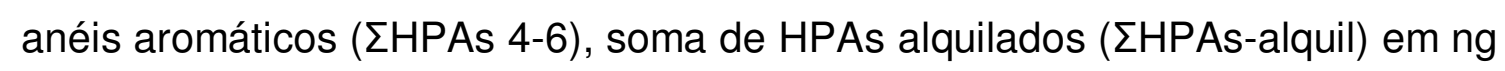
$\mathrm{g}^{-1}$ peso úmido; porcentagem de lipídios (\%); obtidos em músculo do peixe Notothenia rossii coletado em Punta Plaza. Os valores abaixo do Limite de detecção do método (LDM) estão indicados como "n.d.". .125

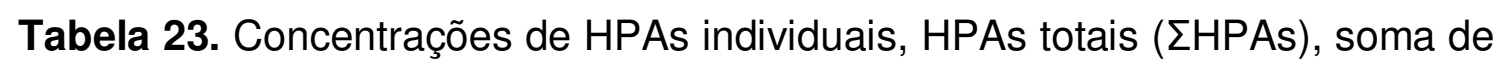
HPAs com 2 e 3 anéis aromáticos (LHPAs 2-3), soma de HPAs com 4 a 6

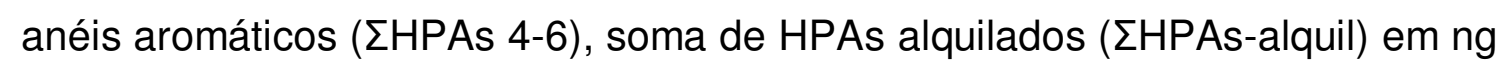
$\mathrm{g}^{-1}$ peso úmido; porcentagem de lipídios (\%); obtidos em músculo do peixe Notothenia rossii coletado em Copacabana. Os valores abaixo do Limite de detecção do método (LDM) estão indicados como "n.d.". 126

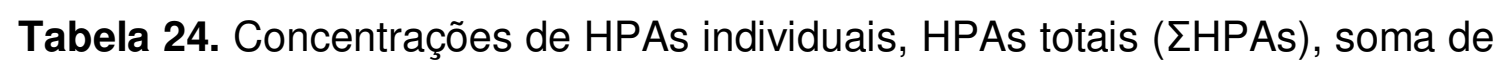
HPAs com 2 e 3 anéis aromáticos (LHPAs 2-3), soma de HPAs com 4 a 6 anéis aromáticos ( $\Sigma$ HPAs 4-6), soma de HPAs alquilados ( HPAs-alquil) em ng $\mathrm{g}^{-1}$ peso úmido; porcentagem de lipídios (\%); obtidos em músculo do peixe Notothenia rossii coletado próxima a estação polonesa Arctowisk. Os valores abaixo do Limite de deteç̧ão do método (LDM) estão indicados como "n.d." 
Tabela 25. Concentrações de HPAs individuais e os parâmetros: HPAs totais ( $\Sigma$ HPAs) em peso úmido (pu) e peso lipídico (pl), HPAs com 2 e 3 anéis

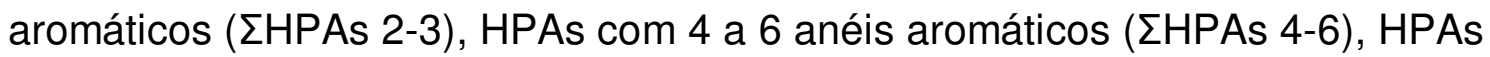

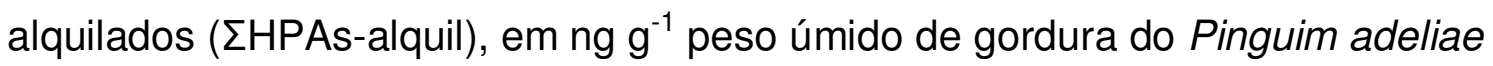
$(n=7)$ e a porcentagem de lipídios (\%). Os valores abaixo do Limite de detecção do método (LDM) estão indicados como "n.d.". 130

Tabela 26. Concentrações de HPAs individuais e os parâmetros: HPAs totais ( $\Sigma$ HPAs) em peso úmido (pu) e peso lipídico (pl), HPAs com 2 e 3 anéis

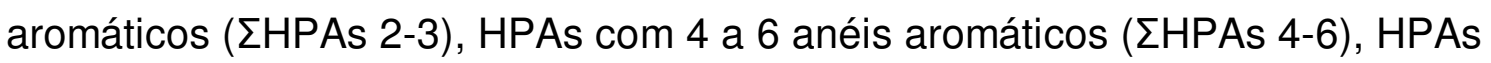
alquilados (इHPAs-alquil), em $\mathrm{ng} \mathrm{g}^{-1}$ peso úmido de gordura do Pygoscelis papua $(\mathrm{n}=2)$ e Pygoscelis antarcticus $(\mathrm{n}=5)$ e a porcentagem de lipídios (\%). Os valores abaixo do Limite de deteç̧ão do método (LDM) estão indicados como "n.d." 131

Tabela 27. Concentrações de HPAs individuais e os parâmetros: HPAs totais ( $\Sigma$ HPAs) em peso úmido (pu) e peso lipídico (pl), HPAs com 2 e 3 anéis

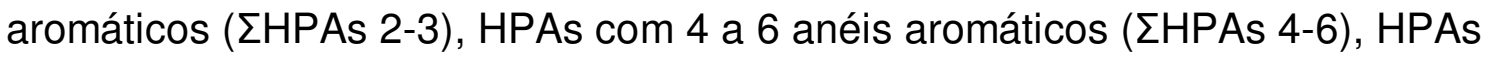
alquilados ( $\Sigma$ HPAs-alquil), em $\mathrm{ng} \mathrm{g}^{-1}$ peso úmido de gordura de Macronectes giganteus $(n=2)$, Catharacta sp. $(n=3)$, Daption capensis $(n=1)$ e Larus dominicanus $(n=1)$ e a porcentagem de lipídios (\%). Os valores abaixo do Limite de detecção do método (LDM) estão indicados como "n.d.". 132 


\section{LISTA DE ABREVIAÇÕES E SIGLAS}

¿HPAs - Somatória de Hidrocarbonetos Policíclicos Aromáticos

AAEG - Área Antártica Especialmente Gerenciada

AICE - Área de Interesse Científico Especial

BaP - Benzo(a)pireno

Bc - Branco

BF - Branco fortificado

CRM - Certified Reference Material

DFA - Diesel Fuel Arctic

EACF - Estação Antártica Brasileira Comandante Ferraz

ECA - Grupo de Ação do SCAR sobre Contaminação Ambiental na Antártica

GC/MS - Cromatografia gasosa acoplada a espectrômetro de massa

HPAs - Hidrocarbonetos Policíclicos Aromáticos

HPLC - Cromatografia em fase líquida de alta eficiência

IUPAC - International Union of Pure and Applied Chemistry

LDM - Limite de detecção de um método

MD - Duplicata da matriz

MF - Matriz fortificada

MOE - Material orgânico extraível

N - Número amostral

$\mathbf{N}_{2}$ - Nitrogênio

NS\&T - National Status and Trends

PE - Padrão externo

PI - Padrão interno 
PS - Peso Seco

PU - Peso Úmido

SCAR - Comitê Científico sobre Pesquisa Antártica

SRM - Standard Referência Material 


\section{AGRADECIMENTOS}

Agradeço Márcia Caruso Bícego pela orientação e oportunidade de completar mais uma etapa na minha vida.

À Rosalinda Montone pela oportunidade concedida e apoio.

Ao Rolf pela oportunidade de poder conviver com alguém com tanto a ensinar.

À Satie, ao Lourival, e ao Silvio por toda dedicação e profissionalismo, que fazem do LABQOM "o melhor laboratório".

Verinha por vários momentos agradáveis e palavras maravilhosas nos momentos difíceis.

As meninas da secretaria Ana Paula e Silvana pelos serviços prestados Ao pessoal da biblioteca Wagner, Cida e D. Ray pelo auxilio na pesquisa Meu especial agradecimento as amigas Josi, Juliana, Mariko e Ana Cecília por todo o auxilio durante esta caminhada, principalmente nas horas mais difíceis. Rafa e Juliana (que saudades!!!), Ana Cecília (a veterana do LABQOM), Caio "Bonitão" (que me batizou de "Hilary"), Caio Vini (pela aventura em Cuba e Costa Rica), Josi (ah!!! grande amiga, coração gigante), Salvador e Chukrut, Fer (amante das aves); Mariana (aquela que deu as costas pra lua); Mauro (o papai mais novo do lab); Edgar (seria um amigão, se não fosse Paraense!!!!), Eliete (pelas massas maravilhosas), Diego, aos são paulinos Renato (pelos cafézes) e Vini por sua colaboração, ao Patik (o marido da Lú) e ao Felipe pelos momentos de descontração.

A todos os colegas que participaram da XXIII/XXIV/XXV/XXVI Expedição Brasileira a Antártica (2004/2007) pelas amostras coletadas. 
Ao pessoal da bio: Sandrinha, Gabriel e a Monica Petti pelas amostras e sugestões sobre bentos.

A minha querida Maria Alice Armelin pela grande ajuda e apoio

Agradeço ao Conselho Nacional de Desenvolvimento Científico e Tecnológico (CNPQ) pela bolsa de doutorado

À Marinha do Brasil e Secretaria da Comissão Interministerial para os Recursos do Mar (SECIRM) pela logística que tornaram possível as expedições à Antártica.

Ao CNPq/PROANTAR, pelo apoio financeiro.

Agradeço também aos membros da banca pela contribuição e sugestão dispensada a esta tese.

E a todos àqueles que contribuíram de qualquer forma para este trabalho. 


\section{RESUMO}

As concentrações de HPAs foram analisadas em invertebrados (Laternula elliptica, Nacella concinna, Yoldia eightsi, Glyptonotus antarcticus, Serolis polita, Euphausia superba, Bovalia gigantea, Sterechinus neumayeri, Odontaster validus e Ophionotus victoriae), peixes (Notothenia rossii), e aves (Pygoscelis Adélia, P. papua, P. antarcticus, Macronectes giganteus, Catharacta sp. e Larus dominicanus) da Baía do Almirantado. As análises de HPAs foram realizadas através de GC/MS. A ocorrência de HPAs nas amostras indicou a biodisponibilidade destes compostos para os organismos da região. As concentrações de HPAs totais para os invertebrados $\left(3,09-174,4 \mathrm{ng} \mathrm{g}^{-1} \mathrm{pu}\right)$ foram maiores que em peixes $\left(0,97-58,9 \mathrm{ng} \mathrm{g}^{-1} \mathrm{pu}\right)$ e menores que em aves (60,1-6861,0 $\left.\mathrm{ng} \mathrm{g}^{-1} \mathrm{pu}\right)$, porém apresentaram similaridade entre si. As aves voadoras adultas apresentaram maiores concentrações que os pinguins. Compostos leves e alquilados predominaram em quase todas as amostras, principalmente os alquilnaftalenos. A principal fonte de HPAs para os organismos foi o DFA utilizado na EACF. Espécies predadoras/necrófagas apresentaram HPAs individuais diferentes das espécies suspensívoras/depositívoras. Não ocorreu relação entre o aumento da concentração de HPAs e o aumento do nível trófico dos grupos, e a absorção de HPAs pelas espécies sofreu a influência de fatores como metabolismo, fisiologia, hábito alimentar e teor de lipídio das espécies analisadas.

Palavras-chaves: HPAs, invertebrados, Notothenia rossii, aves, pingüins, Baía do Almirantado, Antártica. 


\begin{abstract}
The concentrations of PAHs had been analyzed in invertebrates (Laternula elliptica, Nacella concinna, Yoldia eightsi, Glyptonotus antarcticus, Serolis polita, Euphausia superba, Bovalia gigantea, Sterechinus neumayeri, Odontaster validus and Ophionotus victoriae), fish (Notothenia rossii) and birds (Pygoscelis adélia, P. papua, P. antarcticus, Macronectes giganteus, Catharacta sp. and Larus dominicanus) Admiralty Bay. The analyses of HPAs had been carried through GC/MS. The occurrence of PAHs in the samples indicated the bioavailability of these compounds for the organisms of the region. The concentration of total PAHs for the invertebrates $\left(3,09\right.$ to $\left.174,4 \mathrm{ng} \mathrm{g}^{-1} \mathrm{pu}\right)$ were higher than fish $\left(0,97\right.$ to $\left.58,9 \mathrm{ng} \mathrm{g}^{-1} \mathrm{pu}\right)$ and lower than in birds $(60,1$ $6861,0 \mathrm{ng} \mathrm{g}^{-1} \mathrm{pu}$ ) however, they had presented similarity between themselves. The adult flying birds had presented higher concentrations than penguins. Light and alkylated compounds had predominated in almost all samples, mainly the alkylnaphthalenes. The main source of PAHs for the organism was the DFA used in the EACF. Predators/necrophagous species had presented different individual PAHs from the feeder/deposit species. There was no relation between the increase of concentrations of PAHs and the increase of the trophic level of the groups, and the absorption of PAHs for the species had the influence of factors such as metabolism, physiology, alimentary habits and lipid content of the analyzed species.
\end{abstract}

Key words: PAHs, invertebrates, Notothenia rossii, birds, penguins, Admiralty Bay, Antarctica 


\section{INTRODUÇÃO}

No cenário atual em que todas as atenções estão voltadas para as questões ambientais, como as mudanças climáticas e a preservação de regiões prístinas, o futuro da região Antártica é uma das preocupações dos cientistas mundiais.

O continente antártico pode ser considerado um laboratório natural de grande importância científica, sendo os seus valores naturais constituintes de um precioso patrimônio de toda a humanidade, e que precisa ser preservado. Assim, foi criado o Protocolo ao Tratado da Antártica sobre Proteção ao Meio Ambiente conhecido como "Protocolo de Madri" que designou a Antártica como reserva natural, consagrada à paz e à ciência.

O Protocolo estabelece regras a serem seguidas na execução de pesquisas científicas e no apoio logístico às estações antárticas. Como princípio geral, "todas as atividades devem ser planejadas e conduzidas com base em informações suficientes para avaliar o possível impacto sobre 0 ambiente antártico e os ecossistemas associados, bem como no valor da Antártica para conduzir pesquisas científicas". Além de impor rigorosas regras à eliminação de resíduos e medidas preventivas contra a poluição marinha, também exige a avaliação do impacto ambiental das atividades desenvolvidas na região (ATCPs, 1993).

O Brasil, procurando seguir as regulamentações do Protocolo de Madri, juntamente com a Polônia, apresentou uma proposta que designa a Baía do Almirantado como a primeira Área Antártica Especialmente Gerenciada (AAEG) (ATCPs, 1996). Além de desenvolver na Estação Antártica Brasileira 
Comandante Ferraz (EACF) atividades importantes como o tratamento de seus resíduos, promove a retirando o lixo produzido.

A avaliação regional Antártica foi delegada ao Comitê Científico sobre Pesquisa Antártica (SCAR). O Grupo de Ação do SCAR revisou o relatório UNEP 2002 sobre Contaminação Ambiental na Antártica (ECA), no qual recomendou a criação de um banco de dados contendo todos os resultados obtidos no âmbito dos programas nacionais de monitoramento de impacto ambiental local das estações de pesquisa de acordo com o Protocolo de Madri (Fuoco et al., 2009).

\subsection{Contaminação por HPAs no ambiente marinho antártico.}

Na revisão do Grupo de Ação do SCAR sobre Contaminação Ambiental na Antártica (ECA 2009) foram apresentados resultados de trabalhos que relatam a ocorrência de contaminantes químicos no ambiente antártico. Portanto, o continente antártico mesmo sendo uma região remota e inóspita não está totalmente eximido de tais contaminantes.

A introdução de contaminantes nessa região pode ocorrer tanto através de atividades locais, como do transporte atmosférico de outras latitudes (Montone et al., 2003). Como a população na Antártica varia de aproximadamente 1000 indivíduos no inverno a 4000 durante o verão (COMNAP, 2008), a presença de contaminantes no meio ambiente Antártico geralmente está relacionada com as atividades humanas desenvolvidas, como a pesquisa científica, a logística, o tráfego de navios e veículos, o tratamento do lixo, o turismo e a pesca (Cripps \& Priddle, 1991). Todas estas atividades exigem consumo, abastecimento e armazenamento de combustível, 
possibilitando que pequenos vazamentos acidentais ocorram nas proximidades das estações científicas onde são realizadas estas operações (Cripps \& Priddle, 1991). O DFA (Diesel Fuel Arctic) é o combustível mais utilizado em regiões polares. As estações de pesquisa na Antártica consomem por ano aproximadamente 90 milhões de litros de combustíveis, sendo 64 milhões de litros de diesel contra 20 milhões de litros de querosene (Cripps \& Shears, 1997).

Como muitas estações científicas estão localizadas em zonas costeiras, a queima de combustíveis para produção de energia e transporte, a incineração de resíduos, o vazamento de óleo e escoamento do esgoto produzem inevitavelmente contaminação ambiental localizada nessa região (Bargagli, 2008).

Portanto, os contaminantes mais difundidos na Antártica resultam da utilização de produtos do petróleo (Cripps \& Priddle, 1991; Kennicutt et al., 1992; McDonald et al., 1992). O petróleo e seus derivados são constituídos principalmente por hidrocarbonetos, e entre estes estão os hidrocarbonetos policíclicos aromáticos (HPAs), que também podem ser originados na combustão incompleta do próprio petróleo e de outras matérias orgânicas.

Como os HPAs constituem uma ampla categoria de contaminantes locais, pesquisadores têm avaliado HPAs no ambiente antártico através das medidas de suas concentrações tanto em compartimentos abióticos (Weber \& Bícego, 1990; Kennicutt et al., 1992; McDonald et al., 1992; Martins et al., 2004; 2010; Bícego et al., 2009), como em compartimentos bióticos (Platt \& Mackie, 1980; Cripps, 1990; Kennicutt et al., 1991, 1992, 1995; McDonald et al., 1992, 1994; Curtosi et al., 2009). 
Análises de água coletada nas adjacências da llha Elefante (Weber \& Bícego, 1990) e da Baía do Almirantado, mesmo em baixas concentrações, mostraram a presença de HPAs no ambiente marinho antártico que foi atribuída a fontes locais (Bícego et al., 1996).

Kennicutt et al. (1995) analisou sedimentos adjacentes à base americana McMurdo e os teores de hidrocarbonetos foram semelhantes aos encontrados em alguns dos portos mais contaminados do mundo. Também foi observado um gradiente, sendo que a contaminação foi observada dentro de um raio de $1 \mathrm{~km}$ a partir da estação científica, e que as contribuições das fontes locais de contaminantes foram superiores ao transporte atmosférico a longa distância. A ocorrência e a determinação das fontes de HPAs na Baía do Almirantado foram estudadas através das análises de água e do sedimento por Bícego et al. (1996, 1998, 2002, 2003, 2009) e Martins et al. (2004).

A introdução de contaminantes na Baía do Almirantado, Ilha Rei George foi avaliada através da utilização de HPAs em sedimentos por Martins et al., 2010. Observaram que os maiores níveis de HPAs foram detectados nas camadas superiores dos testemunhos relacionados com os últimos 30 anos, refletindo o aumento da ocupação humana da área, que resultou em maior consumo de combustíveis fósseis, combustão da matéria orgânica e de derivados do petróleo. 


\subsection{Hidrocarbonetos policíclicos aromáticos}

Os HPAs constituem um grupo de compostos orgânicos que apresentam em sua estrutura molecular, basicamente, carbono e hidrogênio formando dois ou mais anéis aromáticos condensados com cinco ou seis átomos de carbonos (Tabela 1), podendo estar ou não substituídos por radicais alquilas (metil, etil, dimetil, trimetil, etc.) ou conter heteroátomos.

A partir da estrutura molecular do HPA, pode-se obter informações sobre o nível de degradação desses compostos, as prováveis fontes predominantes, e o seu destino no meio ambiente.

Os HPAs que apresentam em sua estrutura molecular até três anéis aromáticos, alquilsubstituintes e/ou de heteroátomos, geralmente são oriundos do petróleo (Neff 1979) e denominados petrogênicos. Os principais HPAs presentes no petróleo bruto são o naftaleno, o fenantreno e seus derivados alquilados (UNEP, 1991).

Por outro lado, os HPAs que apresentam mais de três anéis aromáticos em sua estrutura molecular e baixo grau de alquilação são principalmente originados na combustão (Neff, 1979) e denominados pirogênicos. São mais resistentes à biodegradação devido a sua forte interação com o material particulado consolidado, que funciona como uma proteção ao ataque microbiano (Bouloubassi \& Saliot, 1993). 
Tabela 1. Nome (IUPAC) e a estrutura de alguns HPAs analisados nesse estudo.

\begin{tabular}{|c|c|c|c|}
\hline Nome (IUPAC) & $\begin{array}{l}\text { Estrutura } \\
\text { HPAs }\end{array}$ & $\begin{array}{l}\text { Nomenclatura } \\
\text { (IUPAC) }\end{array}$ & $\begin{array}{l}\text { Estrutura } \\
\text { HPAs }\end{array}$ \\
\hline Naftaleno & & Fluoranteno & \\
\hline 2-metilnaftaleno & & Pireno & \\
\hline 1-metilnaftaleno & & benzo(a)antraceno & \\
\hline 2,6-dimetilnaftaleno & & Criseno & \\
\hline 2,3,5-trimetilnaftaleno & & benzo(b)fluoranteno & \\
\hline Bifenil & & Benzo $(k)$ fluoranteno & \\
\hline Acenaftileno & & benzo(e)pireno & \\
\hline Acenafteno & & benzo(a)pireno & \\
\hline Fluoreno & & Perileno & \\
\hline Fenantreno & & Indeno $(1,2,3-c, d)$ pireno & \\
\hline Antraceno & & dibenzo $(a, h)$ antraceno & \\
\hline 1-metilfenantreno & & benzo $(g, h, i)$ perileno & \\
\hline
\end{tabular}


As principais fontes antropogênicas de HPAs são a combustão do petróleo, do carvão e do gás natural para fins industriais e domésticos, bem como a combustão interna de um motor e a incineração de lixo. A indústria petrolífera e os destroços dos petroleiros são importantes fontes de HPAs em determinadas áreas. Os incêndios florestais, sendo ou não consequência da atividade humana, são também fontes significativas de HPAs. Podendo ser originados em sínteses feitas por algumas bactérias, plantas e fungos, ou liberados por processos naturais como vulcanismo, emanação natural de petróleo marinho e por diagênese de precursores naturais (Law \& Biscaia, 1994). Em geral, a contaminação ambiental é composta por uma mistura complexa de HPAs, e não por compostos isolados (Walker, 2001).

Devido à fusão dos anéis adjacentes, os HPAs tendem a ter uma estrutura planar rígida. Como mostrado na Tabela 2, eles têm solubilidade baixa em água e lipofilicidade acentuada: quanto maior o peso molecular, maior é a lipofilicidade e maior é o log $\mathrm{K}_{\text {ow. }}$. A pressão de vapor está inversamente relacionada ao peso molecular, assim, quanto maior o peso molecular, menor a pressão de vapor. Os HPAs não têm grupos funcionais e são quimicamente inertes, contudo, podem sofrer degradação fotoquímica ou biológica (Ehrhardt et al., 1992).

A importância ambiental do estudo dos hidrocarbonetos aromáticos se deve aos efeitos toxicológicos, mutagênicos e carcinogênicos de alguns desses compostos e que podem afetar os organismos marinhos (Payne et al., 1988; Vandermeulen et al., 1985; IARC, 1983). A Tabela 3 mostra os resultados de testes realizados para as atividades carcinogênica, genotóxica e mutagênica. 
Tabela 2. Propriedades físico-químicas de alguns HPAs (adaptado de Latimer \& Zheng, 2003).

\begin{tabular}{|c|c|c|c|c|}
\hline HPAs & №. de anéis & $\begin{array}{c}\text { Peso molecular } \\
\left(\mathrm{g} \mathrm{mol}^{-1}\right)\end{array}$ & $\begin{array}{c}\text { Solubilidade em } \\
\left.\text { água (mg L }{ }^{-1}\right)\end{array}$ & $\log K_{\text {ow }}$ \\
\hline Naftaleno & 2 & 128 & 31 & 3,37 \\
\hline Acenaftileno & 3 & 150 & 16,1 & 4,00 \\
\hline Acenafteno & 3 & 154 & 3,8 & 3,92 \\
\hline Fluoreno & 3 & 166 & 1,9 & 4,18 \\
\hline Fenantreno & 3 & 178 & 1,1 & 4,57 \\
\hline Antraceno & 3 & 178 & 0,045 & 4,54 \\
\hline Fluoranteno & 4 & 202 & 0,26 & 5,22 \\
\hline Pireno & 4 & 202 & 0,132 & 5,18 \\
\hline Benz[a]antraceno & 4 & 228 & 0,011 & 5,91 \\
\hline Criseno & 4 & 228 & 0,0020 & 5,86 \\
\hline Benzo(a)fluoranteno** & 5 & 252 & 0,0012 & 6,12 \\
\hline Benz(b)fluoranteno & 5 & 252 & 0,0015 & 5,80 \\
\hline Benz(k)fluoranteno & 5 & 252 & 0,0008 & 6,00 \\
\hline Benzo(a)pireno & 5 & 252 & 0,0038 & 6,04 \\
\hline Indeno[1,2,3-cd]pireno & 6 & 278 & 0,062 & 6,58 \\
\hline Dibenzo(a,h)antraceno & 5 & 278 & 0,0006 & 6,75 \\
\hline Benzo(g,h,i)perileno & 6 & 268 & 0,00026 & 6,50 \\
\hline
\end{tabular}


Tabela 3. Carcinogenicidade, genotoxicidade e mutagenicidade de alguns HPA (IARC, 1986).

\begin{tabular}{|c|c|c|c|}
\hline HPAs & Carcinogenicidade & Genotoxicidade & Mutagenicidade \\
\hline Fluoreno & 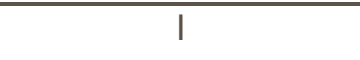 & $L$ & - \\
\hline Fenantreno & I & L & + \\
\hline Antraceno & $\mathrm{N}$ & $\mathrm{N}$ & - \\
\hline Fluoranteno & $\mathrm{N}$ & L & + \\
\hline Pireno & $\mathrm{N}$ & L & + \\
\hline Benzofluorenos & I & I & $?$ \\
\hline Benzofluorantenos & $S$ & I & + \\
\hline Benzo(a)antraceno & $S$ & S & + \\
\hline Criseno & L & L & + \\
\hline Benzo(e)pireno & I & L & + \\
\hline Benzo(a)pireno & $S$ & S & + \\
\hline Perileno & I & I & + \\
\hline Indeno(1,2,3-c,d)pireno & $S$ & 1 & + \\
\hline Dibenzo(a,c)antraceno & L & S & + \\
\hline Dibenzo(a,h)antraceno & $S$ & S & + \\
\hline Dibenzo(a,j)antraceno & L & 1 & + \\
\hline Benzo(g,h,i)perileno & I & 1 & + \\
\hline \multicolumn{4}{|c|}{$\begin{array}{l}\text { S = suficientes; } \\
\mathrm{I}=\text { insuficientes; } \\
\mathrm{L}=\text { = limitados; } \\
\mathrm{N}=\text { não carcinogênico. } \\
\text { Genotoxicidade foi avaliada através dos testes de deterioração do DNA; aberração cromossômica e } \\
\text { mutagenicidade. }\end{array}$} \\
\hline
\end{tabular}


De acordo com a sua estrutura química, os HPAs são pouco reativos e parecem expressar pouca toxicidade. Por outro lado, processos químicos ou bioquímicos podem transformá-los em produtos mais reativos e consequentemente mais tóxicos. A incorporação de oxigênio no anel do HPA tem um efeito de polarização, levando à produção de espécies reativas, tais como íon carbônio. Esta é a razão pela qual os HPAs tornam-se mais tóxicos para peixes, após a exposição à radiação ultravioleta (Oris e Giesy, 1987).

Os HPAs voláteis, embora permaneçam menos tempo no ambiente do que os HPAs de maior massa molecular, são potencialmente tóxicos aos organismos aquáticos, como peixes (Middaugh \& Whiting, 1995; Couillard et al., 2005); estrelas-do-mar (Davis et al., 1981) e crustáceos (Cucci \& Epifanio, 1979; Johns \& Pechenik, 1980). Muitos dos compostos com genotoxicidade acentuada contêm 3 a 7 anéis aromáticos fundidos, por exemplo, Benzo (a) pireno (Tabela 1 e Tabela 3), que é um dos mais estudados (Walker, 2001).

O estudo da toxicidade dos HPAs teve origem no trabalho de Morimura et al. (1964) sobre o efeito dos HPAs em culturas de tecidos humanos. Harrison e Raabe (1967) mostraram que o benzo(a)pireno (BaP) pode ser letal para culturas de Escherichia coli. A partir de então, foram realizados vários trabalhos relacionados às suas propriedades carcinogênicas e mutagênicas.

O estudo realizado por Varanasi et al. (1989) apresentou a primeira evidência da formação do produto cancerígeno em fígados de peixe expostos ao BaP "in vivo".

Em invertebrados os HPAs podem interferir na fertilização e reprodução, (Lewis et al., 2008; Mazurová et al., 2008), além de causar problemas imunológicos (Payne \& Fancey, 1989) e endócrinos (Mazurova et 
al., 2008). Em concentrações elevadas, podem apresentar toxicidade aguda, tanto para peixes como para invertebrados bentônicos (Bellas et al., 2008; Mäenpää et al., 2009), sendo que em peixes podem se acumular em ovos, sendo transferidos para as larvas após a eclosão destes (Goksoyr et al., 1991).

\subsubsection{HPAs no ambiente marinho}

O ambiente marinho recebe diariamente HPAs liberados de diversas fontes, como efluentes industriais e domésticos, deposição atmosférica, escoamento superficial e subterrâneo, que se distribuem por toda a coluna d'água e sedimentos (Figura 1). Uma das principais classes de contaminantes são os hidrocarbonetos aromáticos, constituintes dos derivados do petróleo e produtos de combustão incompleta. São contaminantes persistentes no ambiente, devido à sua propriedade hidrofóbica e baixa volatilidade dos compostos com alto peso molecular (Harvey, 1997). 


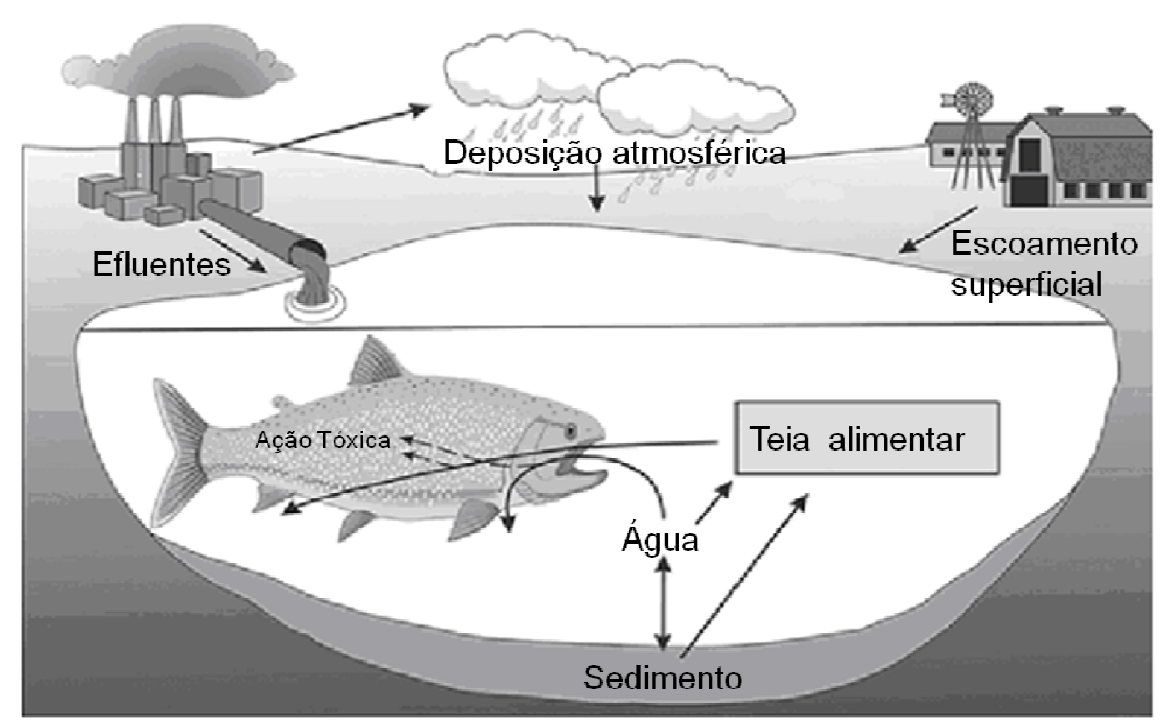

Figura 1. Introdução e distribuição de contaminantes químicos nos sistemas aquáticos, enfatizando o acúmulo em peixes.

Os HPAs, ao serem introduzidos no ambiente marinho, sofrem particionamento: os de baixo peso molecular, com maiores pressões de vapor, tendem a se volatilizar (Payne et al., 1992; Smith et al., 2006). Os HPAs menos voláteis e mais solúveis são adsorvidos ao material particulado e depositados no sedimento (Cullen et al., 1994), onde podem sofrer modificações químicas e bioquímicas muito lentas (Payne et al., 1988; Oliver \& Niimi, 1988; Haritash \& Kaushik, 2009), além de poderem ser redisponibilizados para a coluna d'água e, consequentemente, para a biota.

Os HPAs podem sofrer modificações estruturais que alteram a sua interação, distribuição e tempo de permanência no ambiente, onde a solubilização, a volatilização, a adsorção, a degradação biológica (Figura 2) e a fotoquímica (Ehrhardt et al., 1992; Haritash \& Kaushik, 2009) são os principais processos que regulam estas alterações. Por sua vez, a intensidade destes 
processos é determinada pelas propriedades físico-químicas (Tabela 1) dos hidrocarbonetos (Jaffé, 1991; Neff, 1979).

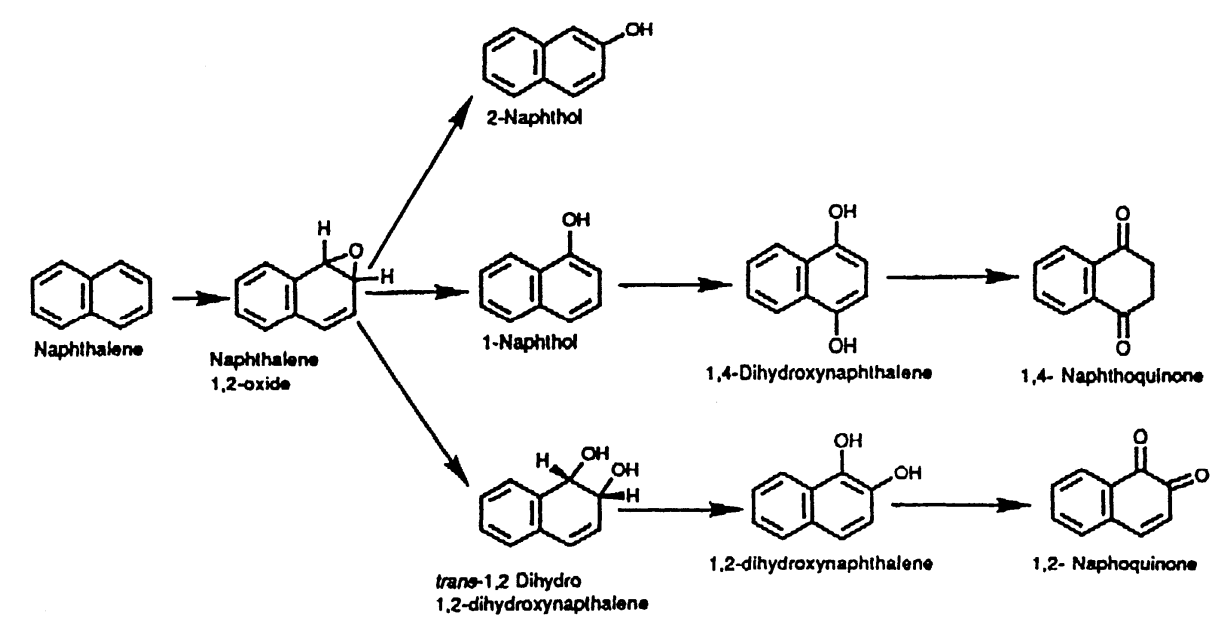

Figura 2. Biodegradação do naftaleno por Cunninghamella elagans. (Adaptado de Rochkind et al. 1986)

O coeficiente de partição octanol-água $\left(\mathrm{K}_{\mathrm{ow}}\right)$ é uma propriedade que pode ser usada para verificar a afinidade de compostos com a matéria orgânica em matrizes ambientais. Quanto maior o valor do logaritmo desse coeficiente, mais hidrofóbica é a substância. Assim, os HPAs que apresentam valores de Log $\mathrm{K}_{\text {ow }}$ acima de 1, no ambiente marinho, tendem a associar-se ao material orgânico particulado em suspensão e ao sedimento.

Os HPAs são compostos hidrofóbicos e pouco solúveis em água, sendo o naftaleno o composto com maior solubilidade $\left(31 \mathrm{mg} \mathrm{L}^{-1}\right)$, como mostra a Tabela 2. Com o aumento do número de anéis aromáticos em sua estrutura e, consequentemente, da massa molecular do composto, a solubilidade diminui chegando a um valor de $0,00026 \mathrm{mg} \mathrm{L}^{-1}$ para o benzo(ghi)perileno. 
A persistência dos HPAs, no meio ambiente, também varia com a massa molecular, sendo que os mais leves são degradados mais facilmente (meia vida no sedimento: 9 e 43 dias para o naftaleno e antraceno, respectivamente), enquanto os mais pesados são mais persistentes (valores de meia vida em solos e sedimentos atingem alguns anos) (CETESB, 2001).

Em altas latitudes, os contaminantes tendem a ser imobilizados devido às baixas temperaturas; no entanto, ainda podem ser redistribuídos por alguns processos físicos de transporte, como as correntes e as ondas (Kennicutt II et al, 1995).

\subsubsection{HPAs na fauna marinha}

Dos HPAs liberados no ambiente marinho, uma parte deles é solubilizada na água e outros tendem a adsorver-se rapidamente ao material em suspensão e ao sedimento, podendo assim ser absorvidos por organismos marinhos através da água, do sedimento contaminado e/ou da cadeia alimentar. Porém, a absorção de HPAs depende da sua biodisponibilidade, bem como da fisiologia dos organismos envolvidos (Meador et al., 1995).

Os principais processos envolvidos na absorção de HPAs por organismos são: bioconcentração, bioacumulação e biomagnificação. A bioconcentração é a absorção de HPAs somente da água, através da respiração e ou pele, resultando em uma concentração de HPAs maior no organismo do que na água. Bioacumulação é a absorção de HPAs por organismos aquáticos através de várias rotas de exposição, como alimentação, respiração e absorção dérmica. E a biomagnificação é o aumento da concentração de contaminantes nos organismos através da alimentação ao 
longo da cadeia trófica (Mackay \& Fraser, 2000).

Devido ao seu caráter lipofílico, os HPAs têm grande facilidade de passar pelas membranas celulares, permitindo o acúmulo em diferentes tecidos (Albers, 1994). Glândula mamária e tecido adiposo, por suas características físicas e químicas, poderiam ser considerados significativos depósitos de estocagem para os HPAs (Modica et al. 1983). No entanto, mamíferos, aves e peixes são capazes de metabolizar parte dos hidrocarbonetos ingeridos, devido ao sistema oxidase bem desenvolvido, onde HPAs não alquilados são rapidamente metabolizados (Varanasi et al., 1989). Os metabólitos produzidos no fígado são secretados na bile e armazenados na vesícula biliar antes de serem excretados (Au et al., 1999). Assim, nos vertebrados, a maioria dos HPAs absorvidos são eficientemente biotransformados e excretados, enquanto nos invertebrados a capacidade metabólica é inferior (Walker, 2001).

No mecanismo metabólico do benzo(a)pireno, devido a ausência de grupos funcionais, o ataque metabólico primário está limitado à oxidação, catalisada pelo citocromo P450. A posição do ataque oxidativo no sistema de anéis (regiosseletividade) depende da forma em que o P450 está ligado ao HPA. Para a ativação metabólica de carcinógenos, como o benzo(a)pireno, os átomos de oxigênio são inseridos em posições próximas a região de baía (Walker, 2001), que é um local com uma maior probabilidade de sofrer reação (Jerina et al. 1978) (Figura 3). O benzo(a)pireno-7,8-diol-9,10-epóxido é apontado como o metabólito final de efeito carcinogênico e mutagênico, devido ao seu alto poder de ligar-se covalentemente ao grupo 2-amino da guanina na fita dupla de DNA (Conney, 1982) (Figura 4). 
Região de baía

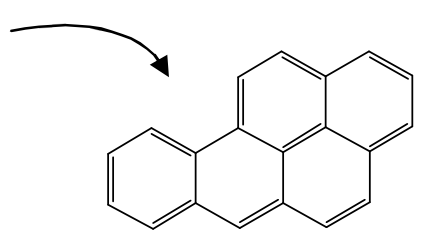

Figura 3. Estrutura do benzo(a)pireno mostrando a região de baía.

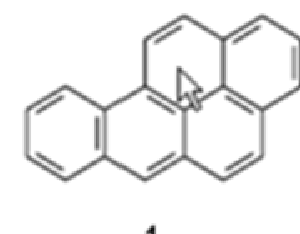

1
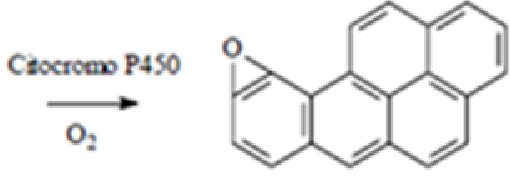

2

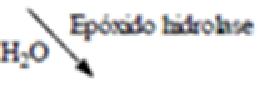<smiles></smiles>

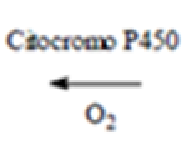<smiles>Oc1c2c3ccc1cccc-2ccc1c2c(O)ccc(c32)C=1</smiles>

3<smiles></smiles>

Figura 4. Mecanismo metabólico do benzo[a]pireno. (1) benzo(a)pireno; (2) benzo(a)pireno-7,8-oxido areno; (3) benzo(a)pireno-7,8-diol; (4) benzo(a)pireno -7,8diol-9,10-epóxido; (5) composto ligado ao DNA (apud Locatelli, 2006; Yu, 2002). 
O citocromo P450 monooxigenases não é bem representado em moluscos e em muitos outros invertebrados aquáticos. Portanto, organismos que vivem muito próximos à fonte de contaminação ou que não possuem sistemas de detoxificação bem desenvolvidos tendem a bioacumular os HPAs mais intensamente (Albers, 1995, 1994).

Os peixes podem converter rapidamente até $99 \%$ dos HPAs em metabólitos no prazo de 24 horas de absorção, alterando o padrão e as concentrações nos diversos tecidos (Varanasi et al., 1989). A meia vida de HPAs, em peixes, é geralmente muito curta, de seis a nove dias para fluoreno, fenantreno, antraceno e fluoranteno (Meador et al., 1995).

As concentrações de HPAs em organismos podem ser influenciadas por fatores como, temperatura da água (Jovanovich \& Marion, 1987), mudanças no comportamento do organismo, qualidade nutricional e estresse, consumo de oxigênio (Lemke \& Kennedy, 1997) e sua fisiologia (Perugini et al., 2007).

Os HPAs podem ser bioacumulados por organismos de baixos níveis tróficos por não possuírem um sistema de metabolização eficiente. Por por outro lado, os organismos de níveis tróficos superiores, facilmente biotransformam esses compostos, não ocorrendo biomagnificação dos HPAs ao longo da cadeia alimentar (Eisler, 1983). Wan et al., 2007 sugeriram que a diluição trófica dos HPAs na cadeia alimentar marinha, pode ser devido a um resultado combinado da baixa eficiência de assimilação e uma eficiente transformação metabólica nos níveis tróficos superiores. Perugini et al., 2007 observaram que nenhuma correlação significativa foi encontrada entre nível 
trófico e o nível de HPAs totais, indicando que não ocorre taxa de acúmulo de HPAs em organismos marinhos.

O estudo dos HPAs na fauna marinha é essencial para estimar a biodisponibilidade desses contaminantes no ambiente, bem como os efeitos toxicológicos da poluição ambiental em animais aquáticos, pois estudos baseados exclusivamente nas concentrações de contaminantes em sedimento e água não são suficientes para essa finalidade (Verweij et al., 2004).

\subsection{HPAs na fauna marinha Antártica}

$\mathrm{Na}$ Antártica, a zona marinha costeira, onde a cobertura de gelo varia ao longo do ano, há uma biomassa bentônica maior do que em locais mais profundos, o que sugere uma relação mais estreita entre a produtividade pelágica e a bentônica, especialmente em algumas partes da península Antártica (Grebmeier \& Barry, 1991). Além da fonte pelágica, em ambientes costeiros polares há outras fontes primárias de alimento, como as microalgas bentônicas, as microalgas associadas ao gelo e as macroalgas, que também contribuem com matéria orgânica para aquelas comunidades (Dayton et al., 1986; Kaehler et al., 2000; Dunton, 2001; Povero et al., 2001; Corbisier et al., 2004).

Utilizando a razão isotópica Corbisier et al. (2004) identificaram na zona costeira rasa da enseada Martel, baía do Almirantado, três fontes primárias de matéria orgânica: o fitoplâncton, o microfitobentos e fragmentos de macroalgas (Figura 5). Este estudo mostrou que, a trama trófica nesta região, é mais complexa do que em áreas oceânicas, onde a matéria orgânica de origem pelágica é a principal fonte de alimento. 


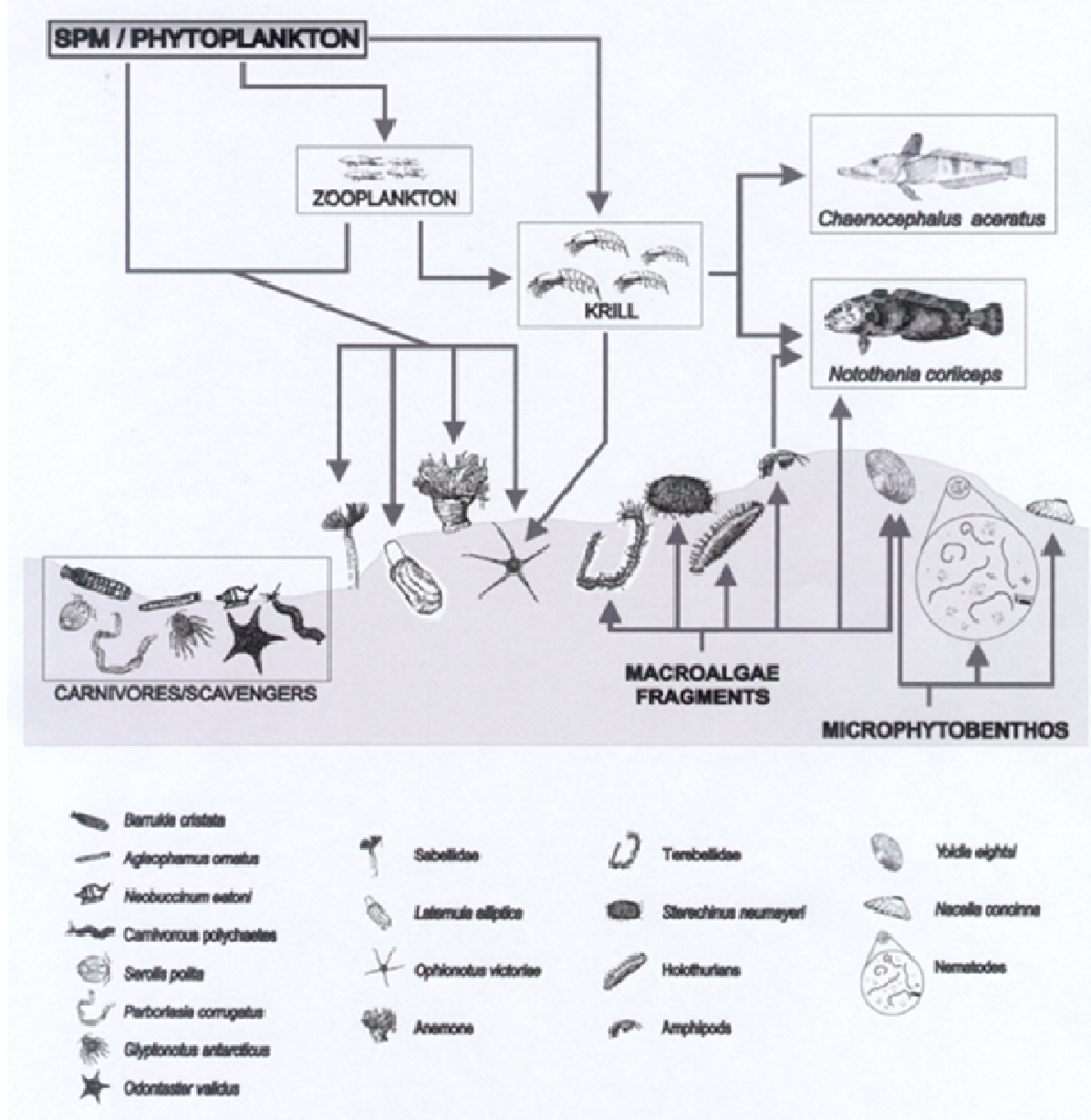

Figura 5. Esquema das relações tróficas na zona costeira rasa da enseada Martel (Corbisier et al., 2004).

Durante as últimas três décadas, tem sido publicada uma série de trabalhos sobre contaminantes persistentes nos organismos da Antártica, visando à determinação de linha de base e monitoramentos para áreas marinhas mais contaminadas. Porém, as análises de HPAs em diversos organismos da trama trófica antártica ainda são limitadas.

Poucos trabalhos realizaram medidas de concentração de HPAs em equinodermos (Clark \& Law, 1981; Platt \& Mackie, 1981) e em crustáceos (Clark \& Law, 1981; Cripps, 1989; Cripps, 1990). 
Moluscos foram analisados para monitorar a extensão espacial e a duração da exposição de HPAs em resposta a incidentes (derrames) em regiões antárticas (Cripps \& Shears, 1997; Kennicutt et al., 1991; Kennicutt \& Sweet, 1992), bem como para verificar a contaminação crônica de fonte local nas proximidades de estações científicas (Kennicutt et al., 1992; McDonald et al, 1994; Cripps \& Priddle, 1995; Curtosi et al., 2009).

Entre os vertebrados, os peixes foram os mais estudados (Platt \& Mackie, 1980; Cripps, 1990; Kennicutt II et al., 1991; McDonald et al., 1992; Kennicutt Il et al., 1995; Curtosi et al., 2009).

Kennicutt et al. (1991) analisaram as penas de aves antárticas em áreas contaminadas por um acidente com óleo; e Taniguchi, et al. (2009), em um trabalho na fauna da Baía do Almirantado, realizou medidas de HPAs em gordura de aves e obteve as maiores concentrações de HPAs em Catharacta antarctica (skua), o que foi relacionado com seus hábitos migratórios. Por outro lado, a detecção de HPAs em pinguins (Pygoscelis antarctica, P.adeliae e P.papua), que são aves mais restritas à região antártica, confirmaram a existência desses compostos no ecossistema antártico e sua incorporação na cadeia trófica.

$\mathrm{Na}$ Baía do Almirantado, área de estudo deste trabalho, foram realizadas medidas de concentrações de HPAs em sedimento, água (Weber \& Bícego, 1990; Bícego et al., 1996; 2002; 2009 ; Martins et al., 2004; 2010) e em aves marinhas (Taniguchi et al., 2009) e mostraram a presença desses compostos nessa região. Por outro lado, ainda não há registros na literatura sobre medidas dos níveis de HPAs em invertebrados e peixes para esta região. Portanto, é muito importante a investigação de HPAs em organismos de 
diferentes níveis da trama trófica antártica, a fim de conhecer o comportamento desses compostos na fauna marinha da Baia do Almirantado.

\section{OBJETIVO}

O objetivo deste trabalho foi estudar a biodisponibilidade de HPAs para a fauna marinha da área de estudo, e verificar a distribuição desses compostos em diferentes níveis tróficos.

\subsection{Objetivos específicos}

- Quantificar as concentrações de HPAs em organismos marinhos de diferentes níveis tróficos coletados na Baía do Almirantado

- Comparar intraespecificamente as concentrações de HPAs

- Comparar interespecificamente as concentrações de HPAs

- Observar se há alguma relação entre as concentrações de HPAs e o nível trófico dos organismos analisados. 


\section{MATERIAIS E MÉTODOS}

\subsection{Caracterização da área de estudo}

A Baía do Almirantado, área de estudo deste trabalho, está localizada na Ilha Rei George, que faz parte do Arquipélago Shetlands do Sul, localizado a $130 \mathrm{~km}$ a noroeste da Península Antártica, entre as latitudes 61ํㅡ e 63ํ30’ S e longitudes $53^{\circ} 55^{\prime}$ e $62^{\circ} 50^{\prime}$ W, região ocidental do Continente Antártico (Figura 6). A llha Rei George, a maior do Arquipélago, tem uma área de $1250 \mathrm{~km}^{2}$,

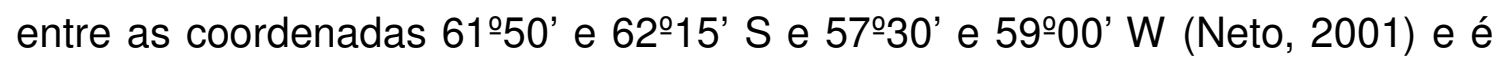
coberta por uma calota de gelo sendo mais de $90 \%$ glaciares. As áreas livres de gelo e zonas costeiras incluem diversificada flora e fauna, como pinguins, focas, petréis e vegetação (musgo, fungos e liquens) (SCAR, 2009).

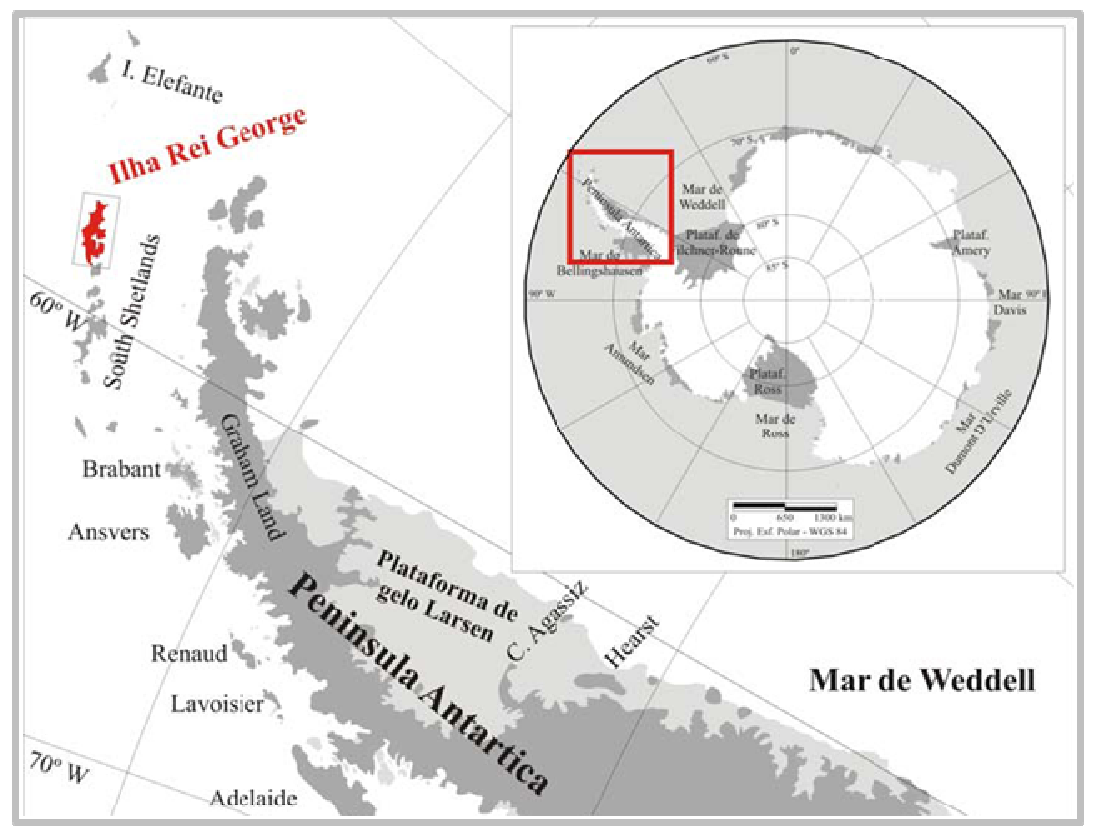

Figura 6. Localização da llha Rei George, Arquipélago Shetlands do Sul na Península Antártica. Fonte: Relatório Rede 2 (2006). 
Ao norte da llha Rei George está o estreito de Drake, região onde se encontram as águas do Atlântico e do Pacifico, e ao sul localiza-se o Estreito de Bransfield, que separa as Shetlands do Sul da Península Antártica (Figura $6)$.

A Baía do Almirantado possui três grandes enseadas, as enseadas Mackellar, Martel e a enseada Ezcurra (Figura 7). Suas águas ocupam 138 km² com profundidades variáveis, desde regiões rasas até locais com profundidades que superam 550 metros, profundidade típica de regiões de fiordes que constitui a baía do Almirantado com o estreito de Bransfield (INCTAntártica, 2009).

A circulação da água dentro da Baía do Almirantado é bastante fragmentada, regida basicamente pelas marés e trocas com as águas do Estreito de Bransfield. As marés são irregulares, sendo que a direção do movimento das águas muda irregularmente em intervalo de 5 a 14 horas. As águas provenientes do Estreito de Bransfield entram pela enseada Ezcurra ressurgindo à superfície ao encontrar elevações de fundo. Retornam ao Estreito de Bransfield pelo lado leste da baía (Rakuza-Swazczewski, 1980). Estima-se que as águas da Baía do Almirantado são trocadas num período de uma a duas semanas (Rakuza-Swazczewski, 1995).

O perfil de fundo é variável, alternando quedas e elevações progressivas. Esta diversidade topográfica é responsável pelo surgimento de várias áreas de ressurgências, caracterizadas por um aporte substancial de silicatos (Rakuza-Swazczewski, 1980).

No sec. XX a Baía do Almirantado foi utilizada por baleeiras, mas desde 1996 foi designada uma Área Antártica Especialmente Gerenciada 
(AAEG) (McGonigal, 2009), designação proposta pelo Brasil e Polônia (ATCPs, 1996). A AAEG da Baía do Almirantado compreende a área imediatamente dentro da bacia de drenagem glacial da Baía do Almirantado, incluindo a Área de Interesse Científico Especial N. 8 (AICE N.8), no oeste da baía (Figura 7), onde a atividades de turismo são proibidas (Neto, 2001).

O Comitê Científico sobre Pesquisa Antártica (SCAR) recomendou a criação de um banco de dados com resultados obtidos sobre impacto ambiental local de estações de pesquisa, de acordo com o Protocolo de Madri (Fuoco et al., 2009).

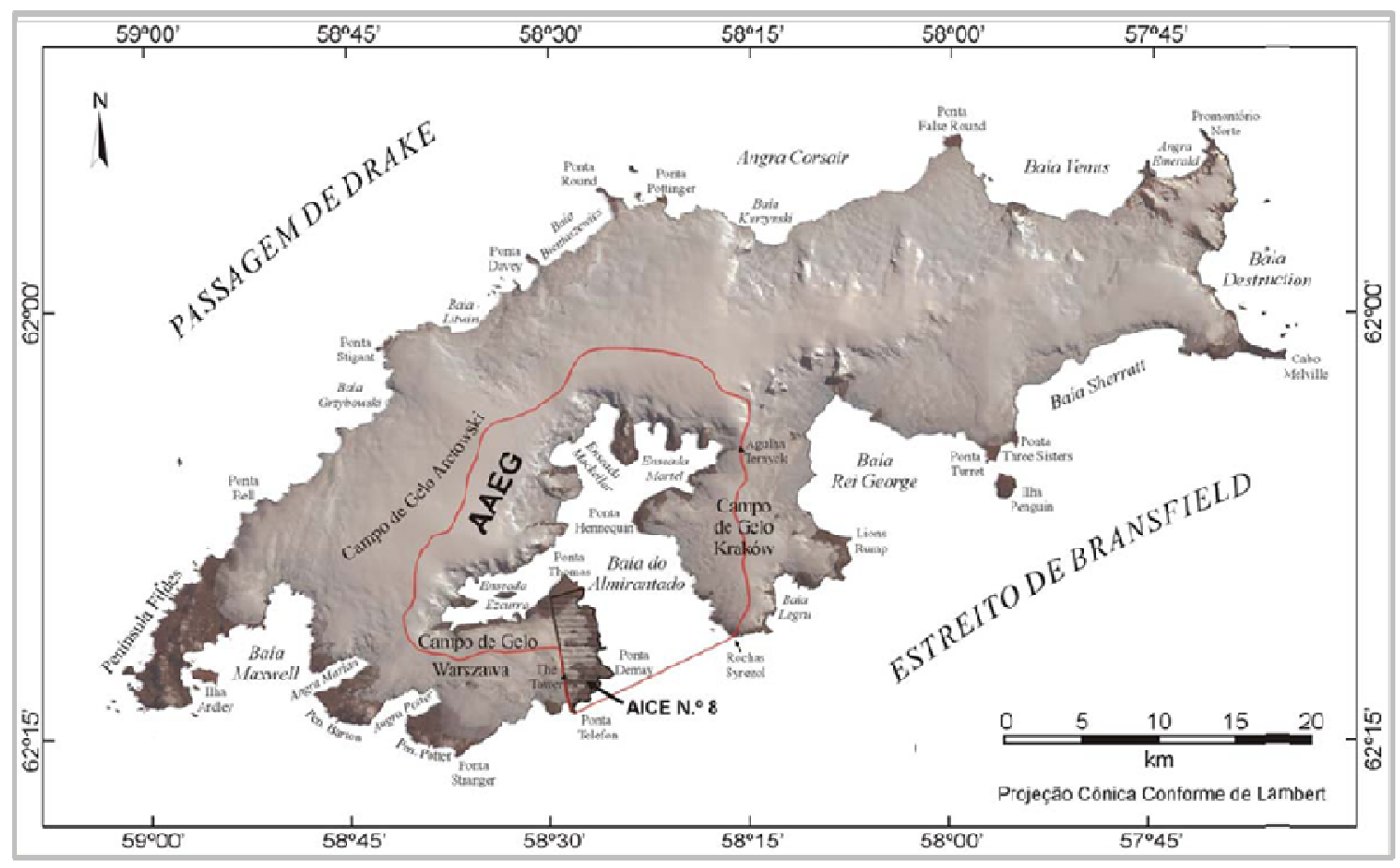

Figura 7. Localização da Baía do Almirantado, Ilha Rei George, Antártica e a Área Antártica Especialmente Gerenciada. (Fonte: Neto, 2001). 
A Baía do Almirantado é densamente ocupada por atividades de pesquisa e de logística, além de ser frequentemente visitada por turistas, dadas as facilidades de acesso a essa região da Antártica. Encontram-se, nessa área, as instalações científicas de cinco países (Brasil, Polônia, Peru, Equador e Estados Unidos) (Figura 8).

A estação peruana (Machu Picchu), localizada na Ponta Crépin, entrada da enseada Mackellar, atualmente é utilizado apenas para as operações de verão (COMNAP, 2001). Uma pequena estação norte-americana (Copacabana, antiga Pieter J. Lenie), localizada na Ponta Llama, na margem oeste da baía e um refúgio equatoriano localizado em Ponta Hennequin, são utilizados apenas no verão. Existem também dois refúgios poloneses, em Angra Paradise, próximo à Ponta Demay e ao Vale Itália, na enseada Ezcurra, além de dois refúgios e dois módulos de pesquisa brasileiros na península Keller.

A estação polonesa (Henry Arctowski) foi construída em fevereiro de 1977, e localizada na entrada da Enseada Ezcurra, consome um total de cerca de 100.000 litros de óleo diesel por ano e opera o ano inteiro. Arctowski possui acomodações para 70 pessoas no verão e 20 no inverno, tanques de combustível revestido duplamente com capacidade total de 1000 toneladas, garagens para botes e veículos terrestres, totalizando uma área ocupada de aproximadamente $100.000 \mathrm{~m}^{2}$ (ATCPs, 1996).

A EACF foi criada no verão de 1984, situada na Península Keller, na enseada Martel (Figura 12). É uma estação de médio porte com uma população que varia de 40 a 60 pessoas no verão e de 10 a 15 pessoas durante o inverno. É mantida por seis geradores e utiliza anualmente 320.000 
litros de DFA, armazenados em 17 tanques com paredes duplas de aço, que são abastecidos no verão. O consumo médio mensal de aproximadamente 23 toneladas de combustível nos geradores a diesel representa um risco potencial de liberação direta de hidrocarbonetos no ambiente (Bícego et al., 2009).

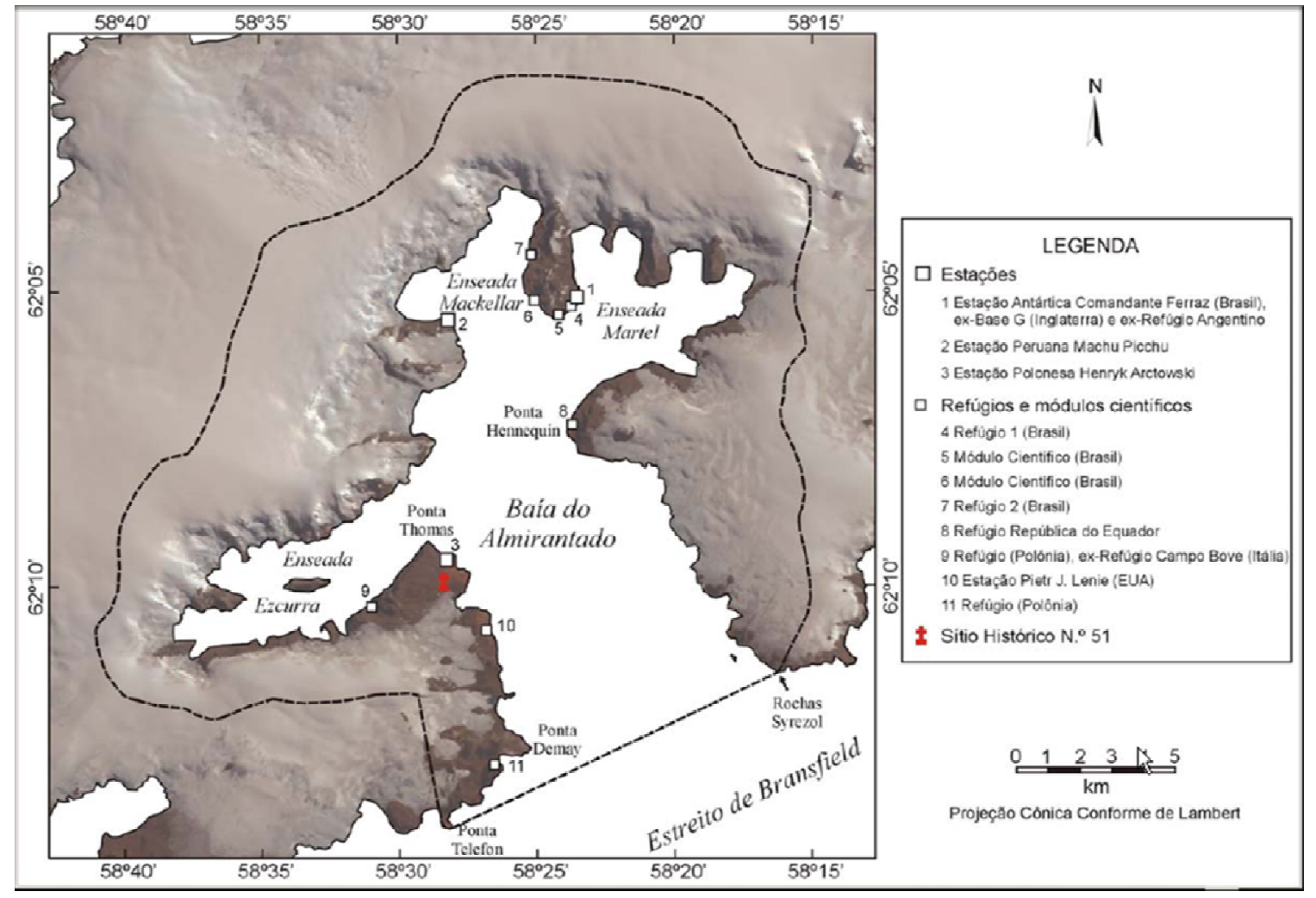

Figura 8. Localização das instalações científicas na Baía do Almirantado, Ilha Rei George dentro da AAEG (Fonte: Neto, 2001). 
Os contaminantes mais difundidos na Antártica provêm dos produtos do petróleo (Cripps \& Priddle, 1991; Kennicutt et al., 1992; McDonald et al., 1992), pois todas as atividades realizadas nessa região, principalmente nas estações de pesquisa, utilizam combustíveis fósseis como fonte de energia, que por sua vez são constituídos por hidrocarbonetos, inclusive HPAs. Portanto, a contaminação de HPAs é mais alta perto de tanques de combustível, aterros, heliponto e áreas onde ocorre o reabastecimento (Cripps \& Priddle, 1991). Assim, a zona entremarés é a mais vulnerável à contaminação de HPAs e o local mais provável de exposição crônica a longo prazo.

\subsection{Amostragem}

Em oceanografia, a coleta das amostras é uma etapa que exige tempo, oportunidades e custos, principalmente quando envolve a fauna marinha de uma região remota e inóspita, como a Antártica. Assim, as dificuldades de coleta foram intensas, o que impossibilitou a obtenção das mesmas espécies em todos os pontos de coletas. As amostragens foram realizadas nos verões de 1993, 1995, 2004, 2005, 2006 e 2007 em 13 pontos distribuídos ao longo da Baía do Almirantado mostrados na Figura 9. 


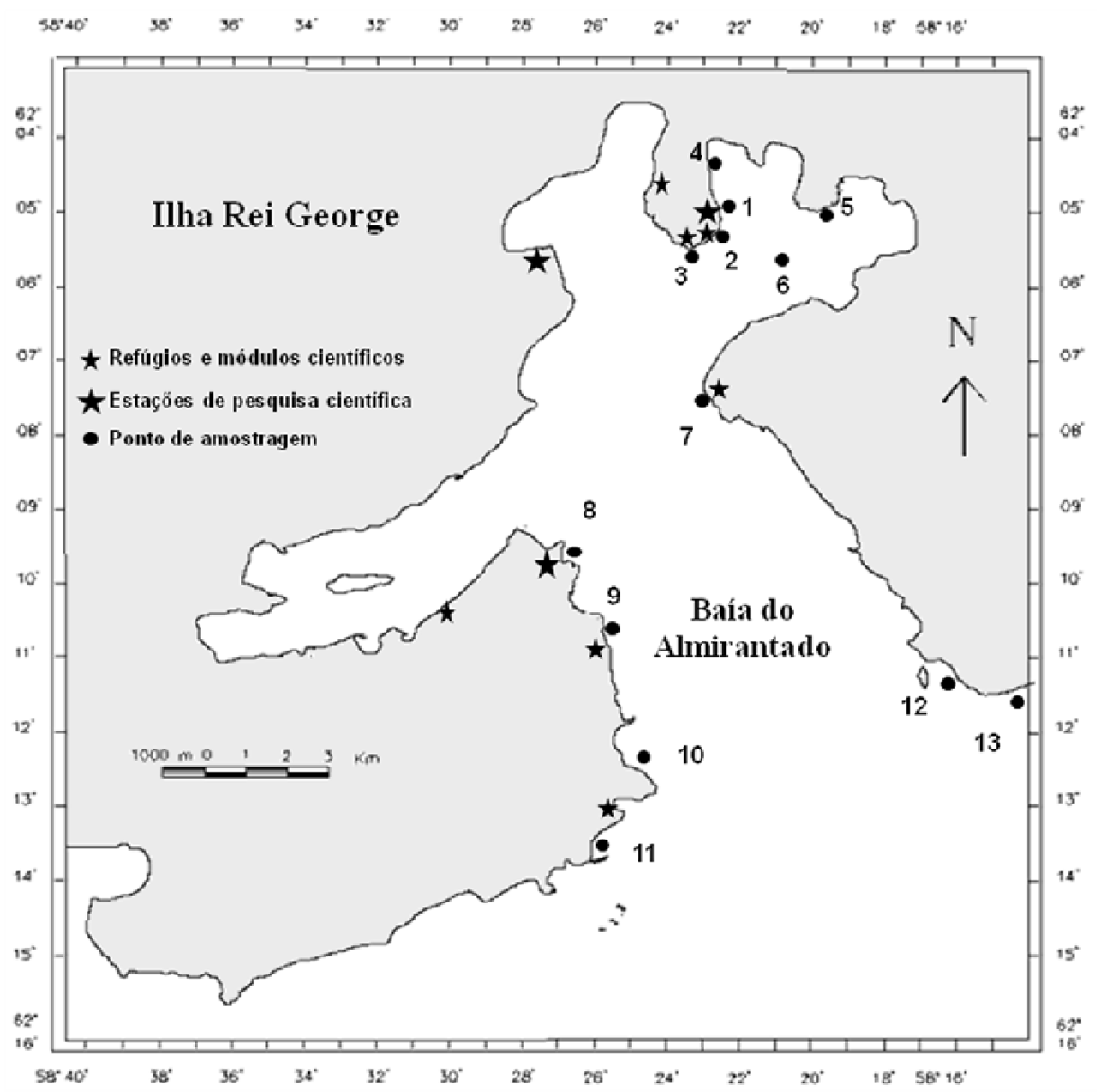

Figura 9. Pontos de coleta das amostras de organismos na Baía do Almirantado.(1) EACF, (2) Refúgio I, (3) Ponta Plaza, (4) Ponta Yellow, (5) Ponta Ullmann, (6) Enseada Martel, (7) Ponta Hennequin, (8) Arctowisk, (9) Copacabana, (10) Ponta Demay, (11) Blue Dick, (12) Ilha Shag, (13) Chabrier Rocks. 
Foram analisadas dez espécies de invertebrados e onze espécies de vertebrados (Tabela 4, 5 e 6). Os animais bentônicos pequenos (Yoldia eightsi, Nacella concinna, Serolis polita, Bovallia gigantea) foram coletados utilizandose um pegador do tipo Van Veen. Os bentônicos maiores (Glyptonotus antarcticus, Odontaster validus, Sterechinus neumayeri, Ophionotus victoria, Laternula elliptica) foram coletados com draga, rede ou com mergulhador. $\mathrm{O}$ krill e os peixes foram capturados com redes manuais. As amostras de gordura de aves e mamíferos foram coletadas de animais encontrados mortos.

Foram analisadas 24 amostras de invertebrados divididos em 8 amostras de equinodermatas, 8 de moluscos e 8 de crustáceos, distribuídas de acordo com a Tabela 4. As amostras de vertebrados somaram 47 exemplares, das quais 26 foram de peixes e 21 de aves (Tabelas 5 e 6), totalizando 71 amostras entre vertebrados e invertebrados (Tabelas 4, 5 e 6).

As análises de invertebrados foram feitas em amostras compostas dos animais inteiros, enquanto que nos vertebrados foram analisados o músculo de peixes e a gordura de aves. 
Tabela 4. Classe/ordem, espécie, número de amostra composta e local de coleta das amostras de invertebrados.

\begin{tabular}{|c|c|c|c|}
\hline Classe/ordem & Local & Ano & Amostras \\
\hline \multicolumn{4}{|l|}{ Ophiuróidea } \\
\hline Ophionotus Victoria & Punta Ullmann & 2004 & 1 \\
\hline \multicolumn{4}{|l|}{ Asteróidea } \\
\hline \multirow[t]{2}{*}{ Odontaster validus } & EACF (heliponto) & 2006 & 2 \\
\hline & Ponta Hennequim & 2007 & \\
\hline \multicolumn{4}{|l|}{ Echinóidea } \\
\hline \multirow[t]{5}{*}{ Sterechinus neumayeri } & Ponta Yellow & 2005 & 5 \\
\hline & EACF (tanque) & 2005 & \\
\hline & Refúgio I & 2005 & \\
\hline & Ponta Ullmann & 2006 & \\
\hline & EACF (heliponto) & 2006 & \\
\hline \multicolumn{4}{|l|}{ Bivalvia } \\
\hline Laternula elliptica & EACF & 2004 & 1 \\
\hline Yoldia eightsi & Ponta Ullmann & 2006 & 1 \\
\hline \multicolumn{4}{|l|}{ Gastropoda } \\
\hline \multirow[t]{6}{*}{ Nacella concinna } & Ponta Plaza & 1993 & 6 \\
\hline & EACF (tanque) & 1995 & \\
\hline & Ponta Demay & 2004 & \\
\hline & EACF & 2005 & \\
\hline & Blue Dick & 2005 & \\
\hline & Ponta Ullmann & 2006 & \\
\hline \multicolumn{4}{|l|}{ Crustacea/Isopoda } \\
\hline \multirow{2}{*}{ Glyptonotus antarcticus } & EACF & 2005 & 2 \\
\hline & Ponta Ullmann & 2006 & \\
\hline Serolis polita & EACF & 2005 & 3 \\
\hline \multicolumn{4}{|l|}{ Crustacea /Amphipoda } \\
\hline Bovallia gigantea & EACF & 2005 & 1 \\
\hline \multicolumn{4}{|l|}{ Crustacea/Euphausiaceae } \\
\hline \multirow[t]{2}{*}{ Euphausia superba } & EACF & 2004 & 2 \\
\hline & Enseada Martel & 2006 & \\
\hline Total & & & 24 \\
\hline
\end{tabular}


Tabela 5. Espécie, nome comum, local, ano da coleta e o número de indivíduos (n) de peixes analisados.

\begin{tabular}{ccccc}
\hline \multicolumn{1}{c}{ Espécie } & Nome comum & Local & Ano & $\mathbf{n}$ \\
\hline Peixes & & & & \\
Notothenia rossii & Bacalhau Antártico & Arctowski & 2006 & 10 \\
Notothenia rossii & Bacalhau Antártico & Copacabana & 2007 & 9 \\
Notothenia rossii & Bacalhau Antártico & Ponta Plaza & 2007 & 7 \\
\hline Total & & & & $\mathbf{2 6}$ \\
\hline
\end{tabular}

Tabela 6. Espécie, nome comum, maturidade, local, ano da coleta e número de indivíduos (n) de aves analisadas.

\begin{tabular}{|c|c|c|c|c|c|}
\hline Espécie & Nome comum & Maturidade & Local & Ano & $\mathbf{N}$ \\
\hline \multicolumn{6}{|l|}{ Pinguins } \\
\hline Pygoscelis antarcticus & Pinguim Antártico & Adulto & $\begin{array}{c}\text { Chabrier } \\
\text { Rocks }\end{array}$ & 2004 & 1 \\
\hline Pygoscelis antarcticus & Pinguim Antártico & - & Demay Point & 2005 & 1 \\
\hline Pygoscelis antarcticus & Pinguim Antártico & Adulto & Shag Island & 2006 & 1 \\
\hline Pygoscelis antarcticus & Pinguim Antártico & Filhote & $\begin{array}{c}\text { Chabrier } \\
\text { Rocks }\end{array}$ & 2006 & 2 \\
\hline Pygoscelis adeliae & Pinguim de Adélia & Filhote & Arctowski & 2006 & 1 \\
\hline Pygoscelis adeliae & Pinguim de Adélia & - & EACF & 2006 & 1 \\
\hline Pygoscelis adeliae & Pinguim de Adélia & Juvenil & Copacabana & 2006 & 2 \\
\hline Pygoscelis adeliae & Pinguim de Adélia & Filhote & Copacabana & 2007 & 3 \\
\hline Pygoscelis papua & Pinguim Gentoo & Filhote & Copacabana & 2005 & 2 \\
\hline \multicolumn{6}{|l|}{ Outra aves } \\
\hline Macronectes giganteus & Petrel Gigante & - & Copacabana & 2005 & 1 \\
\hline Macronectes giganteus & Petrel Gigante & Juvenil & Copacabana & 2005 & 1 \\
\hline Catharacta sp. & Skua & Filhote & Refúgio 2 & 2005 & 1 \\
\hline Catharacta sp. & Skua & - & Refúgio 2 & 2006 & 1 \\
\hline Catharacta sp. & Skua & Adulto & Refúgio 2 & 2007 & 1 \\
\hline Daption capensis & Pomba do Cabo & - & Ponta Demay & 2004 & 1 \\
\hline Larus dominicanus & Gaivotão & Filhote & Refúgio 2 & 2004 & 1 \\
\hline Total & & & & & 21 \\
\hline
\end{tabular}




\subsection{Caracterização das espécies estudadas}

\subsubsection{Espécies de invertebrados analisados}

A classificação taxonômica e ecológica, e o habito alimentar das espécies de invertebrados analisados neste estudo estão listadas na Tabela 7.

Tabela 7. Espécie, classe ou ordem, filo, habito alimentar e classificação ecológica dos invertebrados analisados neste estudo.

\begin{tabular}{|c|c|c|c|}
\hline $\begin{array}{l}\text { Filo } \\
\text { Classe/ordem }\end{array}$ & Espécie & Hábito alimentar & $\begin{array}{c}\text { Classificação } \\
\text { ecológica }\end{array}$ \\
\hline \multicolumn{4}{|l|}{ Mollusca } \\
\hline Gastropoda & $\begin{array}{l}\text { Nacella } \\
\text { concinna }\end{array}$ & $\begin{array}{l}\text { Depositívoro, } \\
\text { Herbívoro }\end{array}$ & Bentônico \\
\hline Bivalvia & $\begin{array}{l}\text { Laternula } \\
\text { elliptica }\end{array}$ & Suspensívoro & Bentônico \\
\hline Bivalvia & $\begin{array}{l}\text { Yoldia } \\
\text { eightsi }\end{array}$ & $\begin{array}{l}\text { Onívoro } \\
\text { Depositívoro } \\
\text { Suspensívoro }\end{array}$ & Bentônico \\
\hline \multicolumn{4}{|l|}{ Echinodermata } \\
\hline Ophiuroidea & $\begin{array}{l}\text { Ophionotus } \\
\text { Victoria }\end{array}$ & $\begin{array}{l}\text { Oportunista } \\
\text { Generalista } \\
\text { Necrófago }\end{array}$ & Bentônico \\
\hline Asteroidea & $\begin{array}{l}\text { Odontaster } \\
\text { validus }\end{array}$ & $\begin{array}{l}\text { Carnívoro } \\
\text { Necrófago }\end{array}$ & Bentônico \\
\hline Echinoidea & Sterechinus neumayeri & $\begin{array}{l}\text { Depositívoro } \\
\text { Herbívoro } \\
\text { Onívoro }\end{array}$ & Bentônico \\
\hline \multicolumn{4}{|l|}{ Arthropoda } \\
\hline Crustacea/lsopoda & Glyptonotus antarcticus & $\begin{array}{l}\text { Carnívoro } \\
\text { Necrófago } \\
\text { Onívoro }\end{array}$ & Bentônico \\
\hline Crustacea/lsopoda & $\begin{array}{l}\text { Serolis } \\
\text { polita }\end{array}$ & $\begin{array}{l}\text { Carnívoro } \\
\text { Necrófago }\end{array}$ & Bentônico \\
\hline Crustacea/Amphipoda & $\begin{array}{l}\text { Bovallia } \\
\text { gigantea }\end{array}$ & $\begin{array}{l}\text { Herbívoro } \\
\text { Onívoro }\end{array}$ & Demersal \\
\hline Crustacea/Euphausiacea & $\begin{array}{l}\text { Euphausia } \\
\text { superba }\end{array}$ & $\begin{array}{l}\text { Suspensívoro } \\
\text { Herbívoro } \\
\text { Onívoro }\end{array}$ & Pelagico \\
\hline
\end{tabular}




\section{- Moluscos}

É um dos grupos de animais marinhos mais abundantes e facilmente observáveis, pois eles se adaptam em todos os principais habitats. É difícil caracterizar um grupo tão grande e diverso como o filo Mollusca, mas alguns traços comuns podem ser observados. Moluscos são animais não segmentados, podem ter concha externa e usam um grande pé muscular para locomoção, fixação e captura alimentos.

Este filo é geralmente dividido em sete classes, dentre as quais cinco são bastante comuns: a Amphineura, a Bivalvia, a Gastropoda, o Scaphopoda e a Cephalopoda. A classe de gastrópodes inclui caracóis e lesmas (marinhos, de água doce e terrestres), lapas, moluscos da califórnia, e nudibrânquios. Apesar de ser característico desta classe ter apenas uma concha, várias espécies não a apresentam. Muitos gastrópodes são bênticos, sendo que alguns sem concha ou com aquelas muito leves se adaptam a um estilo de vida pelágico. São pastadores que se alimentam de algas, de sedimentos e detritos orgânicos (Sumich, 2004).

Outra importante classe é a Bivalvia, que inclui mexilhões e ostras. Possuem duas conchas e são permanentemente presos ao substrato. Seu habitat tem um intervalo extenso de profundidade, de áreas entre - marés a abaixo de $5000 \mathrm{~m}$. Todos os bivalves não tem rádula e são os únicos entre os moluscos que utilizam brânquias tanto como estrutura alimentar como para respirar; suas brânquias são cobertas por cílios que circulam a água para a troca de gás, enquanto na alimentação, partículas extremamente pequenas, são retidas numa camada de muco secretada sobre a superfície da brânquia (Sumich, 2004). 
As espécies de moluscos envolvidas neste estudo foram o gastrópode Nacella concinna e os bivalves Yoldia eightsi e Laternula elliptica.

O gastrópode Nacella concinna (Strebel, 1908) (família Nacellidae) é comum na Península Antártica e em vários grupos de ilhas, incluindo as Órcades do Sul e Shetland do Sul. É muito abundante em águas rasas e fundos rochosos, com uma subpopulação que se move para a área entremarés no verão, podendo ser distinguida morfologicamente da população subtidal não migratória (Walker, 1972). É um depositívoro bentônico, herbívoro, tendo estreito acoplamento aos microfitobentos (algas unicelulares) e ao sedimento (Corbisier et al., 2004).

O bivalve Laternula elliptica é um suspensívoro, amplamente distribuído em águas rasas circundantes do continente e ilhas antárticas. Pode se alojar em galerias escavadas que chegam a $50 \mathrm{~cm}$ de profundidade. É o bivalve de maior biomassa na Antártica, sendo considerado um importante elo entre a produção pelágica e bentônica (Ahn, 1993).

Os moluscos bivalves Yoldia eightsi tem uma distribuição circumpolar, na Antártida e nas águas subantárticas. Ocorrem em várias profundidades (de aproximadamente 5 metros na llha Signy a pelo menos $728 \mathrm{~m}$ próximo da Geórgia do Sul). Esta espécie tem uma estratégia flexível de alimentação, pois é filtradora, alimentando-se de fitoplâncton e depositivora, explorando as camadas superficiais do sedimento (Davenport, 1988). 


\section{- Equinodermatas}

Um filo exclusivamente marinho, os Echinodermata são amplamente distribuídos em todo o oceano. Eles são comuns em zonas intertidais e abundantes em grandes profundidades. Quase todas as formas são bênticas quando adultos. Muitos são caracterizados pelo esqueleto calcário. Os equinodermos desenvolvem simetria bilateral a partir dos estágios larvais; a simetria radial do corpo é uma condição secundária neste filo.

Existem seis classes de equinodermos, entre elas a Echinoidea (ouriço-do-mar), Asteroidea (estrela-do-mar) e Ophiuroidea.

A classe Echinoidea é constituída por vários depositívoros e herbívoros, tendo como exemplo o ouriço-do-mar, que apresenta corpo rígido globular ou achatado feito de ossículos calcários e uma complexa estrutura bucal para pastar e mastigar (Steele et al., 2009).

A asteroidea ou estrela-do-mar possue cinco braços e simetria pentarradiada, podendo ter ou não espinhos. São predadores de baixa mobilidade em zonas intertidal e subtidal (Steele et al., 2009). Muitas estrelasdo-mar são carnívoras, mas, utilizam cílios e muco para coletar pequenas partículas de alimento. (Sumich, 2004).

Os ofiuróides apresentam cinco braços flexíveis, finos e delicados dispostos radialmente em torno de um disco central. Ao contrário das estrelas do mar (classe Asteroidea), todos os órgãos vitais dos ofiúros encontram-se confinados ao disco central. Alguns são depositívoros e outros predadores (Steele et al., 2009).

Os equinodermos analisados neste trabalho foram o ofiuróide Ophionotus victoriae, o ouriço Sterechinus neumayeri e asteroidea Odontaster validus. 
Ophionotus victoriae é uma espécie circumpolar extremamente comum ao longo da Península Antártica. Vive em profundidades de 5 a $1266 \mathrm{~m}$ (Madsen, 1967). Esta espécie é predadora, depositívora, detritívora e extremamente oportunista (Fratt \& Dearborn, 1984), além de necrófaga e canibal (Dearborn, 1977). Pode ingerir uma grande variedade de tipos de alimentos da superfície do substrato e capturar euphausiidas e outros crustáceos da coluna d'água (Dearborne, 1977). O sedimento foi o componente mais abundante no conteúdo estomacal de O. victoriae (Fratt \& Dearborn, 1984).

O. validus Koehler é uma das mais abundantes estrelas-do-mar da Baía do Almirantado (Ilha Rei George), ocorrendo em ambiente bentônico raso circundante ao continente antártico (Dearborn, 1977; McClintock et al., 1988). É muito comum entre 15 e 200m de profundidade (Dearborn, 1977; McClintock et al., 1988). É onívora com variada dieta e hábito alimentar, pode agir como predador ativo, necrófago, herbívoro e suspensívoro (Dayton et al. 1974; Dearborn, 1977; McClintock et al. 1988; McClintock 1994; McClintock et al. 1988; McClintock 1994).

O ouriço $S$. neumayeri é a espécie de equinóide predominante na plataforma sudeste do Mar de Weddell (Battaglia et al., 1997). É depositívoro, herbívoro e onívoro, sendo sua dieta composta por fragmentos de macroalgas e matéria orgânica da superfície do sedimento (Davenport, 1988; Corbisier et al., 2004). 


\section{- Crustáceos}

É uma classe de Artrópodes marinhos extremamente abundante e de distribuição global. Os crustáceos fazem parte dos seres que possuem pernas articuladas, mas sem espinha dorsal, possuem dois pares de antenas e corpo plano com uma grande variedade de formatos. A classificação taxônomica dos crustáceos não está inteiramente estabelecida, devido ao grande número e diversidade de espécies e formas. Dentro da subclasse Eumalacostraca destacam-se os isópodes, anfípodes e os euphausiidas.

Os isópodes são crustáceos que têm o corpo achatado verticalmente, enquanto que nos anfípodes é comprimido lateralmente, exibindo maior especialização de membros para pular e escavar. Ambos os grupos são encontrados em grande variedade de habitats marinhos, sendo os anfípodes mais associados ao sedimento de fundo (Sumich, 2004). Os isópodes são consumidores de detritos, carniça e alguns podem ser carnívoros. Os crustáceos euphausiidas são visíveis membros da comunidade de plâncton do Oceano Austral. Coletivamente, eles são referidos como "krill", embora o termo seja freqüentemente reservado para a espécie dominante Euphausia superba.

Neste estudo, as espécies de crustáceos analisados foram 0 Gliptonotus antarcticus, Serolis polita, Bovallia gigantea e Euphausia superba.

Gliptonotus antarcticus é um grande isópode marinho, encontrado na Geórgia do Sul, Orkneys do Sul e nas Ilhas Shetland do Sul, na Península Antártica. Desempenha um importante papel como invertebrado necrófago (Presler, 1986), além de ser predador e apresentar comportamento de canibalismo. Sua dieta é composta por uma grande variedade de presas, incluindo isópodes, equinodermos, bem como ofiuróides e gastrópodes (Dearborn, 1967). 
O isópode Serolis polita é uma espécie associada a substratos de fundos inconsolidados, comumente encontrada nas Ilhas Sandwich do Sul, Georgia do Sul, Patagonia (Sheppard, 1933; Kussakin, 1967), Ilha de Signy (Luxmoore, 1982) e Baía do Almirantado em profundidades de 3,5 a 700m (Kussakin, 1967). Esta espécie é predadora e necrófaga, (Presler, 1986) alimenta-se de uma variedade de invertebrados menores, principalmente anfípodas e poliquetas (Luxmoore, 1985).

Bovallia gigantea é um grande anfípode avermelhado que tem sido registrado na Península Antártica, Ilhas Shetlands do Sul, Geórgia do Sul, Ilhas Sandwich do Sul, bem como nas Ilhas Orkneys do Sul, a aproximadamente 40 m de profundidade e geralmente está associado a macroalgas (Russell \& Yonge, 1972). B. gigantea é herbívoro, onívoro, predador e tem uma forte preferência por alimentos frescos vivos a detritos (Thurston, 1968).

Euphausia superba, o krill antártico, é um crustáceo importante para a cadeia alimentar da Antártica. Sua densidade pode chegar a 30 mil indivíduos por $\mathrm{m}^{3}$. A estimativa do peso total de krill antártico (biomassa) é de 50 a 500 milhões de toneladas (ASOC, 2007). É uma espécie pelágica predominantemente filtradora, suspensívora, muito importante porque aumenta a eficiência da transferência de energia no ecossistema antártico, reduzindo o número de elos entre os produtores primários e os consumidores de níveis tróficos superiores (Nybakken, 1997). 


\subsubsection{Espécies de vertebrados analisados}

\section{- Peixes}

A espécie Notothenia rossii é bem adaptada às águas frias e vive exclusivamente em águas da Antártida, em especial fora da Geórgia do Sul, Ilhas Orkney do Sul e Shetlands do Sul. Alimenta-se principalmente de krill (Euphausia superba Dana) (Kock, 1992), mas também de crustáceos e poliquetas (Oehlenschlager \& Rehbein,1982). Na fase jovem os indivíduos de N. rossii são demersais, predando principalmente invertebrados da comunidade bentônica associada com macroalgas (Barbera-Oro \& Winter, 2008). Contudo, os hábitos alimentares e habitats preferenciais de $N$. rossii variam ao longo dos estágios de crescimento de seu ciclo de vida (Tarverdiyeva, 1972).

Notothenia rossii é um peixe teleósteo pertencente à Ordem Perciforme, Sub-ordem Notothenioidei e família Nototheniidae, a qual é predominante na região de estudo. Notothenia rossii é uma espécie amplamente distribuída. É é bem adaptada às águas frias e vive exclusivamente em águas antárticas, em especial fora da Geórgia do Sul, nas Ilhas Orkney do Sul e nas Shetlands do Sul, sendo encontrada em profundidades de 20 a 550 metros. Atinge um comprimento total de $92 \mathrm{~cm} \mathrm{e}$ peso em torno de $10 \mathrm{~kg}$ (Gon \& Heemstra, 1990). Alimenta-se principalmente de krill (Euphausia superba Dana) (Kock, 1992)

Os seus hábitos alimentares e habitats preferenciais variam ao longo dos estágios de crescimento do seu ciclo de vida (Tarverdyieva, 1972). Quando jovens (pós-larva) são pelágicos e alimentam-se principalmente de larvas de crustáceos e outros zooplânctons pequenos. Pequenos juvenis ocupam bancos de algas costeiros e alimentam-se de pequenos copépodes planctônicos, 
anfípodes, larvas de peixes e larvas de decápodes. Juvenis maiores permanecem nos bancos de macroalgas e alimentam-se principalmente de peixes, eufasídeos, isópodos, anfípodos e algas. Adultos de N. rossii tornam-se semipelágicos e habitam em áreas de alimentação na plataforma continental, alimentando-se principalmente de ctenóforos, hidrozoários, anfípodos, eufasídeos e peixes, dependendo da abundância das presas (Cardoso, 2005).

\section{- Aves}

A classificação taxonômica das espécies de aves analisadas neste estudo está apresentada na Tabela 8.

Tabela 8. Classificação taxonômica das aves analisadas neste estudo (Schreiber \& Burger, 2002).

\begin{tabular}{ccc}
\hline Ordem & Espécie & Nome popular \\
\hline Sphernisciformes & Pygoscelis antarcticus & pinguim antártico \\
Sphernisciformes & Pygoscelis adeliae & pinguim de Adélia \\
Sphernisciformes & Pygoscelis papua & pinguim gentoo \\
Procellariiformes & Macronectes giganteus & petrel gigante \\
Procellariiformes & Daption capense & pomba ou petrel do cabo \\
Charadriiformes & Catharacta sp. & skua \\
Charadriiformes & Larus dominicanus & gaivotão \\
\hline
\end{tabular}

No Oceano Sul, os pinguins representam cerca de $90 \%$ da biomassa das aves, bem como dos grandes predadores dentro do subantártico e dos ecossistemas da Antártica, consumindo 1,96 milhões de toneladas de carbono anualmente (Woehler, 1995). São importantes aves consumidoras de crustáceos e peixes no Oceano Antártico (Woehler, 1995). 
O pinguim antártico (Pygoscelis antarcticus) habitam exclusivamente em regiões antárticas e subantárticas: $99 \%$ de todos pinguins antárticos vivem no sul do Oceano Atlântico. Alimenta-se quase que exclusivamente krill em zonas costeiras da Península Antártica e na região do Mar de Scotia durante a época de reprodução (McGonigal, 2009). O pinguim antártico quase sempre utiliza o habitat epipelágico de forrageamento na região fora da plataforma. A sua distribuição é apresentada na Figura 10.

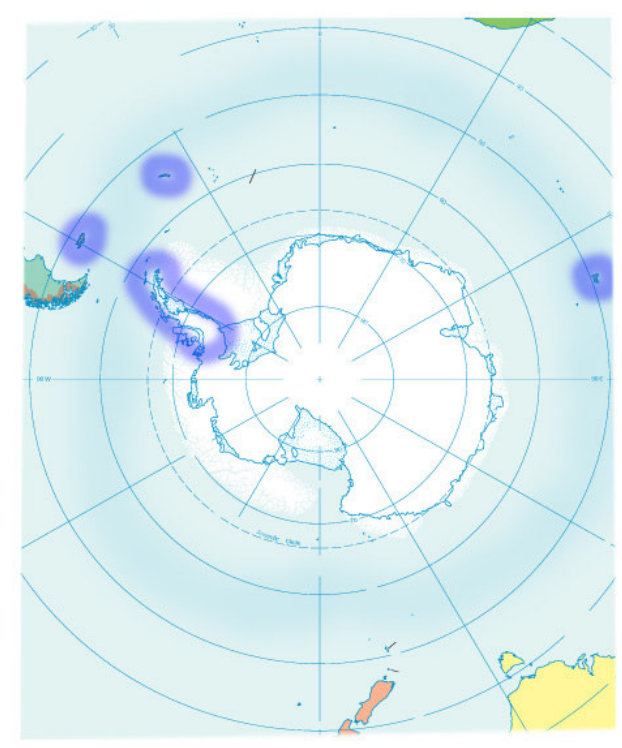

\begin{tabular}{|c|c|}
\hline Espécie & Pygoscelis antarcticus \\
\hline Tamanho & $46-61 \mathrm{~cm}, 4 \mathrm{~kg}$ \\
\hline Presa & krill, peixe pequenos \\
\hline Predador & foca leopardo, skuas \\
\hline População & cerca de $8 \times 10^{6}$ indivíduos \\
\hline Status atuais & $\begin{array}{l}\text { IUCN* classifica essa } \\
\text { espécie como "menos } \\
\text { preocupação" }\end{array}$ \\
\hline
\end{tabular}

Figura 10. P. antarcticus são encontrados na Antártica e nas ilhas da América do Sul. (Fonte:http://www.seaworld.org/animal-info/info-books/penguin/appendix-species.htm)

O pinguim de adélia (Pygoscelis adeliae) é encontrado em mares antárticos, havendo sobreposição de áreas de ocorrência com Pygoscelis antarcticus. É uma espécie circumpolar e se reproduz em grandes colônias, algumas excedendo um milhão de indivíduos, nas Shetlands do Sul, Orkney do 
Sul, Sandwich do Sul, Ilha Bouvet e também ao longo da costa e de outras ilhas do continente antártico. As colônias são formadas em outubro e os ovos são postos em novembro; os juvenis se emplumam e partem em janeiro e fevereiro. São migratórios, porém os percursos ainda não são bem conhecidos. Essa espécie já foi encontrada ao norte das Falklands, Georgia do Sul, Ilhas Kerguelen, Heard e Macquarie (Harrison, 1985). A Figura 11 apresenta a sua distribuição no continente antártico.

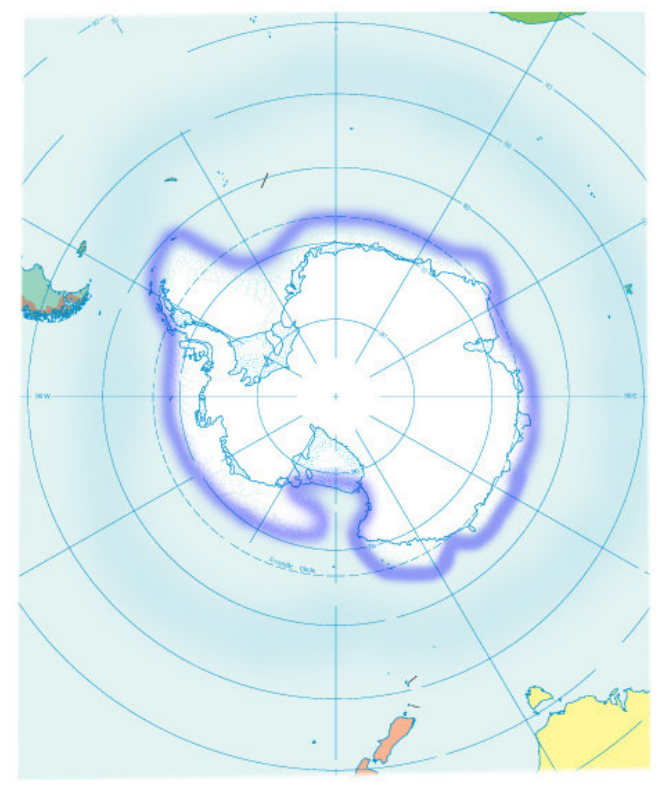

$\begin{array}{ll}\text { Espécie } & \text { Pygoscelis adeliae } \\ \text { Tamanho } & 46-61 \mathrm{~cm}, 3.5-4.5 \mathrm{~kg} \\ \text { Presa } & \text { principalmente krill, lulas e peixes } \\ \text { Predador } & \text { focas leopardo, skuas, sheathbills } \\ \text { População } & \text { cerca de } 4.0 \times 10^{5} \text { a } 5.2 \times 10^{5} \\ & \text { indivíduos } \\ \text { Status atuais } & \text { IUCN classifica essa espécie } \\ & \text { como "pouco preocupantes"; } \\ & \begin{array}{l}\text { aumento da população na } \\ \text { Antártida Oriental e Mar de Ross, } \\ \end{array} \\ & \text { diminuindo na Península Antártica }\end{array}$

Figura 11. Distribuição circumpolar de $P$. adeliae no continente antártico, dentro dos limites da plataforma de gelo.

(Fonte:http://www.seaworld.org/animal-info/info-books/penguin/appendix-species.htm)

O pinguim gentoo (Pygoscelis papua) é uma das mais difundidas espécies de pinguins. Se reproduz a partir das ilhas Crozet $\left(46^{\circ} \mathrm{S}\right)$, no sul do Oceano Índico, à Ilha Petermann (65S) na Península Antártica, sendo que os principais locais de reprodução são nas Ilhas Falkland, Kerguelen e na Geórgia 
do Sul, onde mantém cerca de $70 \%$ da população mundial de gentoo (Figura 12) (Woehler, 1993). Na Península Antártica, geralmente tem ninho em pequenas colônias em simpatria com pinguim adélie e pinguim antártico. Os pinguins gentoo frequentemente utilizam habitats bentônicos de forrageamento na região da plataforma.

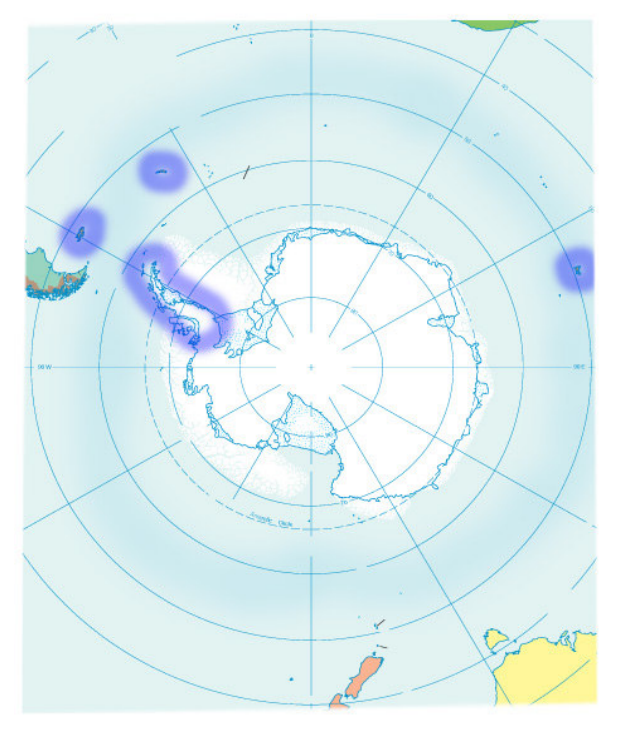

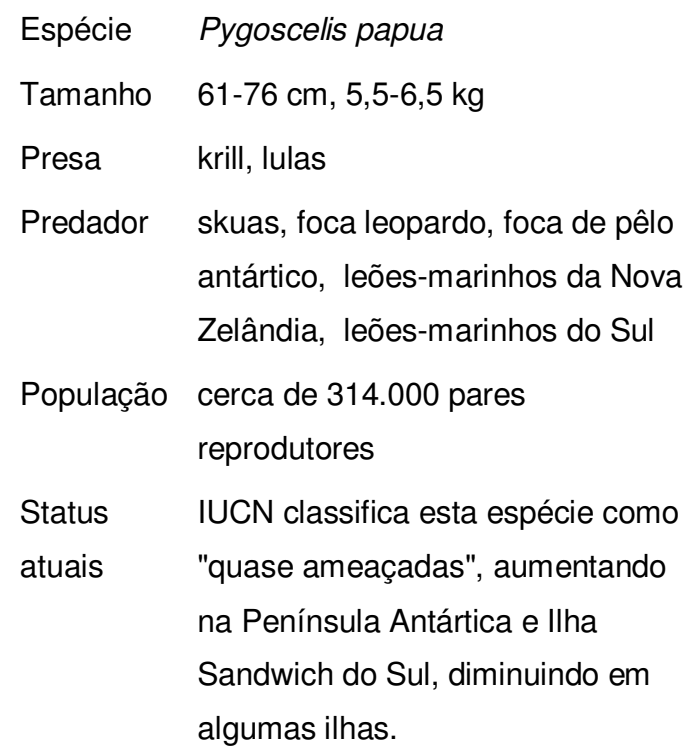

Figura 12. Distribuição circumpolar nas águas subantárticas e antárticas, evita gelo e costas continentais (exceto perto da Península Antártica). (Fonte:http://www.seaworld.org/animal-info/info-books/penguin/appendix-species.htm)

Uma espécie da ordem procellariiformes de grande porte é o Macronectes giganteus (petrel gigante), ave marinha com características pelágicas e distribuição circumpolar no hemisfério sul. Suas colônias de reprodução se estendem desde o sul do Chile e da Argentina ao sudeste da Ilha Heard, nas Ilhas subantárticas, na Península Antártica e em apenas 
algumas localidades no continente antártico (Harrison, 1985). A espécie é de nidificação superficial e tem um único ovo por ano. A conclusão do ciclo de reprodução leva aproximadamente 180 dias, o que limita as aves a iniciarem a reprodução no início da temporada de verão. No Continente Antártico começam a colocar os ovos na segunda quinzena de outubro. (Johnstone et al. 1973).

Daption capense é uma espécie de petrel comum no hemisfério sul. Habitam em latitudes temperadas no Atlântico e no Pacífico, e em nenhuma parte é mais numerosa do que na costa sul da Tasmânia. Possui um extenso intervalo de reprodução e alimentação, com ninhos limitados no continente e nas ilhas da Península Antártica (Soave et al., 1998; Warham, 1990). A dieta de $D$. capense inclui peixes, krill, cefalópodes (Casaux et al., 1998; Ainley et al. 1984). A sua extensa distribuição e abundância sugere que ele desempenha um papel importante como consumidor de topo no sistema marinho pelágico (Soave et al., 1996).

Catharacta sp. (skua) tem uma ampla distribuição circumpolar de reprodução que inclui a maioria das ilhas do Oceano Austral, do Continente Antártico, o norte das Ilhas Chatham (Higgins \& Davies 1996). Nas ilhas subantárticas alimentam-se de presas como peixes e pinguins usando diversas técnicas de alimentação, incluindo predação, necrofagia e cleptoparasitismo (Higgins \& Davies 1996, Reinhardt et al. , 2000). As skuas são geralmente migratórias, passando o verão nas ilhas e, em seguida, nos meses de inverno, dispersam em direção ao norte do mar. As espécies subantárticas podem permanecer em algumas localidades, onde têm presas disponíveis o ano todo, 
especialmente nas ilhas de clima temperado, como as Ilhas Chatham, (Hemmings, 1990).

Larus dominicanus são gaivotas amplamente distribuídas no Hemisfério Sul, reproduzindo-se na América do Sul, África do sul, Austrália, Nova Zelândia, nas ilhas subantárticas e Península Antártica (Higgins \& Davies, 1996). Na Argentina, ocorrem ao longo da costa do mar e em zonas úmidas continentais. Autores sugerem que L. dominicanus são generalistas (Murphy 1936, Humphrey et al. 1970): aproveitam as fontes de alimento resultantes das atividades humanas, tais como lixeiras, descargas de esgotos, matadouros e capturas de pescas (Murphy, 1936).

\subsection{Procedimento metodológico das análises de HPAs}

As análises foram realizadas no Laboratório de Química Orgânica Marinha (LabQOM) do Instituto Oceanográfico da Universidade de São Paulo (IOUSP). O método baseado no procedimento descrito por MacLeod et al. (1986) foi testado e otimizado no LabQOM do IOUSP. Também foram realizados os procedimentos de controle de qualidade analítica e confiabilidade.

\subsubsection{Cuidados analíticos}

Para evitar contaminação, toda a vidraria utilizada foi previamente imersa em detergente Extran alcalino por aproximadamente 12 horas. Depois enxaguada em água corrente e destilada. Foram secas em estufa, cobertas com alumínio e mufladas por 4 horas a $440 \stackrel{\circ}{\circ}$. As vidrarias volumétricas depois de enxaguadas em água corrente foram rinsadas com etanol e secas 
naturalmente. Antes de iniciar as análises todo material foi lavado com nhexano e diclorometano (DCM).

O sulfato de sódio, a sílica cromatográfica e a alumina também foram muflados nas mesmas condições das vidrarias e mantidos em dessecador. Todos os solventes utilizados foram de alto grau de pureza. A água utilizada na desativação da sílica e da alumina foi água Milli-Q extraída cinco vezes com nhexano.

\subsubsection{Reagente e soluções}

Para garantir a qualidade das análises, todos os solventes usados eram específicos para análise de resíduos.

A partir de soluções certificadas, adquiridas do laboratório internacional AccuStandard (EUA), foi preparada uma solução dos analitos padrões que foram analisados neste estudo, uma solução de padrões surrogates e uma solução de padrão interno $(\mathrm{PI})$, todas com concentração de $5 \mathrm{ng} \mathrm{LL}^{-1}$, em hexano. A mistura de analitos padrões era composta por 42 HPAs apresentados na Tabela 9. A solução de surrogates continha cinco hidrocarbonetos aromáticos deuterados (naftaleno-d8, acenafteno-d10, fenantreno-d10, criseno-d12 e perileno-d12), e na solução de padrão Interno (PI) foram utilizados fluoranteno-d10 e benzo(b)fluoranteno-d12. 
Tabela 9. HPAs analisados neste trabalho e seu respectivo íon molecular.

\begin{tabular}{llll}
\hline \multicolumn{1}{c}{ Composto } & Íon & \multicolumn{1}{c}{ Composto } & íon \\
\hline Naftaleno & 128 & 2-metilfenantreno & 192 \\
2-metilnaftaleno & 142 & 9-metilantraceno & 192 \\
1-metilnaftaleno & 142 & Dimetilfenantreno & 206 \\
Bifenil & 154 & Fluoranteno & 202 \\
2-etilnaftaleno & 141 & Pireno & 202 \\
1-etilnaftaleno & 141 & 2-metilfluoranteno & 216 \\
2,6-dimetilnaftaleno & 156 & Reteno & 219 \\
1,3-dimetilnaftaleno & 156 & 1-metilpireno & 216 \\
1,6-dimetilnaftaleno & 156 & benzo(c)fenantreno & 228 \\
1,4-dimetilnaftaleno & 156 & benzo(a)antraceno & 228 \\
1,5-dimetilnaftaleno & 156 & Criseno & 228 \\
Acenaftileno & 152 & Metilcriseno & 242 \\
1,2-dimetilnaftaleno & 156 & benzo(b)fluoranteno & 252 \\
Acenafteno & 153 & benzo(k)fluoranteno & 252 \\
Trimetilnaftaleno & 170 & benzo(e)pireno & 252 \\
Fluoreno & 166 & benzo(a)pireno & 252 \\
Metilfluoreno & 165 & Perileno & 252 \\
Dibenzotiofeno & 184 & indeno(1,2,3-c,d)pireno & 276 \\
Fenantreno & 178 & dibenzo(a,h)antraceno & 278 \\
Antraceno & 178 & benzo(b)criseno & 278 \\
Dimetilfluoreno & 179 & benzo(g,h,i)perileno & 276 \\
\hline
\end{tabular}

\subsubsection{Preparação das amostras e extração}

Os animais que continham carapaças e conchas foram separados das mesmas. Foram pesadas amostras compostas por $5 \mathrm{~g}$ de cada espécie, que foram congeladas e liofilizadas. Após 72 horas de liofilização as amostras compostas foram pesadas novamente, para determinação do peso úmido, e maceradas em almofariz com pistilo. Foi adicionado $100 \mu \mathrm{L}$ de surrogate em todas as amostras e no branco. Em seguida as amostras foram extraídas em um sistema de extrator soxhlet por 8 horas com $80 \mathrm{~mL}$ de uma mistura de $\mathrm{n}$ - 
hexano e diclorometano (1:1). O extrato foi concentrado em evaporador rotativo sob vácuo, com temperatura entre $40^{\circ} \mathrm{C}$ e $50^{\circ} \mathrm{C}$ e fluxo de nitrogênio $\left(N_{2}\right)$, até o volume de $1 \mathrm{~mL}$. Tirou-se uma alíquota de $0,1 \mathrm{~mL}$ para determinação do teor lipídico da amostra.

Nas amostras de vertebrados foram maceradas $5 \mathrm{~g}$ de massa úmida de músculo de peixe e 0,25 g de massa úmida de gordura das aves (Leonel, 2007) com sulfato de sódio.

\subsubsection{Estimativa do peso lipídico e peso seco}

\section{Peso lipídico}

Uma alíquota de $0,1 \mathrm{~mL}$ foi separada do extrato concentrado $(1 \mathrm{~mL})$ e colocada em um pequeno frasco de vidro, previamente pesado, para evaporar naturalmente. Foram feitas várias pesagens até a obtenção de uma medida constante. A diferença entre o peso do vidro e o peso final do mesmo com amostra, resultou na massa do resíduo. A percentagem de lipídios extraíveis de MOE foi determinada por gravimetria, e calculada através da Equação 1:

Equação 1: $\operatorname{MOE}(\%)=[($ resíduo $(\mathrm{mg}) \times$ volume do extrato $(\mathrm{ml})) /($ volume da alíquota $(\mathrm{ml}) \times$ massa amostra extraída $(\mathrm{mg}))]$ × 100 .

Onde,

MOE : material orgânico extraível 


\subsubsection{Purificação}

Os extratos foram submetidos à cromatografia de adsorção em uma coluna cromatográfica de vidro e torneira de teflon. A coluna foi previamente preenchida com n-hexano, adicionada $8 \mathrm{~g}$ de sílica e em seguida $16 \mathrm{~g}$ de alumina, ambas desativadas (5\%), e aproximadamente $1,5 \mathrm{~cm}$ de Sulfato de Sódio. A eluição foi feita com $80 \mathrm{~mL}$ da mistura de $\mathrm{n}$-hexano e diclorometano (1:1). A fração coletada foi concentrada a $0,5 \mathrm{~mL}$, em evaporador rotativo sob vácuo fraco e temperatura entre $40^{\circ} \mathrm{C}$ e $50^{\circ} \mathrm{C}$ e fluxo de $\mathrm{N}_{2}$.

A cromatografia de adsorção elimina alguns lipídios, pigmentos e partículas da amostra. Porém, no caso de amostras biológicas, esse processo não é suficiente para a retirada total dos lipídios, sendo necessária uma nova etapa de purificação. Para isso, as frações foram submetidas à cromatografia em fase líquida de alta eficiência (HPLC). Foram utilizadas duas colunas de exclusão por tamanho para cromatografia de permeação em gel, Phenogel 100 A, com 22,5 x 250 mm e pré-coluna, Phenogel 100 A, com 7,8 mm de diâmetro e $50 \mathrm{~mm}$ de comprimento e como fase móvel utilizou-se diclorometano $100 \%$, por 40 minutos. Foram coletadas duas frações de cada amostra. A primeira, contendo os lipídios, foi coletada a partir do início da corrida até aproximadamente 30 minutos, e posteriormente descartada. A segunda fração, com os analitos, foi coletada entre 30 e 45 minutos de corrida. Foi concentrada e recuperada a $0,9 \mathrm{~mL}$, em $\mathrm{n}$-hexano, utilizando um evaporador rotativo sob vácuo fraco e temperatura entre $40^{\circ} \mathrm{C}$ e $50^{\circ} \mathrm{C}$ e fluxo $\mathrm{N}_{2}$. Adicionou-se $0,1 \mathrm{~mL}$ de padrão interno, completando até $1 \mathrm{~mL}$. A Figura 13 mostra as etapas do método analítico utilizado para determinação de HPAs. 


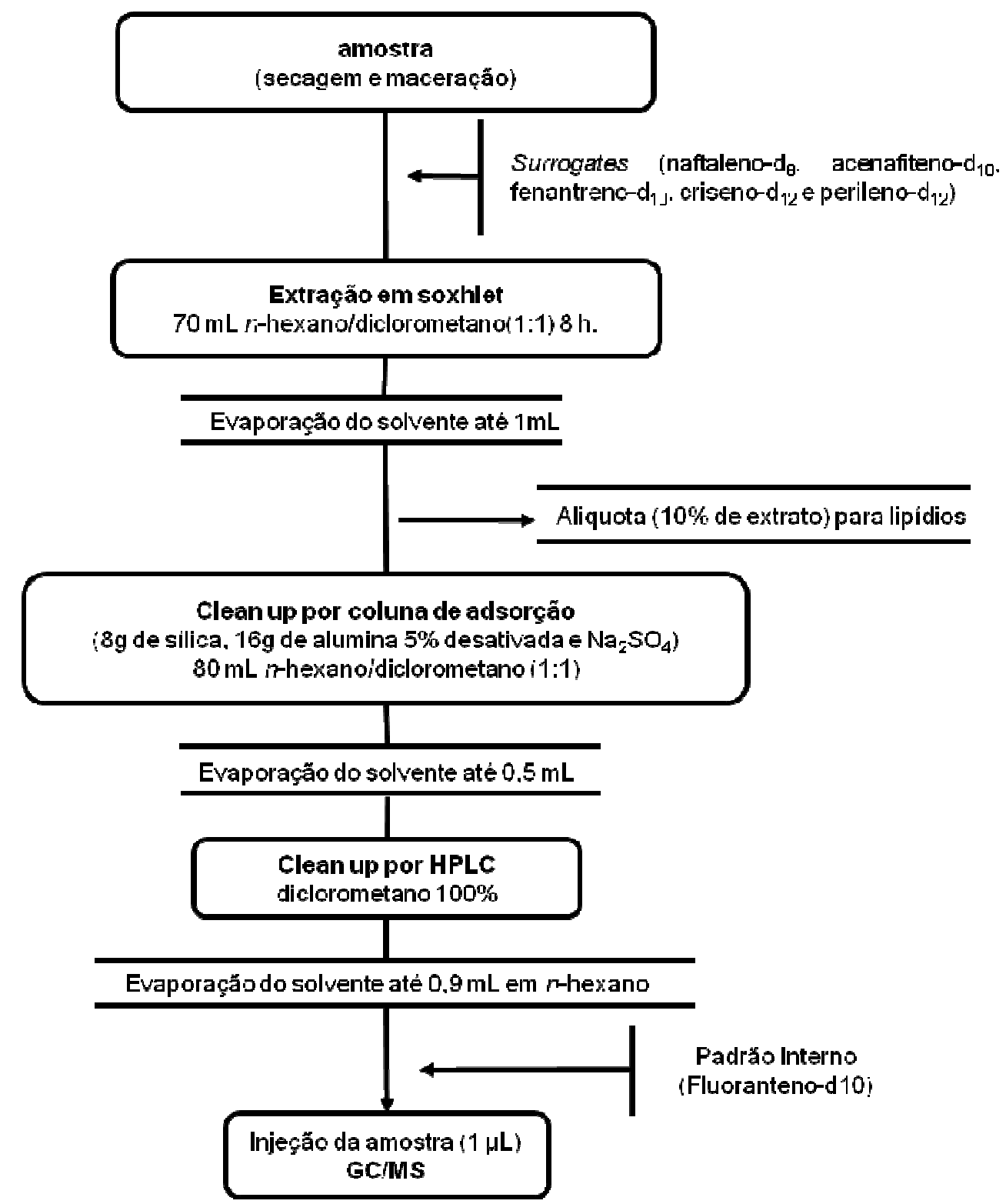

Figura 13. Fluxograma das etapas do método analítico utilizado para determinação dos compostos. 


\subsubsection{Análise cromatográfica}

A análise foi realizada pela injeção de $1 \mu \mathrm{L}$ da amostra em um cromatógrafo a gás (Agilent GC System 6890 Series) acoplado a um espectrômetro de massas (GC-MS Agilent Mass Selective Detector 5973 Network). O equipamento operou no modo de monitoramento seletivo de íons (SIM) $(70 \mathrm{eV})$ com a temperatura da interface a $280^{\circ} \mathrm{C}$ e a da fonte de íons a $300^{\circ} \mathrm{C}$. A coluna capilar utilizada foi a HP 5 MS da Agilent de 30m de comprimento e $0,25 \mathrm{~mm}$ de diâmetro interno com fase estacionária de $0,25 \mu \mathrm{m}$ de fenil-metil-silicona. A rampa de temperatura utilizada na separação dos compostos teve início em $40^{\circ} \mathrm{C}$ por 1 minuto, depois subiu em $20^{\circ} \mathrm{C} / \mathrm{min}$ até 60 $\stackrel{\circ}{ } \mathrm{C}, 5^{\circ} \mathrm{C} / \mathrm{min}$ até $290^{\circ} \mathrm{C}, 10^{\circ} \mathrm{C} / \mathrm{min}$ até $300^{\circ} \mathrm{C}$ e isotérmico por $10 \mathrm{~min}$.

Os compostos foram identificados através da comparação entre os cromatogramas das amostras e os cromatogramas dos analitos padrões, verificando os seus respectivos tempo de retenção e massa do íon molecular. Para a quantificação dos compostos foi utilizado o método da padronização interna. A quantificação foi feita considerando-se a área do fragmento principal de cada composto (Tabela 9), multiplicada pelo fator de resposta do mesmo, presente na curva analítica, em relação à razão massa/carga do fragmento principal do surrogate.

\subsubsection{Controle de Qualidade Analítica}

O controle de Qualidade Analítica consiste em um conjunto de procedimentos, técnicas e estratégias para assegurar uma maior confiabilidade nos resultados analíticos. Através da leitura de amostras de padrões determina-se a precisão, exatidão, limite de detecção e recuperação dos processos analíticos que estão sendo utilizados. Os processos que 
apresentarem uma das características acima, fora das faixas de aceitabilidade, deverão ter os procedimentos metodológicos e a técnica revistos, para correção das inconformidades (Wade \& Cantillo, 1994).

No controle de qualidade deste trabalho foram realizados os seguintes procedimentos:

Utilização de surrogate para monitorar o desempenho do método, sendo que este devia ser recuperado entre 50 e $120 \%$. Dessa forma, os surrogates foram adicionados em todas as amostras, brancos, duplicatas, branco fortificado, matriz fortificada e material de referência, antes da extração.

O Branco $(\mathrm{Bc})$ foi utilizado para verificar possíveis contaminações durante o processo analítico. Sendo que o cromatograma do branco aceitável não deveria ter nenhum analito com concentração maior do que três vezes o limite de detecção. Os valores de concentração do branco foram subtraídos de todas as amostras (Sericano, 1998).

A amostra duplicata da matriz (MD) foi usada para avaliar a homogeneidade da amostra e a precisão analítica do método, sendo que a diferença entre a amostra original e a duplicata não pode ultrapassar $25 \%$.

No branco fortificado (BF) e na matriz fortificada (MF) foi adicionado $50 u L$ do mix de analitos obtendo concentrações conhecidas destes. O BF e a MF foram usados para estimar a exatidão e a precisão do método e verificar a influência da matriz sobre a eficiência do método. Sendo que as recuperações da BF e na MF devem estar entre 50 e $120 \%$. 


\section{- Recuperação dos surrogates}

A recuperação dos surrogates foi usada para verificar o desempenho do método. Ela relaciona a quantidade de padrão adicionada ao início do procedimento analítico, com a quantidade obtida ao término do processo. A quantificação de todos os compostos a serem analisados foi corrigida através dos surrogates. A recuperação dos surrogates é feita de maneira indireta, através da adição de um padrão interno $(\mathrm{Pl})$. Quando a sua recuperação não está dentro dos critérios aceitáveis do controle de qualidade, onde a faixa de recuperação dos surrogates deve ser de 50\% a 120\% (Denoux et al., 1998), o procedimento analítico deve ser repetido.

Neste trabalho a recuperação dos surrogates no BF variou de $55 \%$ a $115 \%$. Enquanto que na MF variou de $50 \%$ a $105 \%$ (Tabela 10). Os resultados estiveram dentro do intervalo aceitável de recuperação (50\% a 120\%). As faixas de recuperação são amplas devido ao comportamento de cada composto durante todo o processo analítico, além da grande variabilidade das amostras ambientais. A menor recuperação foi para o naftaleno-d8 provavelmente devido a sua alta volatilidade (ponto de ebulição $=82^{\circ} \mathrm{C}$ e pressão $=1 \mathrm{~atm})$.

\section{- Recuperação dos analitos padrões}

A recuperação dos padrões externos (PE) é obtida com a diferença entre a concentração do BF e a concentração do branco, e a diferença entre a concentração da MF e a concentração da matriz. O critério de recuperação adotado nesse trabalho foi de acordo com Denoux et al. (1998), segundo os quais a faixa de recuperação dos $\mathrm{PE}$ deve ser de $50 \%$ a $120 \%$ para pelo 
menos $80 \%$ dos analitos. Os valores de recuperação dos PE para o BF variaram entre $50 \%$ e $117 \%$ (Tabela 10 ). A recuperação na MF foi de $50 \%$ a $118 \%$, portanto, todos os resultados obtidos estão dentro da faixa de recuperação aceitável.

Tabela 10. Recuperação dos surrogates e analitos padrões analisados do branco fortificado e a amostra fortificada no controle de qualidade.

\begin{tabular}{lcccc}
\hline Composto & BF (\%) & Avaliação & MF (\%) & Avaliação \\
\hline naftaleno-d8 & 55 & ok & 50 & ok \\
acenafteno-d10 & 75 & ok & 72 & ok \\
fenantreno-d10 & 115 & ok & 105 & ok \\
criseno-d12 & 111 & ok & 100 & ok \\
perileno-d12 & 97 & ok & 78 & ok \\
Naftaleno & 117 & ok & 78 & ok \\
2-metilnaftaleno & 92 & ok & 105 & ok \\
1-metilnaftaleno & 104 & ok & 111 & ok \\
Acenaftileno & 87 & ok & 98 & ok \\
Acenafteno & 82 & ok & 83 & ok \\
Fluoreno & 83 & ok & 90 & ok \\
Fenantreno & 95 & ok & 105 & ok \\
Antraceno & 66 & ok & 81 & ok \\
Fluoranteno & 84 & ok & 87 & ok \\
Pireno & 91 & ok & 83 & ok \\
Benzo(a)antraceno & 59 & ok & 58 & ok \\
Criseno & 102 & ok & 118 & ok \\
Benzo(b)fluoranteno & 50 & ok & 50 & ok \\
Benzo(k)fluoranteno & 97 & ok & 104 & ok \\
Benzo(a)pireno & 57 & ok & 54 & ok \\
indeno[1,2,3-c,d]pireno & 50 & ok & 51 & ok \\
dibenzo(a,h)antraceno & 51 & ok & 52 & ok \\
Benzo(g,h,i)perileno & 91 & ok & 67 & ok \\
\hline
\end{tabular}




\section{- Curva analítica}

Foi construída uma curva analítica injetando-se soluções dos PE com seis concentrações conhecidas $\left(0,1,0,25,0,5,0,8,1,0\right.$ e $\left.1,5 \mathrm{ng} \mathrm{hL}^{-1}\right)$. As concentrações dos pontos da curva analítica foram escolhidas de acordo com os níveis dentro da faixa de linearidade do detector e faixa da estimada para as concentrações das amostras. Os picos obtidos no GC/MS (Tabela 9) foram integrados por um sistema de aquisição de dados (HP Enhanced Chemstation

G1701 CA), determinando o fator de resposta, os índices de retenção e a curva. O índice de correlação linear de Pearson foi igual ou superior a $99 \%\left(r^{2}=\right.$ 0,996).

Os compostos foram quantificados com a curva analítica. Para assegurar que a curva estava adequada para ser usada, era verificada continuamente a cada conjunto de amostras, no qual os resultados da quantificação não poderiam variar mais que $25 \%$ do valor real. Caso essa variação fosse maior, uma nova curva analítica deveria ser feita.

\section{- Material de referência certificado}

O uso de material de referência certificado, SRM (Standard Referência Materia ${ }^{\circledR}$ ) ou CRM (Certified Reference Material), é um dos mais importantes métodos para validação de um procedimento metodológico. É realizado para demonstrar que o método produz resultados que são comparáveis aos obtidos por uma organização independente. O material de referência é uma amostra bem caracterizada com relação aos analitos de interesse. No certificado de análise que acompanha a amostra, constam os valores certificados e suas incertezas (Schantz et al.,1993). 
O material de referência utilizado na validação do procedimento metodológico foi o SRM 2978 (Organics Contaminants - Freeze-Dried Mussel Tissue), adquirida do National Institute of Standards and Technology. A quantidade de SRM utilizada nesta análise foi de $1 \mathrm{~g}$.

De acordo com o critério adotado pelo programa NS\&T (National Status and Trends), que utiliza um intervalo de $35 \%$ acima e abaixo das incertezas das concentrações encontradas nos materiais de referência. Portanto, 0 procedimento metodológico adotado foi considerado confiável, pois, $80 \%$ dos compostos analisados estiveram dentro da faixa apresentada no certificado, acrescido de $\pm 35 \%$. Os resultados apresentados na Tabela 8 mostraram que 0 procedimento metodológico utilizado nesse trabalho é confiável para realização das análises. 
Tabela 11. Resultados obtidos na análise do material de referência certificado SRM 2978.

\begin{tabular}{|c|c|c|c|c|c|c|}
\hline Compostos & $\begin{array}{l}\text { Valor certificado } \\
\text { desvio padrão } \\
\text { (ng g } \\
\text { (-1 peso seco) }\end{array}$ & $\begin{array}{c}\text { Intervalo } \\
\text { de } \\
\text { confiança }\end{array}$ & $\begin{array}{l}\text { Critéric } \\
35 \%(-)\end{array}$ & $\begin{array}{l}\text { NS\&T* } \\
35 \%(+)\end{array}$ & $\begin{array}{c}\text { valor obtido } \\
\text { (ng } \mathrm{g}^{-1} \text { peso seco) }\end{array}$ & Avaliação \\
\hline Naftaleno & $31 \pm 6$ & $25-37$ & 16.3 & 50.0 & 31.8 & ok \\
\hline 2-metilnaftaleno & $23 \pm 4$ & $19-27$ & 12.4 & 36.5 & 32.9 & ok \\
\hline 1-metilnaftaleno & $21 \pm 5$ & $16-26$ & 10.4 & 35.1 & 29.8 & ok \\
\hline Bifenil & $8 \pm 1$ & $7-9$ & 4.6 & 12.2 & 6.7 & ok \\
\hline Acenaftileno & $4 \pm 1$ & $3-5$ & 2.0 & 6.8 & 3.7 & ok \\
\hline Acenafteno & $6 \pm 2$ & $4-8$ & 2.6 & 10.8 & 10.1 & ok \\
\hline Fluoreno & $7 \pm 1$ & $6-8$ & 3.9 & 10.8 & 9.8 & ok \\
\hline Fenantreno & $74 \pm 7$ & $67-81$ & 43.6 & 109 & 105 & ok \\
\hline Antraceno & $5.4 \pm 2.2$ & $3.2-7.6$ & 2.1 & 10.3 & 7.3 & ok \\
\hline Fluoranteno & $166 \pm 12$ & $154-178$ & 100 & 240 & 160 & ok \\
\hline Pireno & $256 \pm 21$ & $235-277$ & 153 & 374 & 312 & ok \\
\hline benzo(a)antraceno & $25 \pm 7$ & $18-32$ & 11.7 & 43.2 & 26.9 & ok \\
\hline Criseno & $59 \pm 10$ & $49-69$ & 31.9 & 93.2 & 82.6 & ok \\
\hline benzo(b)fluoranteno & $58 \pm 15$ & $43-73$ & 28.0 & 98.6 & 60.3 & ok \\
\hline benzo(j)fluoranteno & $23 \pm 2$ & $21-25$ & 13.7 & 33.8 & 26.9 & ok \\
\hline benzo(k)fluoranteno & $24.1 \pm 3.4$ & $20.7-27.5$ & 13.5 & 37.1 & 24.3 & ok \\
\hline benzo(e)pireno & $89.3 \pm 6.3$ & $83-95.6$ & 54.0 & 129 & 90.7 & ok \\
\hline benzo(a)pireno & $7 \pm 3$ & $4-10$ & 2.6 & 13.5 & 5.4 & ok \\
\hline \multicolumn{7}{|l|}{ indeno[1,2,3- } \\
\hline c,d]pireno & $12.2 \pm 2.9$ & $9.3-15.1$ & 6.0 & 20.4 & 8.9 & ok \\
\hline benzo(g,h,i)perileno & $19.7 \pm 4.4$ & $15.3-24.1$ & 9.9 & 32.5 & 13.9 & ok \\
\hline
\end{tabular}

${ }^{*}$ Critério de aceitação em programas desenvolvidos pelo NS\&T (Wade \& Cantillo, 1994)

\section{- Limite de Detecção do Método (LDM)}

O limite de detecção de um método (LDM) é definido como a concentração mínima de uma substância que pode ser medida com $95 \%$ de confiança de que essa concentração é maior que zero e pode ser determinada em uma matriz contendo o analito. Uma das maneiras de realizar o LDM é através da quantificação de uma pequena quantidade de analitos adicionados a uma matriz que não contenha os compostos em estudo ou que apresente baixas concentrações dos analitos. 
Amostras complexas, como a biota, podem apresentar uma série de interferentes que influenciam na análise. Dessa forma, a determinação da LDM com uso de matrizes possibilita avaliar a influência da matriz durante a análise. Para o cálculo do LDM adotou-se três vezes o valor do desvio padrão de cada um dos compostos em sete replicatas (Wade \& Cantillo, 1994).

Para a realização do limite de detecção utilizou-se $1 \mathrm{~g}$ de músculo de peixe, Robalo flexa (Centropomus paralelos), coletado na ilha da moela Santos. Foram realizadas 12 réplicas de amostra fortificada com uma solução contendo os analitos de interesse e mais surrogates. Foram escolhidas apenas sete réplicas com concentrações mais próximas para a determinação do LDM.

Os limites de detecção dos compostos neste estudo variaram de 0,6 a $5,3 \mathrm{ng} \mathrm{g}^{-1}$ (Tabela 12).

\subsection{Análise do DFA}

Neste trabalho também foi analisado o DFA foi analisado a fim de obter o perfil de HPAs individuais e comparar com o perfil dos HPAs obtidos nas amostras.

Foram pesados $5 \mathrm{~g}$ de óleo cru e diluído em $5 \mathrm{~mL}$ de $\mathrm{n}$-hexano, obtendo uma concentração de $1000 \mathrm{ng} \mathrm{uL}^{-1}$. Foi injetado em GC/MS utilizando o mesmo método da análise das amostras. 
Tabela 12. O limite de detecção do método (LDM) para os compostos analisados. Dados apresentados em ng g ${ }^{-1}$

\begin{tabular}{|c|c|c|c|}
\hline Composto & $\operatorname{LDM}\left(\mathrm{ng} \mathrm{g}^{-1}\right)$ & Composto & LDM (ng g $\left.{ }^{-1}\right)$ \\
\hline Naftaleno & 4.1 & 2-metilfenantreno & 1.4 \\
\hline 2-metilnaftaleno & 5.3 & 9-metilantraceno & 1.4 \\
\hline 1-metilnaftaleno & 3.8 & Dimetilfenantreno & 1.4 \\
\hline Bifenil & 3.8 & Fluoranteno & 2.4 \\
\hline 2-etilnaftaleno & 3.8 & Pireno & 3.8 \\
\hline 1-etilnaftaleno & 3.8 & 2-metilfluoranteno & 3.8 \\
\hline 2,6-dimetilnaftaleno & 3.8 & Reteno & 3.8 \\
\hline 1,3-dimetilnaftaleno & 3.8 & 1-metilpireno & 3.8 \\
\hline 1,6-dimetilnaftaleno & 3.8 & benzo(c)fenantreno & 3.8 \\
\hline 1,4-dimetilnaftaleno & 3.8 & benzo(a)antraceno & 3.9 \\
\hline 1,5-dimetilnaftaleno & 3.8 & Criseno & 0.6 \\
\hline Acenaftileno & 3.3 & Metilcriseno & 0.6 \\
\hline 1,2-dimetilnaftaleno & 3.3 & benzo(b)fluoranteno & 0.6 \\
\hline Acenafteno & 0.8 & benzo(j/k)fluoranteno & 1.7 \\
\hline Trimetilnaftaleno & 0.8 & benzo(e)pireno & 1.7 \\
\hline Fluoreno & 1 & benzo(a)pireno & 2.9 \\
\hline Metilfluoreno & 1 & Perileno & 2.9 \\
\hline Dibenzotiofeno & 1 & indeno $(1,2,3-\mathrm{c}, \mathrm{d})$ pireno & 3.8 \\
\hline Fenantreno & 2.2 & dibenzo(a,h)antraceno & 2.5 \\
\hline Antraceno & 1.4 & benzo(b)criseno & 2.5 \\
\hline Dimetilfluoreno & 1.4 & benzo(g,h,i)perileno & 1.2 \\
\hline
\end{tabular}

\subsection{Análises estatísticas}

Análise de dados estatísticos foi realizado com BioEstat 5.0. Para as amostras com concentrações abaixo do limite de detecção, o zero foi usado no cálculo. A normalidade dos dados de HPAs foi avaliada, com as concentrações em peso úmido, por meio de teste de Kolmogorov-Smirnov. Como não foi observada uma distribuição normal dos dados, foi utilizado teste não paramétrico Kruskal-Wallis para detectar diferenças significativas entre os grupos. 


\section{RESULTADOS E DISCUSSÃO}

Este estudo apresentou pela primeira vez a análise das concentrações de HPAs em peixes e invertebrados da Baía do Almirantado. Foram analisadas 71 amostras de diversas espécies de organismos, sendo que 24 foram de invertebrados (moluscos, equinodermos e crustáceos) e 47 de vertebrados (peixes e aves). A fim de melhor relacionar as concentrações obtidas e as espécies com comportamentos semelhantes, a apresentação e a discussão dos resultados dos invertebrados foram divididas de acordo com a classificação taxonômica das espécies, ou seja, moluscos, equinodermos e crustáceos.

Para avaliação dos resultados foram analisadas as concentrações dos HPAs individuais, os HPAs totais ( $\Sigma$ HPAs), a soma dos HPAs alquilados ( $\Sigma$ HPAs-alquil), a soma dos HPAs com 2 a 3 anéis aromáticos (LHPAs 2-3) e a soma dos HPAs com 4 a 6 anéis aromáticos (इHPAs 4-6). Para comparar os resultados encontrados no presente estudo com os da literatura e com os resultados dos vertebrados, as concentrações apresentadas foram em peso seco (ps) e peso úmido (pu).

\subsection{Hidrocarbonetos policíclicos aromáticos em invertebrados}

\subsubsection{Hidrocarbonetos policíclicos aromáticos em moluscos}

Os fatores que influenciam na absorção de HPAs pelos organismos não são determinados simplesmente pela fonte de hidrocarbonetos. Outros fatores importantes, que devem ser considerados são o habitat, o hábito alimentar e a capacidade de metabolização do organismo. Estas particularidades da absorção de HPAs pelos organismos serão discutidas nos itens a seguir. 
Os moluscos bivalves e gastrópodes representam um dos grupos de organismos aquáticos que são mais utilizados em estudos de biomonitoramento de contaminação por petróleo no ambiente aquático (Sericano et al., 1995; Baumard et al., 1998a; 1998b; 1999a, 1999b; Nasci et al., 2000; Piccardo et al., 2001; Binelli \& Provini et al., 2003; Fung et al., 2004; Perugini et al., 2007; Solé et al., 2009). As principais vantagens da utilização desses organismos são a sua ampla distribuição geográfica, seu hábito séssil e sua capacidade de acumular hidrocarbonetos e outros contaminantes.

A distribuição dos hidrocarbonetos no tecido dos moluscos é condicionada por fatores externos, sendo o mais importante a disponibilidade dos hidrocarbonetos para os organismos aquáticos e a proximidade das fontes (Prest et al.,1995). A absorção de HPAs por organismos depende do seu habitat, habito alimentar e das características químicas dos contaminantes. Uma pequena parte solúvel dos HPAs de menor peso molecular é absorvida pelas brânquias, enquanto que os HPAs de maior peso molecular são agregados ao material particulado, sendo absorvidos através das partículas filtradas que passam pelo sistema digestivo dos organismos (Baumard et al., 1999a). A bioacumulação dos HPAs depende da sua biodisponibilidade, bem como da fisiologia do organismo envolvido (Meador et al., 1995).

A Tabela 13 apresenta concentrações de HPAs obtidas por outros autores que analisaram moluscos antárticos e observaram que estes organismos acumulam HPAs. Neste estudo, foram analisadas oito amostras de moluscos, sendo seis de Nacella concinna, coletadas entre 2004 e 2006 e duas coletadas em 1993 e 1995, uma amostra de Yoldia eightsi (2006) e uma de Laternula elliptica (2004). Devido ao número de amostras, a comparação 
intraespecífica só foi possível para a espécie $N$. concinna.

A Tabela 14 apresenta as concentrações dos HPAs totais e individuais das amostras de moluscos. As concentrações de HPAs totais variaram de 11,4 a $149,4 \mathrm{ng} \mathrm{g}^{-1}$ ps $\left(3,09\right.$ a $\left.50,2 \mathrm{ng} \mathrm{g}^{-1} \mathrm{pu}\right)$, sendo que o maior valor foi obtido para $N$. concinna coletada próximo aos tanques de combustível da EACF.

Tabela 13. Concentrações de HPAs em moluscos obtidas por outros autores em diferentes locais da região Antártica.

\begin{tabular}{|c|c|c|}
\hline Local & $\begin{array}{c}\text { HPA total } \\
\mu \mathrm{kg}^{-1} \text { peso seco }\end{array}$ & Referência \\
\hline \multicolumn{3}{|l|}{ Nacella concinna } \\
\hline Baía do Almirantado, Ilha Rei George & $11,4-149,4$ & Este trabalho \\
\hline Faraday Station, Galindez Island & $219-428$ & Cripps \& Shears (1997) \\
\hline Palmer Station & $15-2932$ & Kennicutt et al. (1992) \\
\hline Old Palmer Station & $47-1204$ & Kennicutt et al. (1992) \\
\hline Arthur Harbour & $25-382$ & Kennicutt et al. (1992) \\
\hline Arthur Harbour, Bahia Paraiso & $32-528$ & Kennicutt \& Sweet (1992) \\
\hline Arthur Harbour, Bahia Paraiso & $10000-125000$ & Kennicutt et al. (1991) \\
\hline \multicolumn{3}{|l|}{ Yoldia eightsii } \\
\hline Baía do Almirantado, Ilha Rei George & $85,6(29,7 p u)$ & Este trabalho \\
\hline Signy Island, South Orkney Islands & $5,3-25 \mathrm{pu}$ & Cripps \& Priddle (1995) \\
\hline \multicolumn{3}{|l|}{ Laternula elliptica } \\
\hline Baía do Almirantado, Ilha Rei George & 91,3 & Este trabalho \\
\hline Arthur Harbour, Bahia Paraiso & $1212-17498$ & Kennicutt et al. (1991) \\
\hline Bemacchi Bay, McMurdo sound & $32,6-56,2$ & McDonald et al (1994) \\
\hline Winter Ouarters Bav, McMurdo sound & $145,3-177$ & McDonald et al (1994) \\
\hline Cinder Cones, McMurdo sound & $69,2-155,9$ & McDonald et al (1994) \\
\hline Maxwell Bay, King George Island & $65,3-162,7$ & Curtosi et al., (2009) \\
\hline
\end{tabular}


Tabela 14. Concentrações de HPAs individuais, HPAs totais ( HPAs) (peso seco e peso úmido) soma de HPAs com 2 e 3 anéis aromáticos ( $\Sigma$ HPAs 2-3), soma de HPAs com 4 a 6 anéis aromáticos ( $\Sigma$ HPAs 4-6), soma de HPAs alquilados ( $\Sigma$ HPAsalquil) em ng g ${ }^{-1}$ peso seco, porcentagem de lipídios (\%) e porcentagem de umidade (\%) obtidos em moluscos. Os valores abaixo do Limite de detecção do método (LDM) estão indicados como "n.d.".

\begin{tabular}{|c|c|c|c|c|c|c|c|c|c|}
\hline Composto & $\begin{array}{c}\text { N. concinna } \\
\text { P.Plazza } \\
\text { Jan-93 }\end{array}$ & $\begin{array}{c}\text { N. concinna } \\
\text { EACF tanques } \\
\text { Fev-95 }\end{array}$ & $\begin{array}{l}\text { N. concinna } \\
\text { EACF } \\
\text { Dez-05 }\end{array}$ & $\begin{array}{l}\text { N. concinna } \\
\text { P. Demay } \\
\text { Dez-04 }\end{array}$ & $\begin{array}{l}\text { N. concinna } \\
\text { B. Dick } \\
\text { Jan-05 } \\
\end{array}$ & $\begin{array}{c}\text { N. concinna } \\
\text { P. Ullmann } \\
\text { Jan-06 }\end{array}$ & $\begin{array}{l}\text { Y. eightsi } \\
\text { P. Ullmann } \\
\text { Jan-06 }\end{array}$ & $\begin{array}{l}\text { L. elliptica } \\
\text { EACF } \\
\text { Dez-04 }\end{array}$ & LDM \\
\hline Naftaleno & n.d. & 22.7 & 12.6 & n.d. & 11.42 & 7.3 & 8.20 & 9.1 & 4.10 \\
\hline Bifenil & n.d. & 4.68 & n.d. & n.d. & n.d. & n.d. & n.d. & 4.40 & 3.80 \\
\hline Acenaftileno & n.d. & n.d. & n.d. & n.d. & n.d. & n.d. & n.d. & n.d. & 3.30 \\
\hline Acenafteno & n.d. & 1.03 & 1.28 & n.d. & n.d. & n.d. & 1.27 & n.d. & 0.80 \\
\hline ¿Alquilnaftalenos & 27.2 & 113.6 & 60.8 & 19.3 & n.d. & 16.5 & 40.7 & 70.6 & 3.80 \\
\hline $\begin{array}{l}\text { Fluoreno } \\
\end{array}$ & n.d. & n.d. & 1.91 & n.d. & n.d. & n.d. & 1.71 & 1.15 & 1.00 \\
\hline$\sum$ Alquilfluorenos & n.d. & 1.66 & 2.54 & n.d. & n.d. & n.d. & 2.04 & n.d. & 1.00 \\
\hline Dibenzotiofeno & n.d. & n.d. & 1.74 & n.d. & n.d. & n.d. & 1.40 & n.d. & 1.00 \\
\hline Fenantreno & n.d. & 3.94 & 9.82 & n.d. & n.d. & n.d. & 5.89 & n.d. & 2.20 \\
\hline Antraceno & n.d. & n.d. & n.d. & n.d. & n.d. & n.d. & n.d. & n.d. & 1.40 \\
\hline$\sum$ Alquilfenantreno & 85.6 & 1.86 & 15.4 & 13.6 & n.d. & 7.92 & 15.3 & 6.10 & 1.40 \\
\hline $\begin{array}{l}\text { Fluoranteno } \\
\text { Plo }\end{array}$ & n.d. & n.d. & n.d. & n.d. & n.d. & n.d. & 2.81 & n.d. & 2.40 \\
\hline Pireno & n.d. & n.d. & 5.56 & 5.46 & n.d. & n.d. & 6.40 & n.d. & 3.80 \\
\hline$\sum$ Alquilfluoranteno & n.d. & n.d. & n.d. & n.d. & n.d. & n.d. & n.d. & n.d. & 3.80 \\
\hline Reteno & n.d. & n.d. & n.d. & n.d. & n.d. & n.d. & n.d. & n.d. & 3.80 \\
\hline ¿Alquilpireno & n.d. & n.d. & n.d. & n.d. & n.d. & n.d. & n.d. & n.d. & 3.80 \\
\hline Benzo(c)fenantreno & n.d. & n.d. & n.d. & n.d. & n.d. & n.d. & n.d. & n.d. & 3.80 \\
\hline Benzo(a)fenantreno & n.d. & n.d. & n.d. & n.d. & n.d. & n.d. & n.d. & n.d. & 3.90 \\
\hline Criseno & n.d. & n.d. & 0.65 & n.d. & n.d. & n.d. & n.d. & n.d. & 0.60 \\
\hline$\sum$ Alquilcriseno & n.d. & n.d. & n.d. & n.d. & n.d. & n.d. & n.d. & n.d. & 0.60 \\
\hline Benzo(b)fluoranteno & n.d. & n.d. & n.d. & n.d. & n.d. & n.d. & n.d. & n.d. & 0.60 \\
\hline Benzo(k)fluoranteno & n.d. & n.d. & n.d. & n.d. & n.d. & n.d. & n.d. & n.d. & 1.70 \\
\hline Benzo(e)pireno & n.d. & n.d. & n.d. & n.d. & n.d. & n.d. & n.d. & n.d. & 1.70 \\
\hline Benzo(a)pireno & n.d. & n.d. & n.d. & n.d. & n.d. & n.d. & n.d. & n.d. & 2.90 \\
\hline Perileno & n.d. & n.d. & n.d. & n.d. & n.d. & n.d. & n.d. & n.d. & 2.90 \\
\hline Indeno $(1,2,3-\mathrm{c}, \mathrm{d})$ pireno & n.d. & n.d. & n.d. & n.d. & n.d. & n.d. & n.d. & n.d. & 3.80 \\
\hline Dibenzo(a,h)antraceno & n.d. & n.d. & n.d. & n.d. & n.d. & n.d. & n.d. & n.d. & 2.50 \\
\hline Benzo(b)criseno & n.d. & n.d. & n.d. & n.d. & n.d. & n.d. & n.d. & n.d. & 2.50 \\
\hline Benzo(g,h,i)perileno & n.d. & n.d. & n.d. & n.d. & n.d. & n.d. & n.d. & n.d. & 1.20 \\
\hline$\sum$ HPAs peso seco & 112.8 & 149.4 & 112.3 & 38.4 & 11.4 & 31.8 & 85.6 & 91.3 & \\
\hline HPAs (2-3) & 112.8 & 149.4 & 106.1 & 33.7 & 11.4 & 31.8 & 76.4 & 91.3 & \\
\hline$\sum$ HPAs (4-6) & n.d. & n.d. & 6.2 & 5.5 & n.d. & n.d. & 9.20 & n.d. & \\
\hline$\sum$ HPAs-alquil & 112.8 & 117.1 & 78.8 & 33.0 & n.d. & 24.5 & 58.0 & 76.7 & \\
\hline Lipídio (\%) & 9.58 & 1.16 & 6.41 & 16.3 & 5.85 & 8.66 & 4.80 & 4.39 & \\
\hline Umidade (\%) & 71 & 66 & 71 & 67 & 73 & 68 & 65 & 90 & \\
\hline$\sum$ HPAs peso úmido & 33.2 & 50.2 & 32.1 & 12.7 & 3.09 & 10.2 & 29.7 & 8.98 & \\
\hline
\end{tabular}


As concentrações de HPAs totais tenderam a diminuir com o distanciamento entre o local de coleta e as instalações da EACF, como mostrado na Figura 14. Isso pode ser atribuído à degradação fotoquímica ou biológica. Experimentos realizados por Ehrhardt et al. (1992), demonstraram que a taxa de decréscimo fotoquímico dos aromáticos alquilados excede a taxa dos não substituídos. Davies \& Tibbet (1987) demonstraram que a degradação microbiológica pode ter o mesmo efeito. Assim, as amostras mais próximas às fontes contêm características típicas de compostos provenientes do óleo e, à medida que se afastam, sofrem transformações químicas ou biológicas. Esse mesmo fato foi observado em regiões onde as contribuições são tipicamente de petróleo (Ehrhardt \& Petrick, 1993; Ehrhardt \& Burns, 1990,1993).

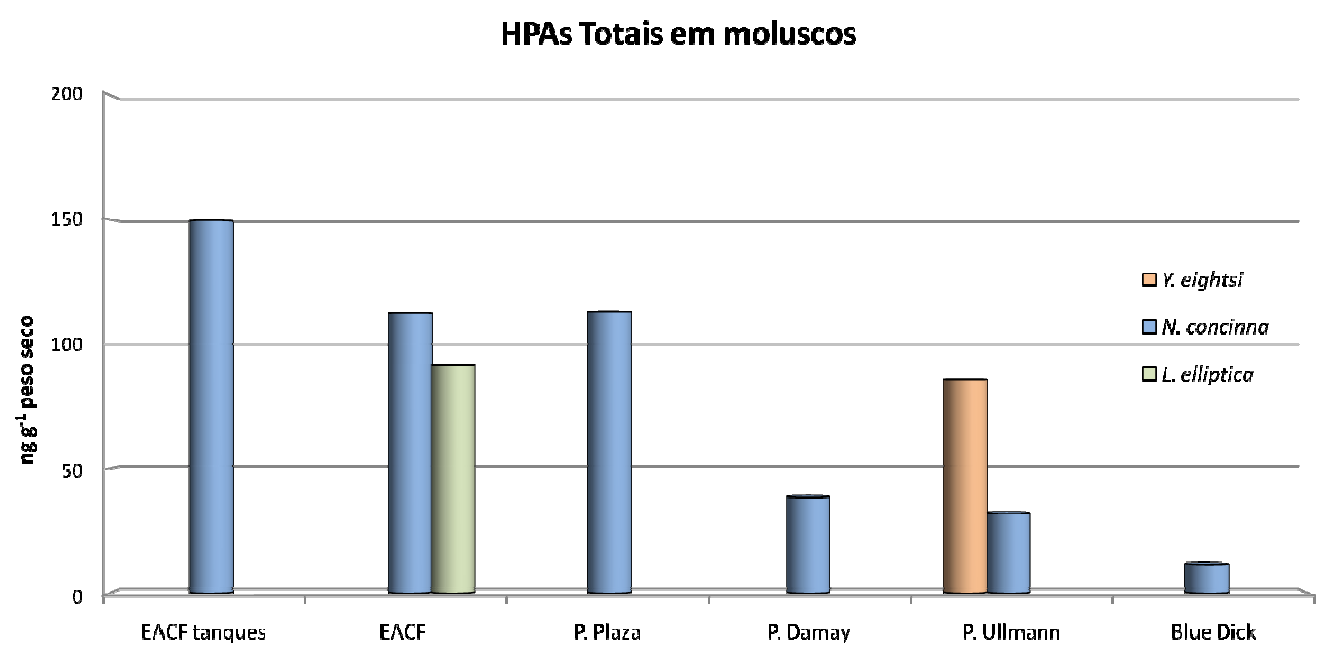

Figura 14. Concentrações de HPAs totais, em ng g ${ }^{-1}$ peso seco, obtidas em $Y$. eightsi, N. concinna e L. elliptica. 
A partição dos HPAs no meio aquático está relacionada à suas propriedades físico-químicas e ao seu peso molecular. Assim, os HPAs leves, por serem menos hidrofóbicos, geralmente encontram-se mais solubilizados na água, enquanto que os mais pesados, por serem mais hidrofóbicos, adsorvemse ao material particulado em suspensão e acabam se associando ao sedimento. No caso específico da região de estudo, é importante ressaltar que a principal fonte de HPAs para o ambiente marinho é o DFA, o qual é composto principalmente por compostos mais leves.

Como os bivalves são filtradores/suspensívoros é esperado que absorvam os HPAs leves através da ingestão de água e de materiais particulados em suspensão.

A Figura 15 apresenta a relação entre as concentrações dos HPAs leves e pesados, onde predominam os compostos leves. E na Figura 16 temos a relação entre os compostos alquilados e não alquilados, onde predominam os HPAs alquilados, com exceção de uma amostra de Nacella coletada em B. Dick, ponto de coleta mais afastado da EACF, na qual houve o predomínio de HPAs não alquilados. Este fato pode estar relacionado com as transformações químicas ou biológicas sofridas pelos HPAs com o distanciamento da EACF.

Curtosi et al. (2009) mediram concentrações de HPAs em L. elliptica da Baía Maxwell, Ilha Rei George e também observaram o predomínio dos HPAs leves, cerca de $87 \%$ dos HPAs totais. 


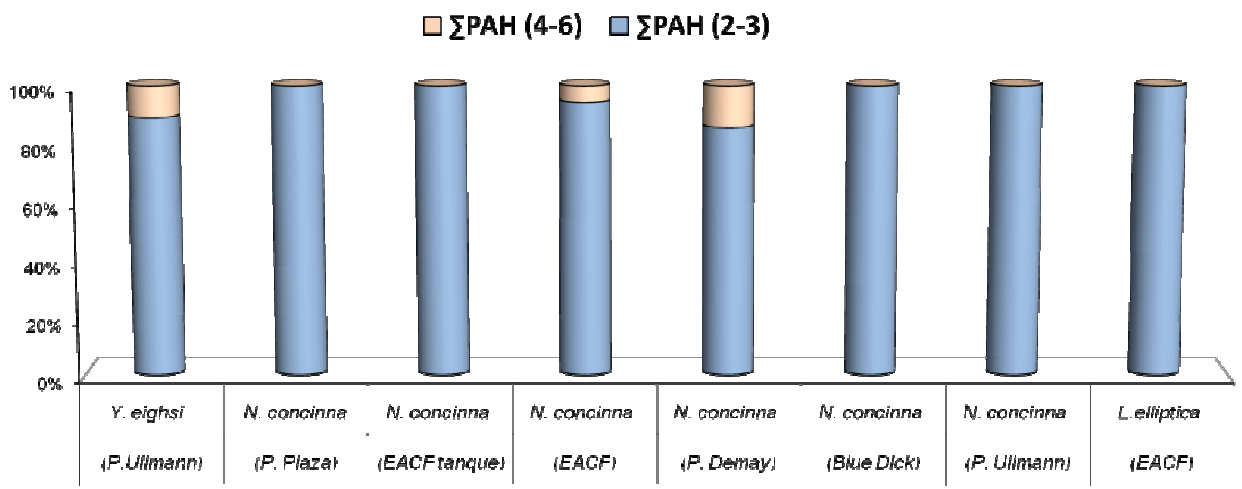

Figura 15. Composição dos parâmetros de $\Sigma$ HPAs (2-3 anéis) e $\Sigma$ HPAs (2-3 anéis) (\%) obtidos em Y. eightsi, N. concinna e L. elliptica.

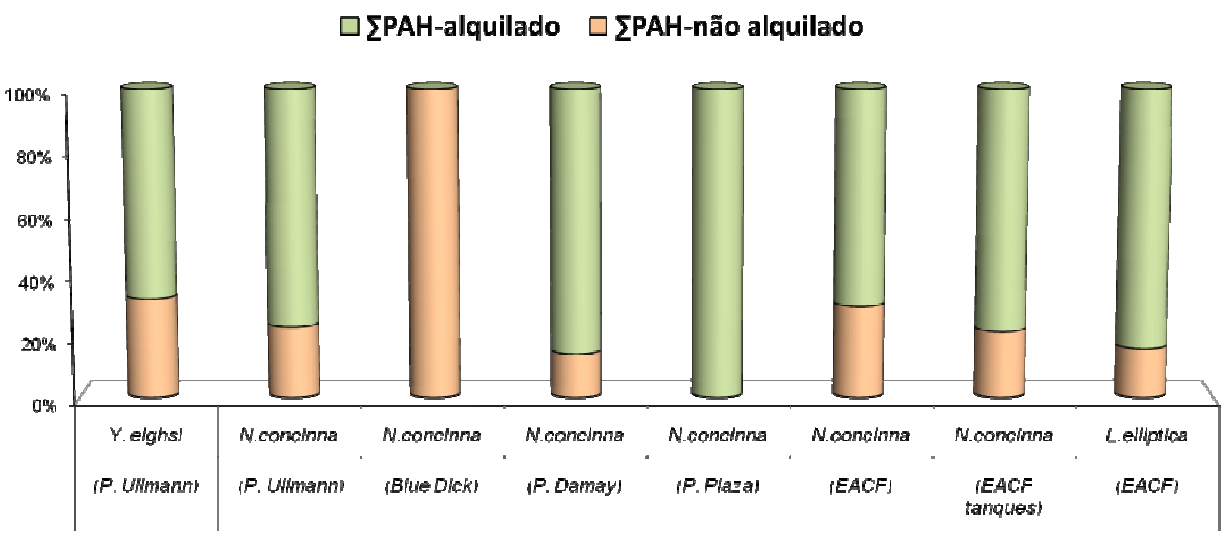

Figura 16. Composição dos parâmetros de $\Sigma$ HPAs alquilados e $\Sigma$ HPAs não alquilados (\%) obtidos em Y. eightsi, N. concinna e L. elliptica.

Os HPAs individuais presentes nos moluscos foram o naftaleno, 0 fenantreno e os grupos dos alquilnaftalenos e dos alquilfenantrenos (Figura 17). Também ocorreram o pireno e o fluoranteno, compostos que apresentam mais de três anéis aromáticos (Figura 17). Na maioria das amostras a distribuição desses compostos foi similar à distribuição obtida para o DFA 
(Figuras 17 e 18).

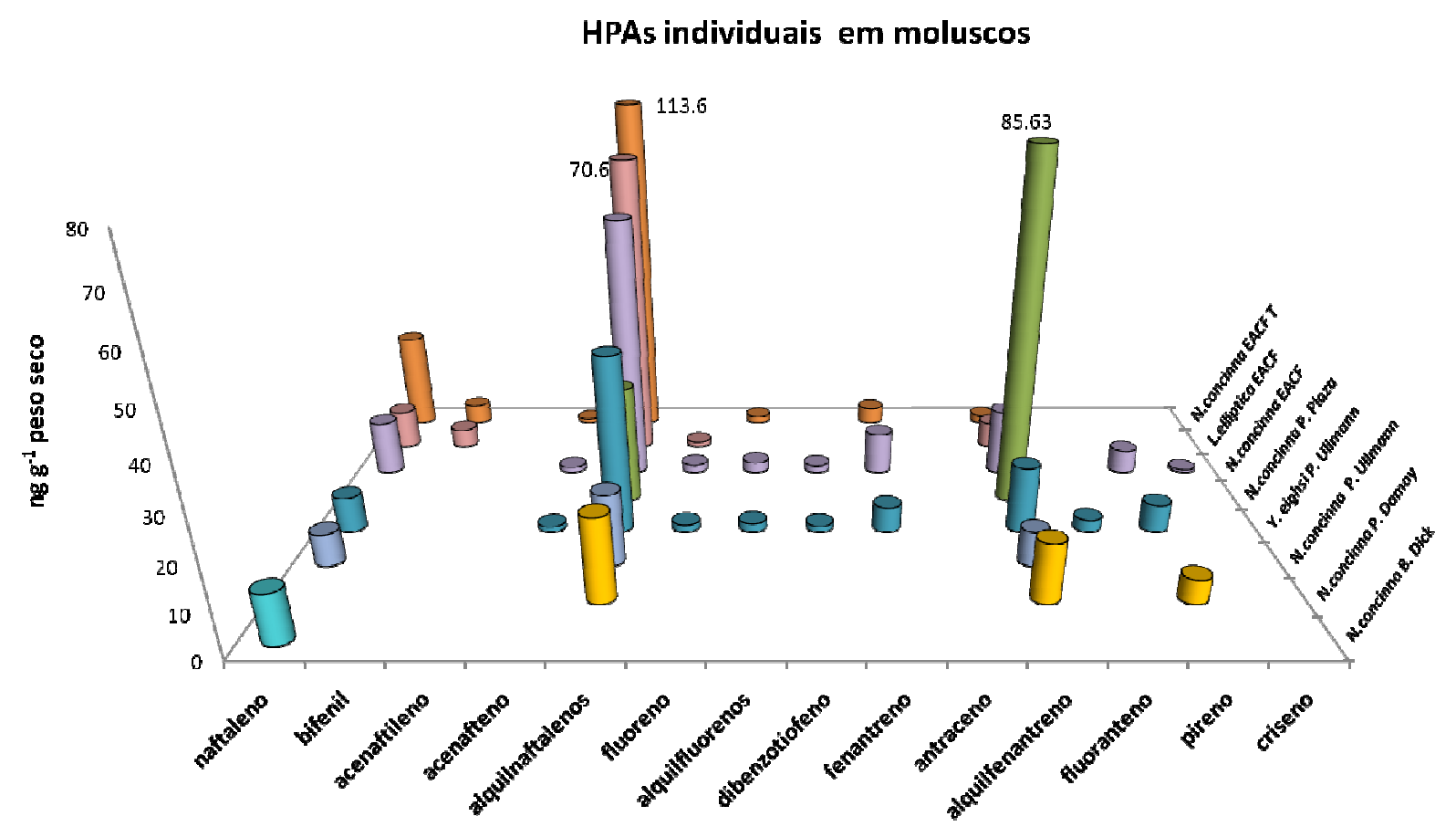

Figura 17. Concentrações de HPAs individuais, em $\mathrm{ng} \mathrm{g}^{-1}$ peso seco, obtidos em Y.eightsi, N. concinna e L. elliptica.

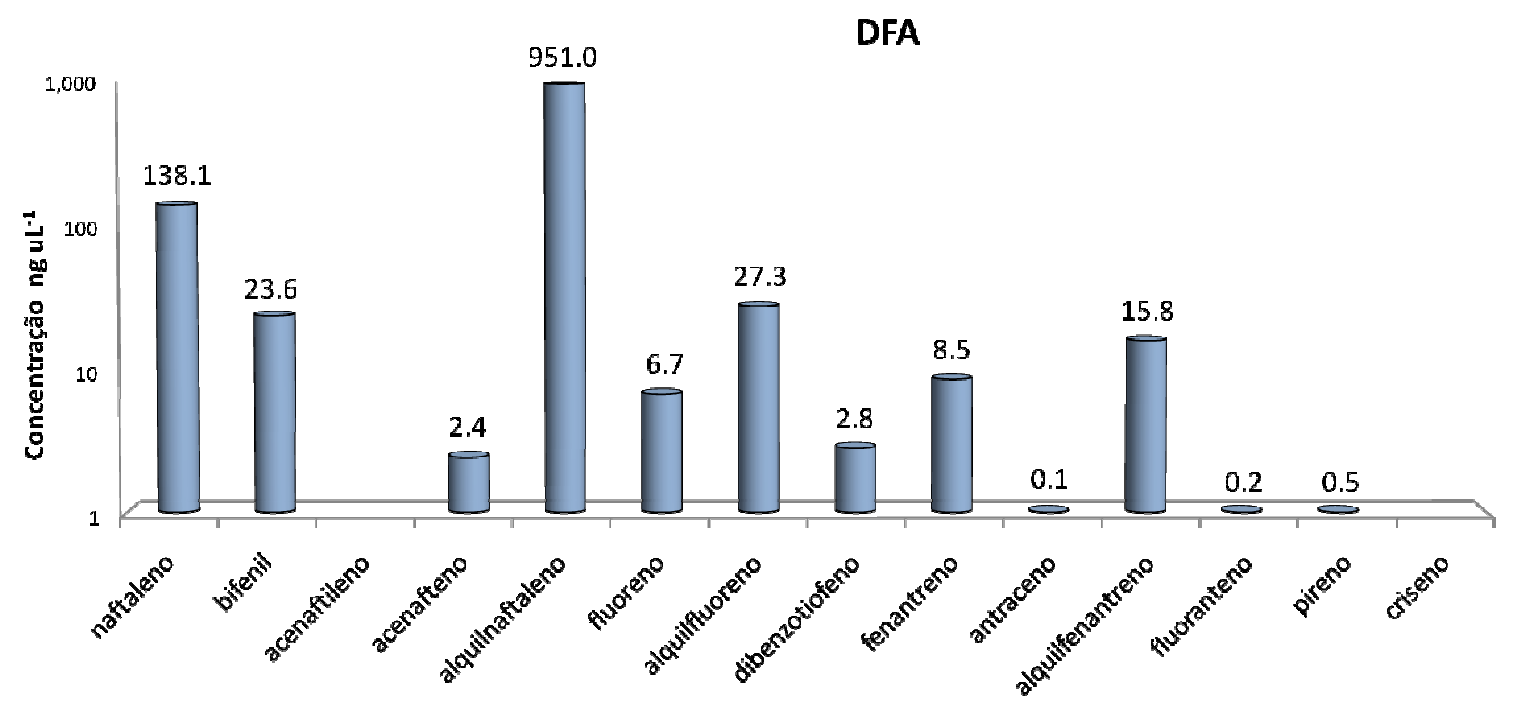

Figura 18. Concentrações, em ng g ${ }^{-1}$ peso seco (transformada em log), obtidas no Diesel Fuel Arctic - DFA. 
Observou-se que as maiores concentrações de HPAs totais para $N$. concinna foram obtidas em duas amostras coletadas próximo a EACF tanques e estação (149,4 e 112,3 $\mathrm{ng} \mathrm{g}^{-1}$ ps ou 50,2 e $32,1 \mathrm{ng} \mathrm{g}^{-1} \mathrm{pu}$ ) e em P. Plaza - próximo a estação (112,8 $\mathrm{ng} \mathrm{g}^{-1}$ ps ou 33,2 $\mathrm{ng} \mathrm{g}^{-1} \mathrm{pu}$ ) (Figura 19).

Kennicutt et al. (1991) analisaram HPAs em N. concinna para avaliar a contaminação por HPAs na Península Antártica (Palmer Station, Old Palmer Stations e Arthur Harbour), um ano após o derrame de 600.000 L de DFA do Bahia Paraíso (1989), encontrando concentrações que variam de 10.000 a $125.000 \mathrm{ng} \mathrm{g}^{-1}$ ps. Na mesma região, dois anos após o derrame Kennicutt et al. (1992) e Kennicutt \& Sweet (1992) analisaram novamente HPAs em N. concinna e obtiveram concentrações que variam de 15 a $2932 \mathrm{ng} \mathrm{g}^{-1} \mathrm{ps}$. Na Baía do Almirantado, as concentrações obtidas para HPAs totais $\left(11,4 \mathrm{ng} \mathrm{g}^{-1}\right.$ ps ou $149,4 \mathrm{ng} \mathrm{g}^{-1} \mathrm{ps}$ ) foram menores que as destes autores ao avaliarem locais contaminados por derrame de derivados de petróleo. Esses resultados também foram inferiores aos encontrados por Cripps \& Shears (1997) (219 a $428 \mathrm{ng} \mathrm{g}^{-1}$ os), ao analisarem HPAs em $N$. concinna na região da Faraday Station, Galindez Island, após o derrame de 1.000 litros de óleo diesel em 1992. Por outro lado, os resultados obtidos na Baia do Almirantado, estão dentro do intervalo de concentração encontrado por Curtosi et al. (2009), de 57,2 a $253,1 \mathrm{ng} \mathrm{g}^{-1}$, que analisou $N$. concinna na enseada Potter, Itha Rei George. 


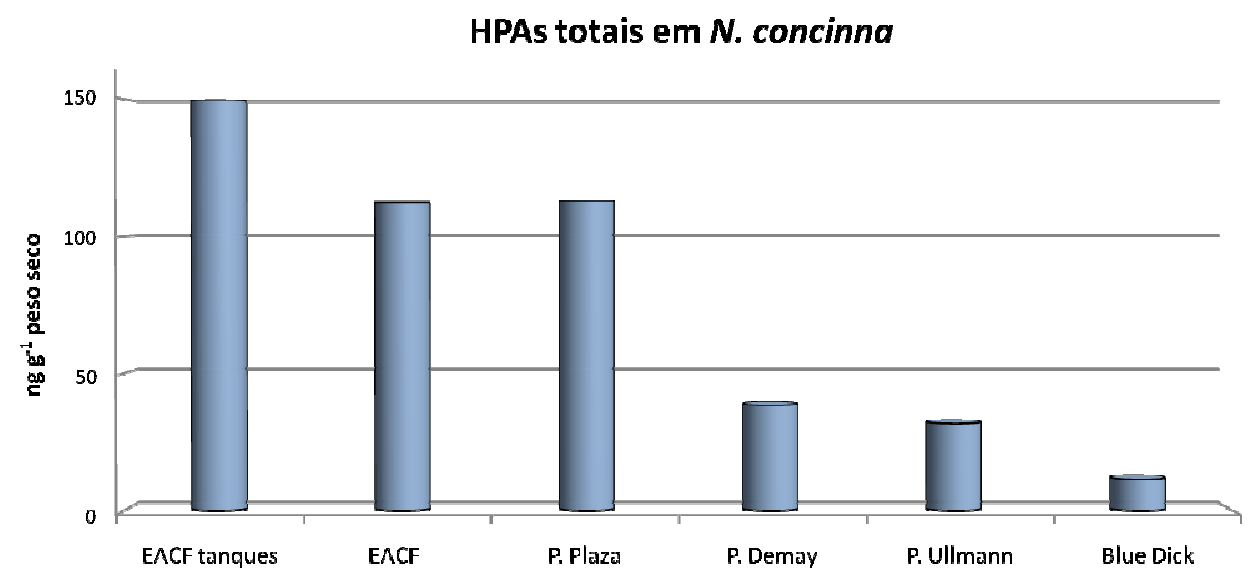

Figura 19. Concentrações de HPAs totais, $\mathrm{em} \mathrm{ng} \mathrm{g}^{-1}$ peso seco, obtidas em $N$. concinna.

Bícego et al, (2009) sugeriram que as maiores concentrações de HPAs encontradas em amostras de água nas proximidades de P. Plaza, são de contaminação por óleo, recebida principalmente da EACF, e provavelmente carregadas por correntes locais. Além disso, P. Plaza está localizada na rota de embarcações entre as estações Polonesa e Brasileira. Isso também explica o fato da concentração para a amostra de N. concinna, coletada em P. Plaza, ter concentração de HPAs totais, próxima às obtidas nas amostras coletadas nas proximidades da EACF.

A Figura 21 mostra a distribuição dos HPAs individuais obtidos em $N$. concinna, na qual os compostos predominantes foram o naftaleno e os grupos de alquilnaftalenos e alquilfenantrenos, mostrando uma similaridade com a distribuição de compostos do DFA, como mostram os cromatogramas apresentados na Figura 20. 

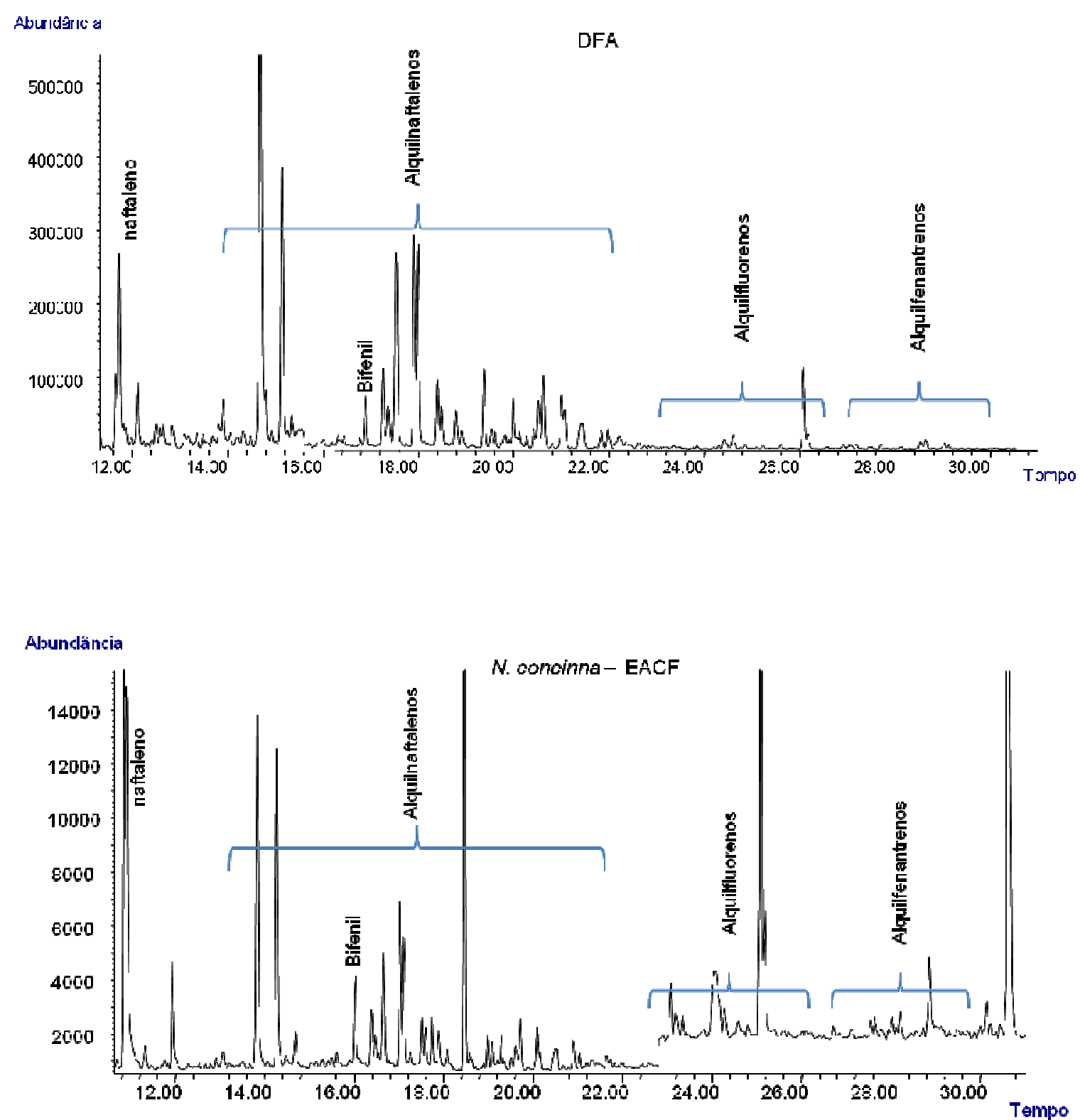

Figura 20. Cromatogramas obtidos nas análises do DFA e de uma amostra de N. concinna. 


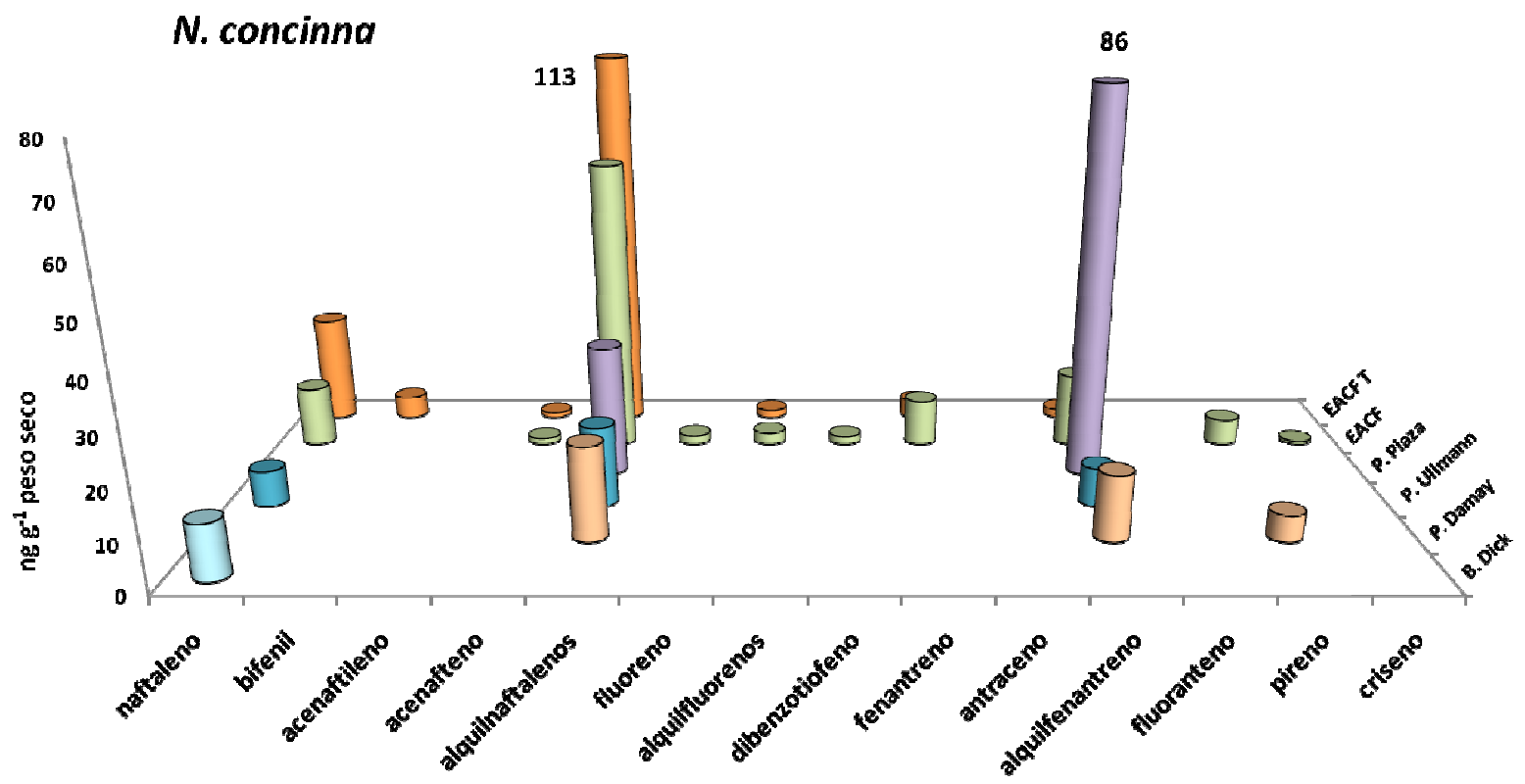

Figura 21. Concentrações de HPAs individuais, em $\mathrm{ng} \mathrm{g}^{-1}$ peso seco, obtidas em N. concinna.

Observou-se que em locais mais distantes da EACF, a concentração dos alquilnaftalenos diminuiu em relação ao naftaleno e aos alquilfenantrenos. Nas proximidades da EACF as concentrações de alquilnaftalenos foram cinco vezes maiores que as de naftaleno. Por outro lado, em local afastado da EACF, mas dentro da enseada Martel, a concentração de alquilnaftalenos foi o dobro da concentração de naftaleno. Fora da enseada Martel, em B. Dick, local próximo à saída da Baía, ocorreu somente o naftaleno. Em P. Demay as concentrações de alquilnaftalenos e alquilfenantrenos foram próximas, perdendo assim a similaridade com o perfil do DFA, onde a concentração de alquilnaftalenos é aproximadamente sete vezes a concentração de naftaleno. 
Esse comportamento observado nas concentrações dos HPAs individuais das amostras coletadas ao longo da Baía do Almirantado pode ser relacionado às propriedades físico-químicas desses compostos. Os alquilnaftalenos são mais voláteis e solúveis (pressão de vapor de 36,8 pa a $25^{\circ} \mathrm{C}$ e solubilidade de $31 \mathrm{mg} \mathrm{L}^{-1}$ ) que os alquilfenantrenos (pressão de vapor de $0,113 \mathrm{~Pa}$ a $25^{\circ} \mathrm{C}$ e solubilidade de $1,1 \mathrm{mg} \mathrm{L}^{-1}$ ), além do que, os compostos não alquilados possuem um sistema aromático mais estável que os substituídos, tornando-os mais suscetíveis aos processos relacionados com o intemperismo. Este fato também foi demonstrado por Ehrhardt et al. (1992), quando observou que a taxa de decréscimo fotoquímico dos aromáticos alquilados excede a taxa dos não substituídos. Mesmo tendo apresentando uma diferente distribuição de HPAs individuais entre as amostras, estas podem indicar uma mesma fonte de contaminação.,

As concentrações de HPAs totais obtidas para a amostra de L. elliptica coletada nas proximidades da EACF, foi de $91,3 \mathrm{ng} \mathrm{g}^{-1}$ ps $\left(8,98 \mathrm{ng} \mathrm{g}^{-1} \mathrm{pu}\right)$, estão compreendidas no intervalo de concentração (32 a $156 \mathrm{ng} \mathrm{g}^{-1}$ ps) determinado por McDonald et al., (1994), em L. elliptica coletada em MacMurdo Sound, Antártica. Resultados similares aos obtidos por Curtosi et al., (2009), em L. Elliptica, coletadas em locais não contaminados na enseada Potter, llha Rei George, Antártica (65,3 a 162,7 ng g ${ }^{-1}$ ps).

Embora não tenha sido possível aplicar análises estatísticas nos dados, foi observada uma diferença quanto ao número de HPAs individuais absorvidos nas amostras de L. elliptica e N. concinna, coletadas nas proximidades da EACF. Enquanto que na espécie L. elliptica ocorreram os compostos naftaleno, bifenil, fluoreno e os grupos alquilnaftalenos e 
alquilfenantrenos, na espécie $N$. concinna ocorreram naftaleno, acenafteno, alquilnaftalenos, fluoreno, dibenzotiofeno, fenantreno, pireno, criseno e os grupos alquilnaftalenos e alquilfenantrenos (Figura 22).

O bivalve L. elliptica que é um suspensívoro e se alimenta através da filtração da água tende a absorver os HPAs mais solúveis, como o fenantreno e - naftaleno (Tabela 2). Já o gastrópode $N$. concinna que é um depositívoro/herbívoro e se alimenta de partículas do substrato, pode absorver uma maior variedade de HPAs, inclusive compostos com mais de três anéis (pireno e criseno), que estão mais associados ao sedimento (Figura 21). Estes HPAs pesados, geralmente estão relacionados a fontes pirolíticas, as quais são introduzidas na região de estudo por embarcações e queima de DFA para produção de energia nas estações de pesquisas. Assim, a absorção de HPAs individuais pelas espécies $N$. concinna e $L$. elliptica evidenciou a importância do habito alimentar na absorção destes compostos.

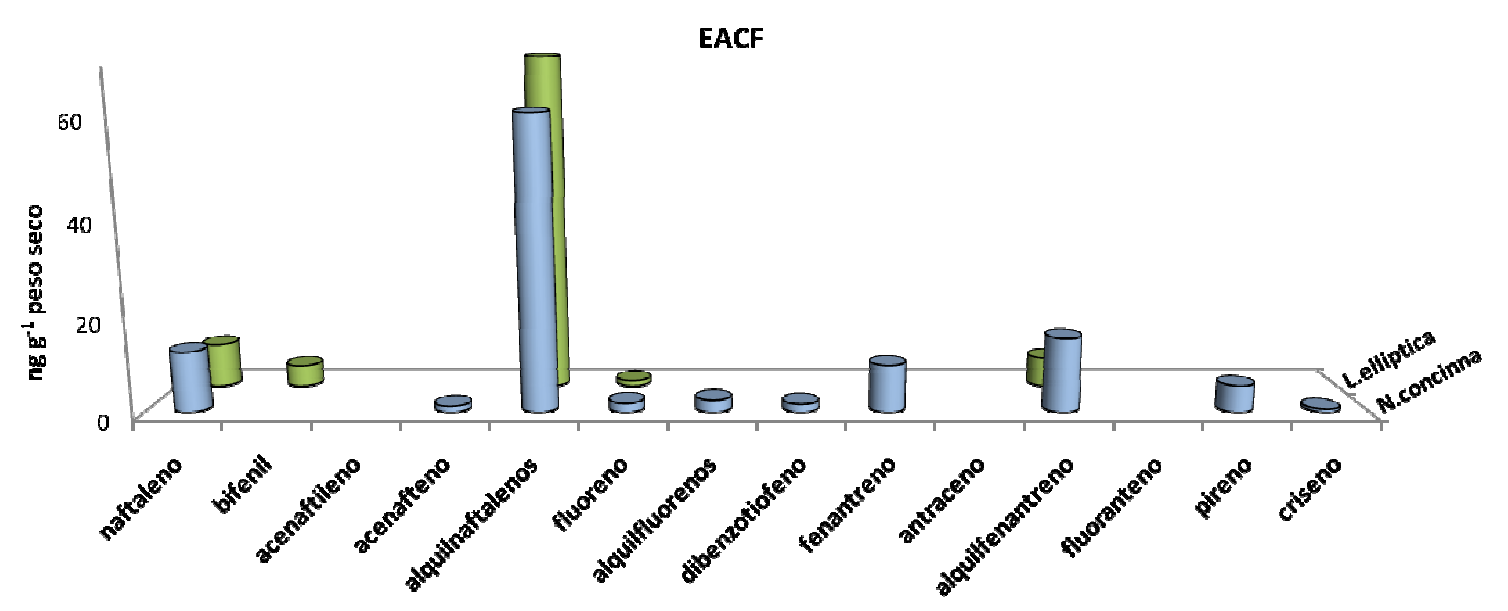

Figura 22. Concentrações de HPAs individuais, em $\mathrm{ng} \mathrm{g}^{-1}$ peso seco, obtidas em N. concinna e L. elliptica coletadas próximo a EACF. 
Cripps \& Priddle (1995) relataram níveis de concentrações de HPAs (5 a $25 \mathrm{ng} \mathrm{g}^{-1} \mathrm{pu}$ ) no bivalve $Y$. eightsi coletadas em Signy Island, South Orkney Island, similares aos obtidos para Y. eightsi coletada em P. Ullmann, Baia do Almirantado $\left(85,6 \mathrm{ng} \mathrm{g}^{-1}\right.$ ps ou $\left.29,7 \mathrm{ng} \mathrm{g}^{-1} \mathrm{pu}\right)$.

Em P. Ulmann $N$. concinna absorveu apenas os compostos mais disponibilizados na região (naftaleno, alquilnaftaleno e alquilfenantreno), enquanto que $Y$. eightsi, que além de suspensívoro também é depositívoro, absorveu naftaleno, acenafteno, alquilnaftaleno, fluoreno, alquilfluoreno, dibenzotiofeno, fenantreno, alquilfenantreno, fluoranteno e pireno, mostrando que os HPAs encontrados na EACF também estão presentes em P.Ullmann (Figura 23).

$\mathrm{Na}$ distribuição de HPAs individuais foi observado que as espécies Y.eightsi e L. elliptica mantiveram a proporção entre as concentrações de alquilnaftaleno e naftaleno, sendo esta proporção similar ao do DFA.

As espécies depositívoras alimentam-se de partículas associados ao substrato, logo, espera-se que $N$. concinna e $Y$. eightsi, tendo hábitos alimentares semelhantes, absorvam HPAs da mesma maneira. Porém, esse resultado contrário, pode estar relacionado com a capacidade de eliminação de HPAs da $N$. concinna, indicando que $N$. concinna possa ter uma taxa de eliminação maior do que a $Y$. eightsi. 


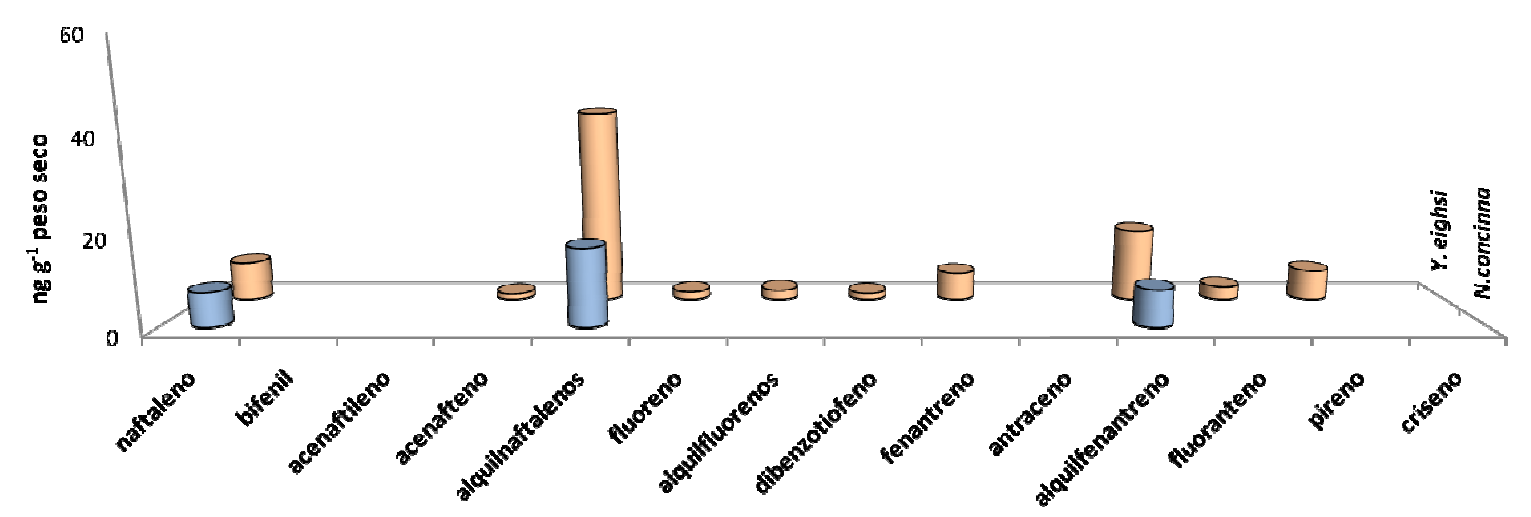

Figura 23. Concentrações de HPAs individuais, em ng g ${ }^{-1}$ peso seco, obtidas em N. concinna e Y. eightsi, coletadas em P. Ullmann.

\subsubsection{Hidrocarbonetos policíclicos aromáticos em equinodermos}

Na região Antártica há poucos estudos (Tabela 15) sobre medidas de HPAs em equinodermos. Clarke \& Law (1981) a fim de estabelecer uma linha de base para HPAs em organismos, analisaram a estrela do mar Odontaster validus da llha Signy e obtiveram concentração de $10,1 \mathrm{ng} \mathrm{g}^{-1} \mathrm{pu}$, valor similar a menor concentração $\left(12,6 \mathrm{ng} \mathrm{g}^{-1} \mathrm{pu}\right)$ obtida neste estudo. 
Tabela 15. Concentrações de HPAs em equinodermos analisados por outros autores em diferentes regiões na Antártica.

\begin{tabular}{lcl}
\hline Amostra & $\begin{array}{c}\text { HPA total } \\
\text { ng g }^{-1} \text { peso úmido }\end{array}$ & \multicolumn{1}{c}{ Referência } \\
\hline Odontaster validus & $\begin{array}{c}12,6-22,9^{*} \\
(42,1-179,1 \mathrm{ps})\end{array}$ & $\begin{array}{l}\text { Este trabalho, Baía do Almirantado, llha Rei } \\
\text { George }\end{array}$ \\
Odontaster validus & $85,5-815,6$ & $\begin{array}{l}\text { Clark \& Law (1981), King Edward Cove, South } \\
\text { Georgia }\end{array}$ \\
Odontaster validus & $10,1-22,8$ & $\begin{array}{l}\text { Clark \& Law (1981), Signy Island, South } \\
\text { Orkney Islands }\end{array}$ \\
Diplasterias & 0.1 & $\begin{array}{l}\text { Platt \& Mackie (1981), South Georgia } \\
\text { meridionalis }\end{array}$ \\
\hline
\end{tabular}

${ }^{*}$ Concentração em peso úmido para comparar com os dados da literatura.

Como não há registros disponíveis na literatura sobre medidas de concentração de HPAs no ofiuróide Ophionotus victoriae e no ouriço-do-mar Sterechinus neumayeri, este estudo estabeleceu as primeiras medidas de HPAs para essas espécies, além de efetuar as primeiras medidas de concentração de HPAs para a O. validus da Baía do Almirantado.

Foram analisadas cinco amostras de ouriço do mar S. neumayeri, duas amostras de estrela-do-mar 0 . validus e uma do ofiuróide $O$. victoriae. As concentrações de HPAs totais e individuais estão apresentadas na Tabela 16. 
Tabela 16. Concentrações de HPAs individuais, HPAs totais ( HPAs), soma de HPAs com 2 e 3 anéis aromáticos ( $\Sigma$ HPAs 2 3), soma de HPAs com 4 a 6 anéis aromáticos ( $\Sigma$ HPAs 4-6), soma de HPAs alquilados ( $\Sigma$ HPAs-alquil) em ng g ${ }^{-1}$ peso seco; porcentagem de lipídios (\%); porcentagem de umidade (\%); HPAs totais $\mathrm{ng} \mathrm{g}^{-1}$ peso úmido, obtidos em equinodermos. Os valores abaixo do limite de detecção do método (LDM) estão indicados como "n.d.".

\begin{tabular}{|c|c|c|c|c|c|c|c|c|c|}
\hline Composto & $\begin{array}{l}\text { O. victoria } \\
\text { P. Ullmann } \\
\text { Dez-04 }\end{array}$ & $\begin{array}{c}\text { O. validus } \\
\text { EACF heliponto } \\
\text { Fev-06 }\end{array}$ & $\begin{array}{l}\text { O. validus Hennequin } \\
\text { Dez-07 }\end{array}$ & $\begin{array}{c}\text { S. neumayeri } \\
\text { EACF heliponto } \\
\text { Jan-06 }\end{array}$ & $\begin{array}{c}\text { S. neumayeri EACF tanques } \\
\text { Dez-05 }\end{array}$ & $\begin{array}{l}\text { S. neumayeri } \\
\text { P. Ullmann } \\
\text { Jan-06 }\end{array}$ & $\begin{array}{c}\text { S. neumayeri } \\
\text { Refúgio I } \\
\text { Dez-05 }\end{array}$ & $\begin{array}{l}\text { S. neumayeri } \\
\text { P. Yelow } \\
\text { Dez-05 }\end{array}$ & LDM \\
\hline Naftaleno & 33.5 & 34.7 & 13.9 & 36.1 & 17.9 & 10.9 & 18.3 & 10.3 & 4.10 \\
\hline Bifenil & n.d. & n.d. & n.d. & n.d. & n.d. & n.d. & n.d. & n.d. & 3.80 \\
\hline Acenaftileno & 3.68 & 4.28 & n.d. & n.d. & n.d. & n.d. & n.d. & n.d. & 3.30 \\
\hline Acenafteno & n.d. & n.d. & n.d. & 1.53 & 1.15 & 0.96 & n.d. & n.d. & 0.80 \\
\hline$\sum$ Alquilnaftalenos & 23.0 & 22.2 & 6.06 & 112.8 & 75.9 & 52.1 & 37.5 & 29.9 & 3.80 \\
\hline Fluoreno & 1.73 & n.d. & n.d. & 2.33 & 2.26 & 1.25 & 1.03 & n.d. & 1.00 \\
\hline ¿Alquilfluorenos & n.d. & 4.30 & n.d. & n.d. & n.d. & n.d. & n.d. & n.d. & 1.00 \\
\hline Dibenzotiofeno & 1.00 & n.d. & n.d. & 2.70 & 1.21 & 1.55 & n.d. & 1.13 & 1.00 \\
\hline Fenantreno & 8.11 & n.d. & n.d. & 6.10 & 4.37 & 4.67 & 3.57 & 3.01 & 2.20 \\
\hline Antraceno & n.d. & n.d. & n.d. & n.d. & n.d. & n.d. & n.d. & n.d. & 1.40 \\
\hline$\sum$ Alquilfenantreno & 7.19 & 24.6 & 15.5 & 12.3 & 10.5 & 11.9 & 10.4 & 9.0 & 1.40 \\
\hline Fluoranteno & n.d. & n.d. & n.d. & n.d. & n.d. & 2.73 & n.d. & n.d. & 2.40 \\
\hline Pireno & n.d. & 9.65 & 6.65 & 5.25 & 4.95 & 8.29 & 5.30 & 6.30 & 3.80 \\
\hline$\sum$ Alquilfluoranteno & n.d. & n.d. & n.d. & n.d. & n.d. & n.d. & n.d. & n.d. & 3.80 \\
\hline Reteno & n.d. & n.d. & n.d. & n.d. & n.d. & n.d. & n.d. & n.d. & 3.80 \\
\hline ¿Alquilpireno & n.d. & n.d. & n.d. & n.d. & n.d. & n.d. & n.d. & n.d. & 3.80 \\
\hline Benzo(c)fenantreno & n.d. & n.d. & n.d. & n.d. & n.d. & n.d. & n.d. & n.d. & 3.80 \\
\hline Benzo(a)fenantreno & n.d. & n.d. & n.d. & n.d. & n.d. & n.d. & n.d. & n.d. & 3.90 \\
\hline Criseno & n.d. & n.d. & n.d. & n.d. & n.d. & n.d. & n.d. & 1.15 & 0.60 \\
\hline$\sum$ Alquilcriseno & n.d. & n.d. & n.d. & n.d. & n.d. & n.d. & n.d. & n.d. & 0.60 \\
\hline Benzo(b)fluoranteno & n.d. & n.d. & n.d. & n.d. & n.d. & n.d. & n.d. & n.d. & 0.60 \\
\hline Benzo(k)fluoranteno & n.d. & n.d. & n.d. & n.d. & n.d. & n.d. & n.d. & n.d. & 1.70 \\
\hline Benzo(e)pireno & n.d. & n.d. & n.d. & n.d. & n.d. & n.d. & n.d. & n.d. & 1.70 \\
\hline Benzo(a)pireno & n.d. & n.d. & n.d. & n.d. & n.d. & n.d. & n.d. & n.d. & 2.90 \\
\hline $\begin{array}{l}\text { Perileno } \\
\end{array}$ & n.d. & n.d. & n.d. & n.d. & n.d. & n.d. & n.d. & n.d. & 2.90 \\
\hline Indeno(1,2,3-c,d)pireno & n.d. & n.d. & n.d. & n.d. & n.d. & n.d. & n.d. & n.d. & 3.80 \\
\hline Dibenzo(a,h)antraceno & n.d. & n.d. & n.d. & n.d. & n.d. & n.d. & n.d. & n.d. & 2.50 \\
\hline Benzo(b)criseno & n.d. & n.d. & n.d. & n.d. & n.d. & n.d. & n.d. & n.d. & 2.50 \\
\hline Benzo(g,h,i)perileno & n.d. & n.d. & n.d. & n.d. & n.d. & n.d. & n.d. & n.d. & 1.20 \\
\hline$\sum$ HPAs & 78.2 & 99.8 & 42.1 & 179.1 & 118.2 & 94.4 & 76.1 & 60.8 & \\
\hline$\sum$ HPAs(2-3) & 78.2 & 118.5 & 38.6 & 173.8 & 113.2 & 83.38 & 70.8 & 53.4 & \\
\hline$\sum$ HPAs(4-6) & n.d. & 17.2 & 7.17 & 5.3 & 5.0 & 11.02 & 5.3 & 7.5 & \\
\hline$\sum$ PAH-alquil & 30.2 & 74.2 & 27.2 & 125.1 & 86.4 & 64.098 & 47.9 & 38.9 & \\
\hline Lipídio (\%) & 2.49 & 7.74 & 23.9 & 16.0 & 18.0 & 9.13 & 11.8 & 9.61 & \\
\hline Umidade (\%) & 15 & 23 & 30 & 35 & 35 & 35 & 35 & 29 & \\
\hline$\sum$ HPAs peso úmido & 25.8 & 23.0 & 12.5 & 62.7 & 41.1 & 33.0 & 26.6 & 17.3 & \\
\hline
\end{tabular}


No geral, as concentrações de HPAs totais variaram de $42,1 \mathrm{ng} \mathrm{g}^{-1} \mathrm{ps}$ a $179,1 \mathrm{ng} \mathrm{g}^{-1}$ ps (12,5 a 62,7 $\left.\mathrm{ng} \mathrm{g}^{-1} \mathrm{pu}\right)$. A Figura 24 mostra que a maior concentração obtida foi para $S$. neumayeri coletado próximo ao heliponto da EACF, local onde ocorre maior atividade de pequenas embarcações, e a menor concentração foi obtida para O. validus coletado em Hennequin , local afastado da EACF e fora da enseada Martel, a qual esteve no intervalo $\left(10,1-22,8 \mathrm{ng} \mathrm{g}^{-}\right.$ ${ }^{1}$ pu) obtido por Clarke \& Law, 1981.

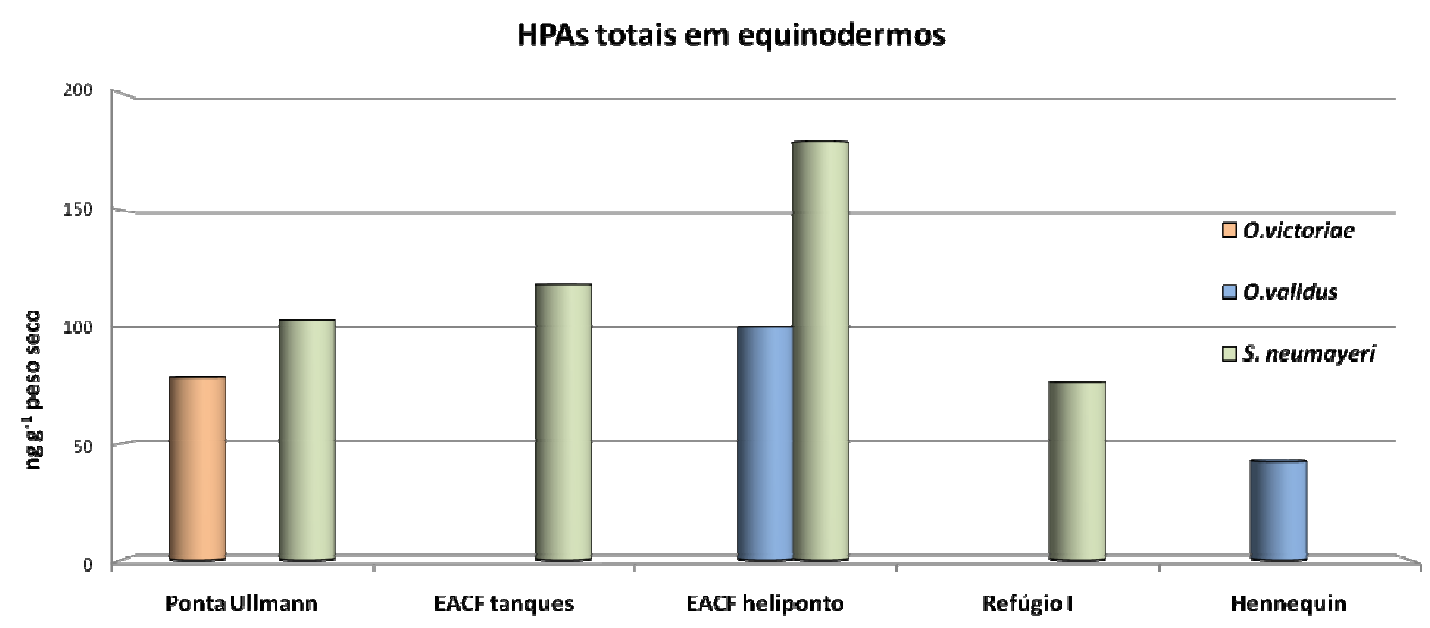

Figura 24. Concentrações de HPAs totais, em ng g ${ }^{-1}$ peso seco, obtidas em $O$. victoria, $O$. validus e $S$. neumayeri.

Os HPAs leves e alquilados (Figuras 25 e 26) também predominaram nas amostras de equinodermos, sendo observada a ocorrência de HPAs com mais de três anéis. 


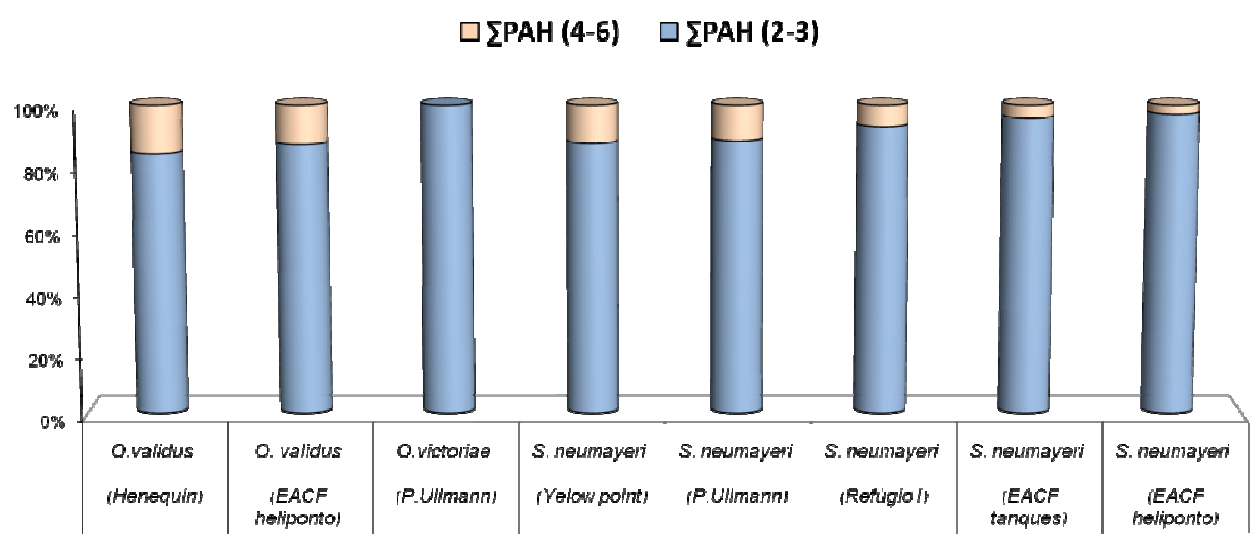

Figura 25. Composição dos parâmetros de $\Sigma$ HPAs (2-3 anéis) e $\Sigma$ HPAs (2-3 anéis) (\%) detectados em O. victoria, O. validus e S. neumayeri.

\section{$\square \sum$ PAH-alquilado $\square \sum$ PAH-não alquilado}

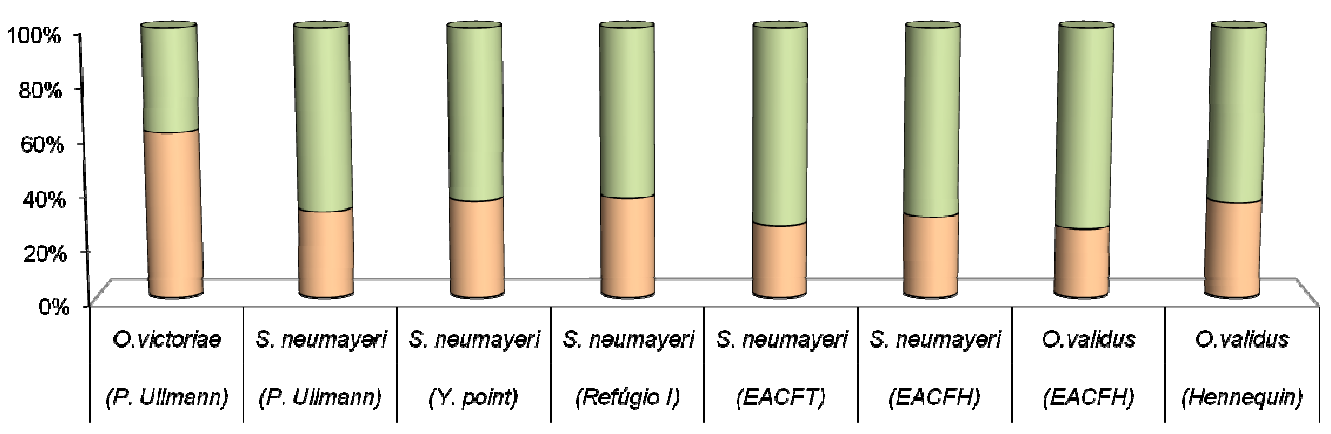

Figura 26. Composição dos parâmetros de $\Sigma$ HPAs alquilados e $\Sigma$ HPAs não alquilados (\%) detectados em 0 . victoria, O. validus e S. neumayeri.

Os compostos individuais presentes nas amostras de equinodermos foram o naftaleno, acenaftileno, acenafteno, fluoreno, dibenzotiofeno, fenantreno, fluoranteno, pireno, criseno e os grupos de alquilfluorenos, alquilfenantrenos e alquilnaftalenos (Figura 27). 
Mesmo em locais próximos da fonte de HPAs, observou-se que amostras de ofiuróide e estrela-do-mar apresentaram maior concentração dos compostos não alquilados relativamente aos seus homólogos.

HPAs individuais em equinodermos

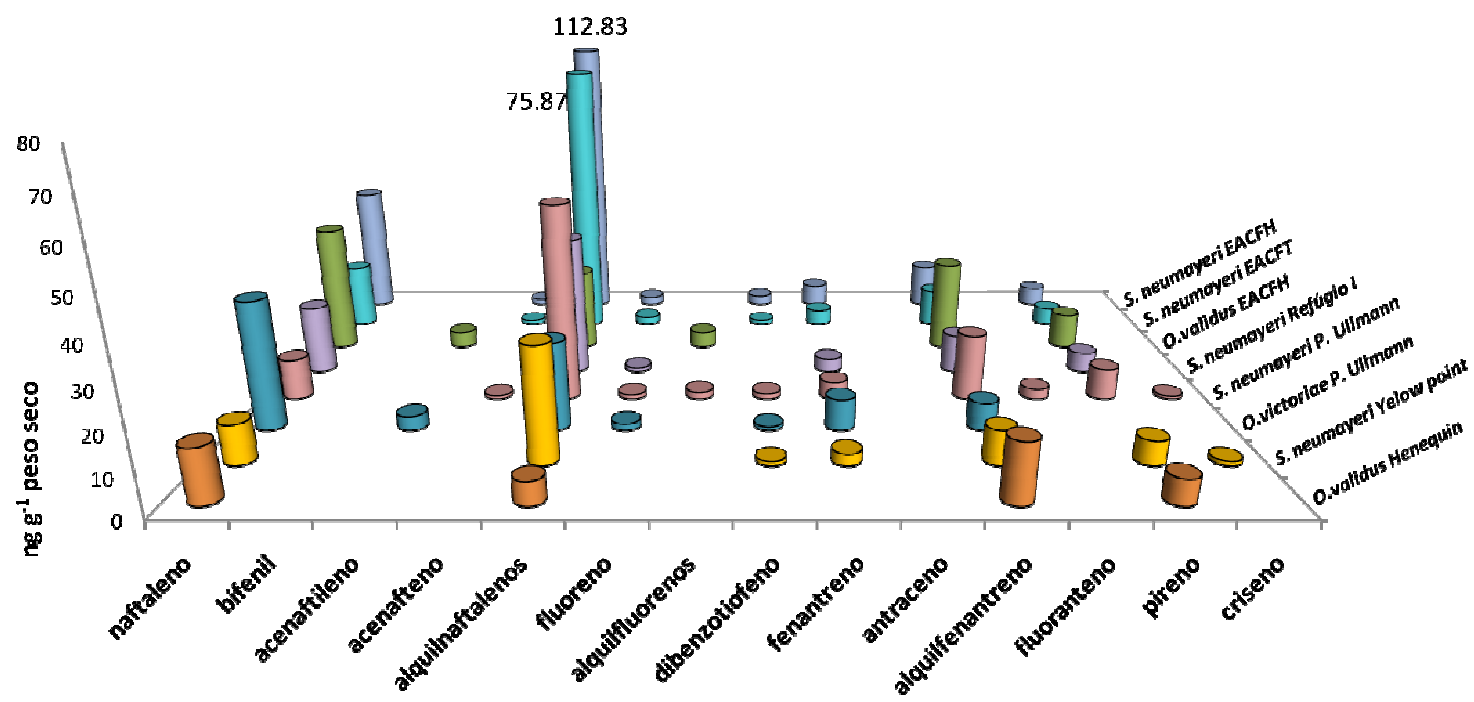

Figura 27. Concentrações de HPAs individuais, em ng g-1 peso seco, obtidas em O. victoria, $O$. validus e $S$. neumayeri.

As concentrações das cinco amostras do ouriço $S$. neumayeri variaram de $179,1 \mathrm{ng} \mathrm{g}^{-1}$ ps (62,7 $\mathrm{ng} \mathrm{g}^{-1}$ pu) na estação EACF a $60,8 \mathrm{ng} \mathrm{g}^{-1}$ ps $(17,3 \mathrm{ng}$ $\mathrm{g}^{-1} \mathrm{pu}$ ) em P. Yelow, local afastado da estação e dentro da enseada Martel.

As concentrações de HPAs totais em $S$. neumayeri tenderam a diminuir com o distanciamento entre o local de coleta e as instalações da EACF, como mostrado na Figura 28. Isso pode ser atribuído tanto à degradação fotoquímica ou biológica dos HPAs, como ao hábito alimentar e fisiologia das espécies. 


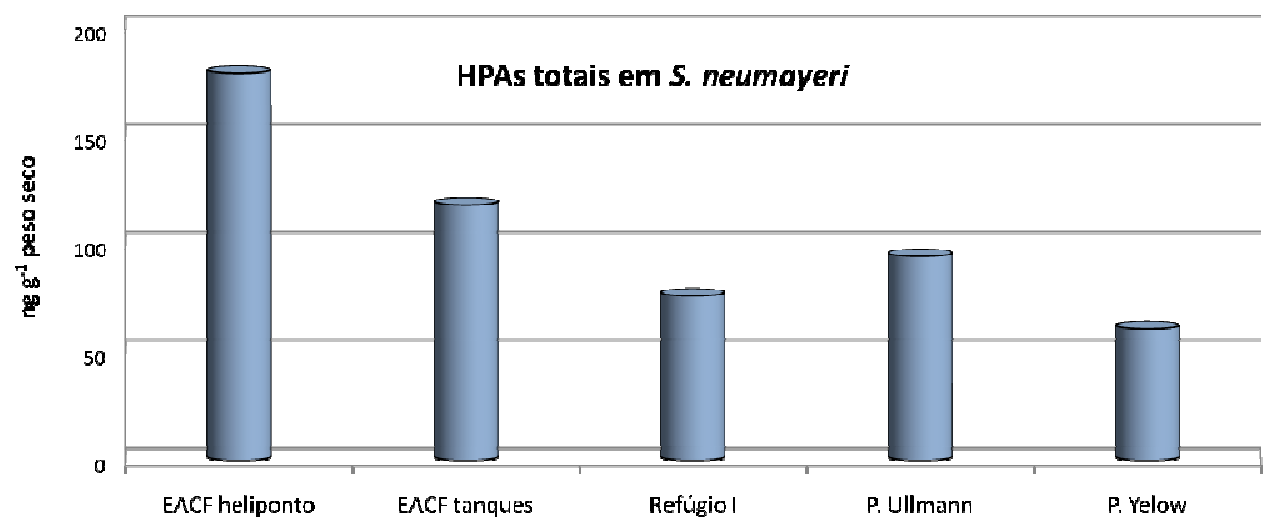

Figura 28. Concentrações de HPAs totais, em $\mathrm{ng} \mathrm{g}^{-1}$ peso seco, obtidas em $S$. neumayeri.

Em todas as amostras de ouriço-do-mar $S$. neumayeri, ocorreu o naftaleno, fenantreno, pireno, os grupos dos alquilnaftalenos e alquilfenantrenos, sendo que o predomínio foi dos alquilnaftalenos, e a distribuição de HPAs individuais foi similar a do DFA. Em amostra coletada em P. Ullmann, a concentração dos alquilnaftalenos foi cerca de cinco vezes maior que o naftaleno, enquanto que, em amostras coletadas nas proximidades da EACF, a concentração de alquilnaftalenos foi de três a quatro vezes maiores que o naftaleno. Assim, podemos observar uma similaridade na distribuição dos compostos individuais (Figura 29), para todas as amostras coletadas na Baía do Almirantado, seja o ponto de coleta próximo ou afastado da EACF. 


\section{S. neumayeri}

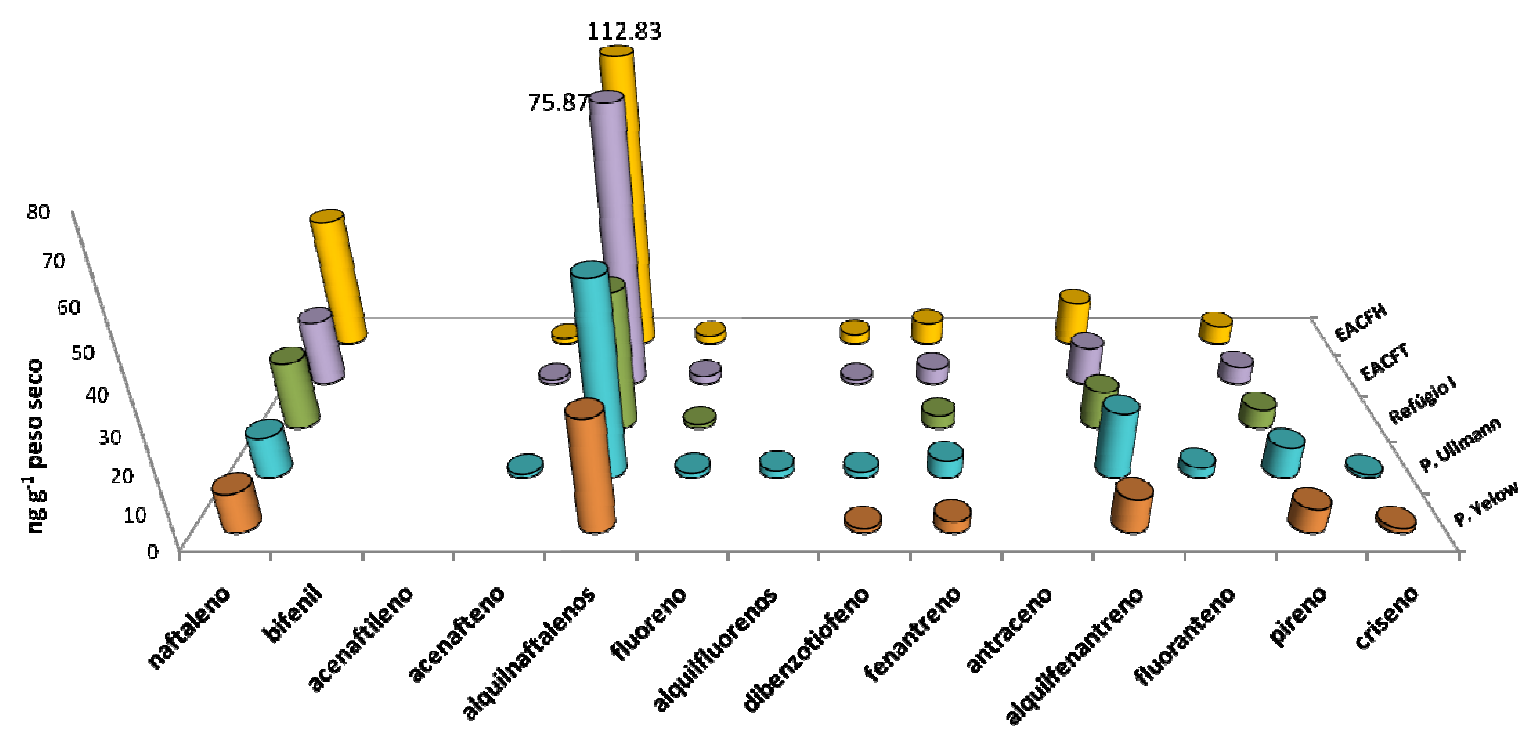

Figura 29. Concentrações de HPAs individuais, $\mathrm{ng} \mathrm{g}^{-1} \mathrm{ps}$, obtidas em $S$. neumayeri.

As concentrações de HPAs totais obtidas na estrela-do-mar O. validus coletadas próximo ao heliponto da EACF (99,8 $\mathrm{ng} \mathrm{g}^{-1}$ ps ou 22,9 $\left.\mathrm{ng} \mathrm{g}^{-1} \mathrm{pu}\right) \mathrm{e}$ em Hennequin (42,1 $\mathrm{ng} \mathrm{g}^{-1}$ ps ou 12,6 $\mathrm{ng} \mathrm{g}^{-1} \mathrm{pu}$ ) foram similares às concentrações obtidas (10,9 $\mathrm{ng} \mathrm{g}^{-1} \mathrm{pu}$ ) por Clarke \& Law (1981), quando analisaram a mesma espécie coletada nas proximidades da llha Signy, área considerada pouco afetada pela presença humana. No mesmo estudo, Clarke \& Law (1981), também analisaram amostras de O. validus na Geórgia do Sul e observaram maiores concentrações de HPAs totais $\left(85,5\right.$ a $\left.815,6 \mathrm{ng} \mathrm{g}^{-1} \mathrm{pu}\right)$ as quais atribuíram a uma fonte local desconhecida.

Nas amostras de $O$. validus houve a presença de naftaleno, acenaftileno, pireno e os grupos alquilnaftalenos, alquilfenantrenos e alquilfluorenos, mas não foi observado o predomínio dos compostos alquilados 
(Figura 30), apresentando assim uma distribuição do HPAs individuais diferente do DFA, como mostrado nos cromatogramas da Figura 31.

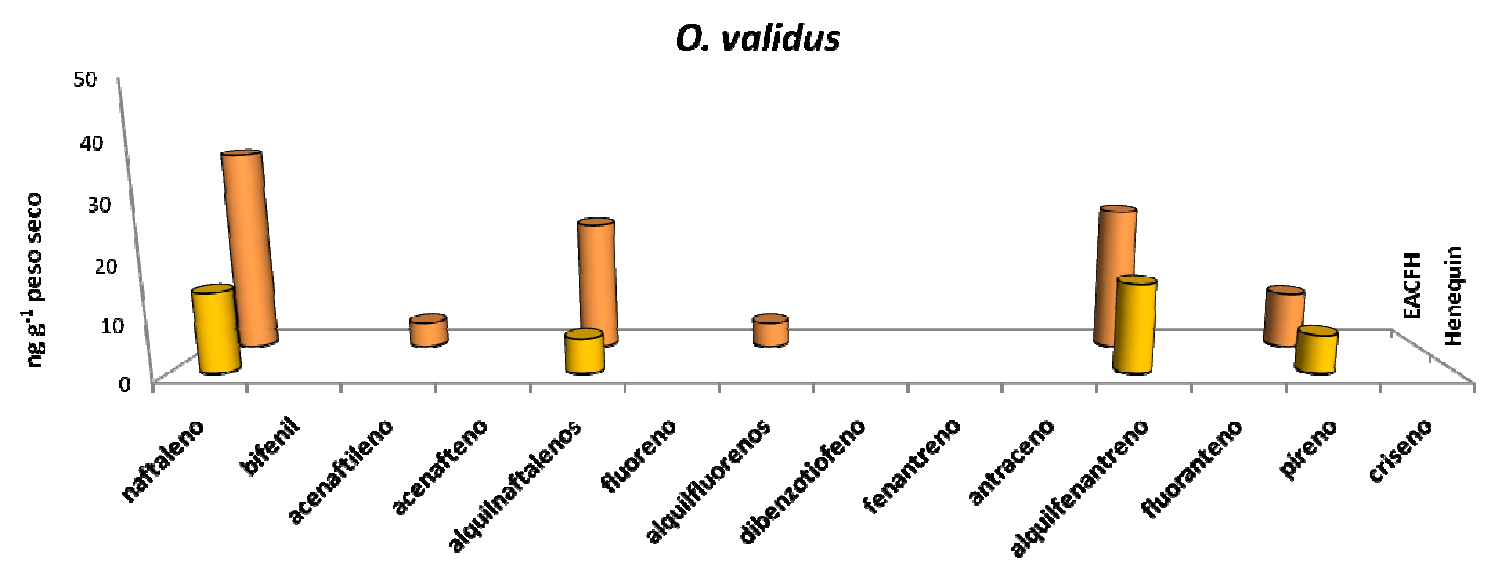

Figura 30. Concentrações de HPAs individuais, em $\mathrm{ng} \mathrm{g}^{-1}$ peso seco, obtidas em $O$. validus.

Segundo Baumard et al. (1998) o acúmulo de compostos hidrofóbicos é diferente entre os organismos que se alimentam diretamente ou vivem em estreito contato com o sedimento, dos carnívoros, que se alimentam de outros organismos, e assim estão expostos a um menor grau de partículas sedimentares. Então, a acumulação de HPAs também pode ser influenciada pela capacidade de biotransformação desses compostos pelo organismo, bem como pela concentração de HPAs nas presas das quais se alimentou.

Martins et al. (2004) analisaram sedimentos na Baía do Almirantado, e encontraram a predominância de HPAs não alquilados. A causa do acúmulo preferencial desses compostos neste compartimento, foi atribuída a uma maior atividade dos processos de degradação nos compostos alquilados, pois, segundo Ehrhardt et al. (1992) HPAs alquilados podem ser degradados fotoquimicamente mais rápido do que seus homólogos não alquilados. 
o. Validus - EACF heliponto
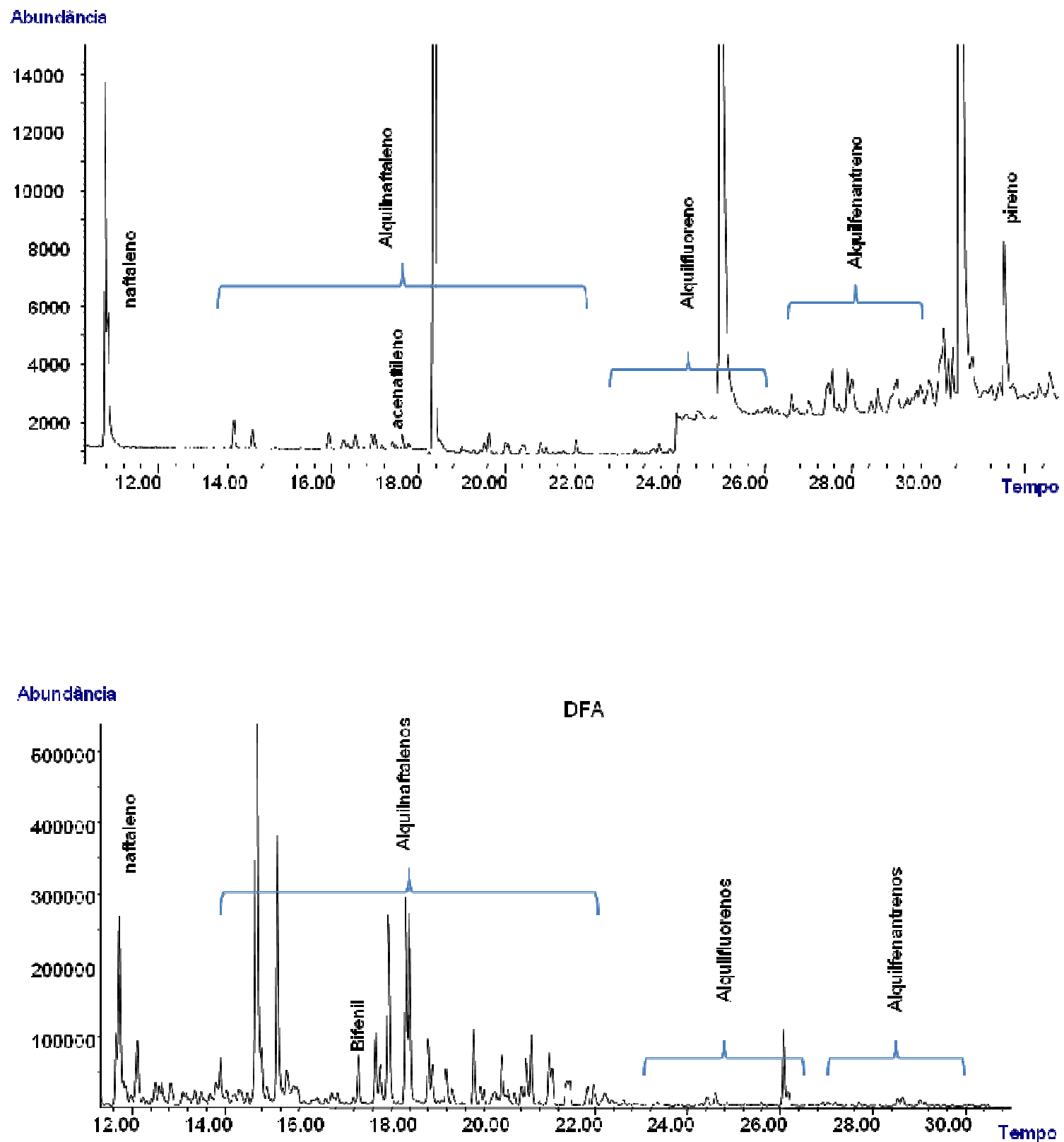

Figura 31. Cromatograma obtido das análises de uma amostra de $O$. validus e do Diesel Fuel Arctic - DFA. 
Assim, como a estrela-do-mar alimenta-se preferencialmente de presas e animais mortos, a sua forma de absorção de HPAs torna-se indireta e dependente da concentração dos compostos presentes no alimento, podendo absorver HPAs metabolizados ou não por suas presas e ainda HPAs provenientes dos produtos de degradação dos organismos em decomposição. Desta maneira, direta ou indiretamente, a principal fonte de HPAs para a estrela-do-mar, também, é o DFA.

A Figura 32 mostra a diferença na ocorrência de HPAs individuais no ouriço $S$. neumayeri, espécie depositívora e no ofiuróide $O$. victoriae, espécie carnívorora e necrófaga, enquanto que a Figura 33 mostra a diferença na ocorrência de HPAs individuais no ouriço $S$. neumayeri e $O$. validus, espécie também carnívorora e necrófaga. O ouriço, espécie depositívora, absorveu HPAs de forma direta do ambiente pela água, por partículas ou sedimento, sendo o seu perfil similar ao do DFA, enquanto que e as espécies carnívoras, necrófagas, absorveram HPAs de forma indireta e dependente das concentrações e compostos presentes em suas presas. Assim, a distribuição dos HPAs individuais nas amostras de equinodermos ocorreu de acordo com o hábito alimentar das espécies. 


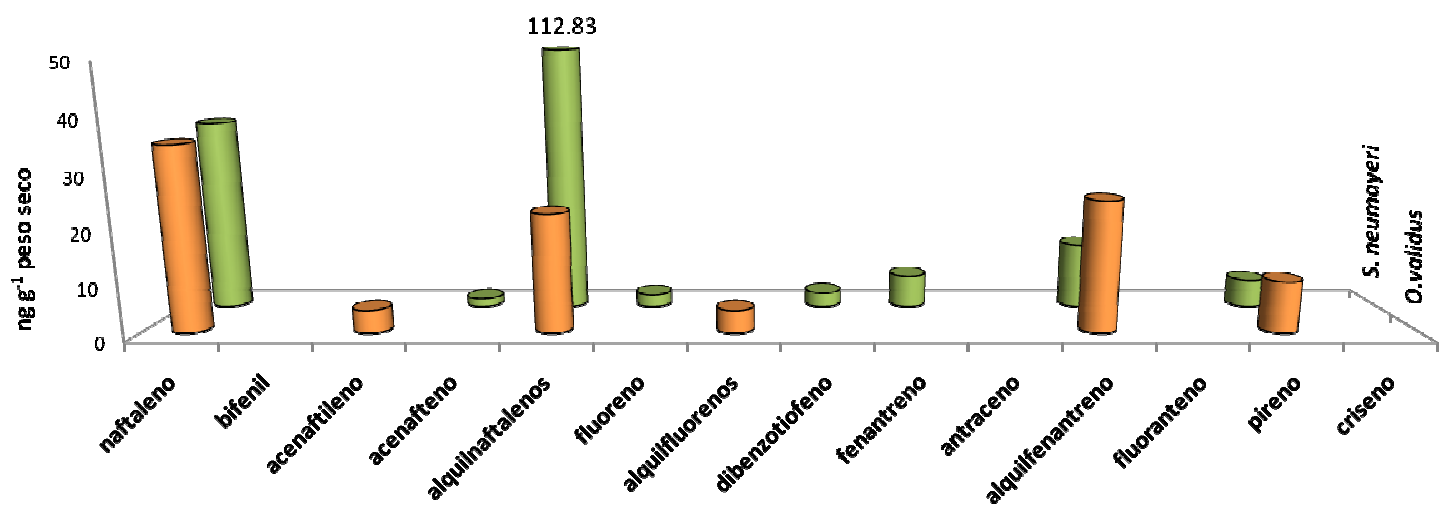

Figura 32. Concentrações de HPAs individuais, em $\mathrm{ng} \mathrm{g}^{-1}$ peso seco, obtidas em S. neumayeri e Ophionotus victoriae, coletadas na EACF próximo ao heliponto.

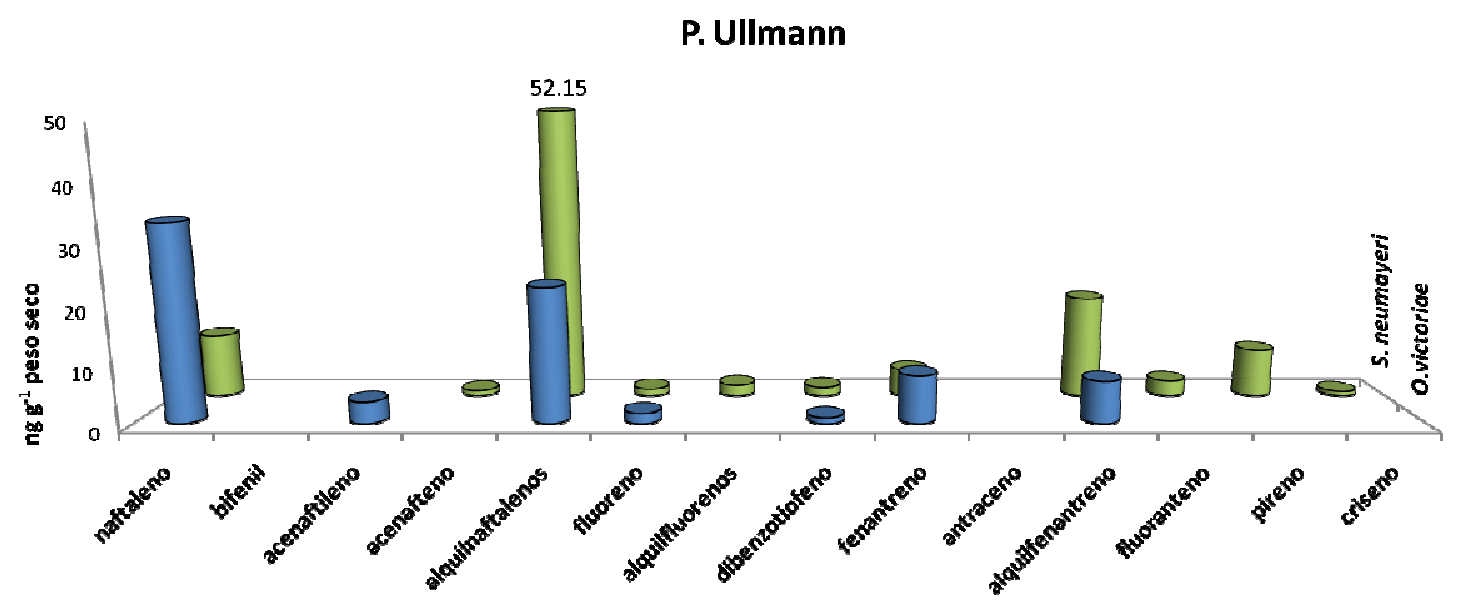

Figura 33. Concentrações de HPAs individuais, em $\mathrm{ng} \mathrm{g}^{-1}$ peso seco, obtidas em S. neumayeri e Odontaster validus, coletadas na EACF próximo ao heliponto 


\subsubsection{Hidrocarbonetos policíclicos aromáticos em crustáceos}

Crustáceos são encontrados em grande variedade de habitats marinhos, sendo os anfípodes mais associados ao sedimento de fundo (Sumich, 2004). Os isópodes são consumidores de detritos, carniça e alguns podem ser carnívoros, enquanto que os euphausiidas, coletivamente referidos como "krill", são uma espécie pelágica e predominantemente suspensívoro/onívoro (Nybakken, 1997).

Embora os crustáceos sejam muito abundantes, na região antártica, são pouco utilizados em trabalhos de monitoramento de contaminação por HPAs. Isso provavelmente se deve à mobilidade dos crustáceos (Peck et al. 1999). Ainda assim, Clark \& Law (1981) e Cripps (1989, 1990), realizaram algumas medidas de concentração de HPAs em várias espécies deste grupo, entre elas, o krill antártico e duas espécies de Serolis, mostrando que esses organismos também acumulam HPAs (Tabela 17). 
Tabela 17. Concentrações de HPAs em crustáceos analisados em diferentes regiões na Antártica.

\begin{tabular}{|c|c|c|}
\hline Amostras & $\begin{array}{c}\text { HPA total } \\
\mu \mathrm{kg}^{-1} \\
\text { peso úmido }\end{array}$ & Referência \\
\hline \multirow[t]{2}{*}{ Euphausia superba } & $17,4-82,2$ & Este trabalho, Baía do Almirantado, Ilha Rei \\
\hline & $(102,4-523,8 \mathrm{ps})$ & George \\
\hline \multirow[t]{2}{*}{ Serolis polita } & $65,6-174,4$ & Este trabalho, Baía do Almirantado, Ilha Rei \\
\hline & $(246,5-613,7 \mathrm{ps})$ & George \\
\hline \multirow[t]{2}{*}{ Bovallia Gigantea } & 51,1 & Este trabalho, Baía do Almirantado, Ilha Rei \\
\hline & (230 ps) & George \\
\hline \multirow[t]{2}{*}{ Gliptonotus Antarcticus } & $14,0-16,4$ & Este trabalho, Baía do Almirantado, Ilha Rei \\
\hline & $(69,8-107,1 \mathrm{ps})$ & George \\
\hline \multirow[t]{2}{*}{ Serolis cornuta } & $14-23$ & Clark \& Law (1981), Signy Island, South Orkney \\
\hline & & Islands \\
\hline \multirow[t]{2}{*}{ Serolis pagenstecheri } & $40-118$ & Clark \& Law (1981), King Edward Cove, South \\
\hline & & Georgia \\
\hline \multirow[t]{2}{*}{ Euphausia superba } & 282 & Clark \& Law (1981), King Edward Cove, South \\
\hline & & Georgia \\
\hline Euphausia superba & 5,7 & Cripps (1989), South Georgia \\
\hline Euphausia superba & 5,9 & Cripps (1990), Bransfield Strait* \\
\hline Euphausia & 2,5 & Cripps (1990), Bransfield Strait* \\
\hline \multicolumn{3}{|l|}{ crystallorophias } \\
\hline Euphausia triacantha & 4,2 & Cripps (1990), Bransfield Strait* \\
\hline Thysanoessa sp. & 5,5 & Cripps (1990), Bransfield Strait* \\
\hline Notocrangon antarcticus & $2,3-7,8$ & Cripps (1990), Bransfield Strait* \\
\hline Themisto gaudichaudii & 6,4 & Cripps (1990), Bransfield Strait* \\
\hline Rhincalanus sp. & 11,6 & Cripps (1990), South Georgia* \\
\hline
\end{tabular}

*Dados retirados de Cripps \& Priddle (1991). 
Neste estudo, foram analisadas três amostras de Serolis polita, coletadas nas proximidades EACF, duas de Glyptonotus antarcticus, uma de Bovallia gigantea e duas de Euphausiida Euphausia superba. As concentrações de HPAs totais e individuais estão apresentadas na Tabela $18 \mathrm{e}$ na Figura 34.

As concentrações de HPAs totais variaram de $69,8 \mathrm{ng} \mathrm{g}^{-1} \mathrm{ps}\left(14,0 \mathrm{ng} \mathrm{g}^{-1}\right.$ pu) a $613,7 \mathrm{ng} \mathrm{g}^{-1} \mathrm{ps}\left(174,4 \mathrm{ng} \mathrm{g}^{-1} \mathrm{pu}\right)$ respectivamente para $\mathrm{G}$. antarcticus coletado em P. Ullmann e para uma amostra de S. polita (denominada S. polita 3), coletada na EACF. Da mesma forma que para os moluscos e equinodermos, as maiores concentrações ocorreram nas amostras da EACF e são comparáveis com as concentrações (40-118 $\mathrm{ng} \mathrm{g}^{-1} \mathrm{pu}$ ) encontradas por Clark \& Law (1981), em Serolis pagenstecheri, coletadas em King Edward Cove, South Georgia. As menores concentrações (14-17,4 $\mathrm{ng} \mathrm{g}^{-1} \mathrm{pu}$ ), também foram similares às concentrações (14-23 $\mathrm{ng} \mathrm{g}^{-1} \mathrm{pu}$ ), propostas como linha base, por Clark \& Law (1981) em Serolis cornuta coletadas em Signy Island, South Orkney Islands. 
Tabela 18. Concentrações de HPAs individuais, HPAs totais ( $\Sigma$ HPAs) (peso seco e peso úmido), soma de HPAs com 2 e 3

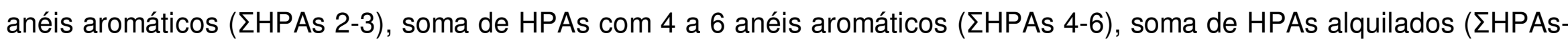
alquil) em ng g ${ }^{-1}$ peso seco, porcentagem de lipídios (\%) e porcentagem de umidade (\%) obtidas em crustáceos. Os valores abaixo do limite de detecção do método (LDM) estão indicados como "n.d.".

\begin{tabular}{|c|c|c|c|c|c|c|c|c|c|}
\hline Composto & $\begin{array}{c}\text { G. antarcticus } \\
\text { EACF } \\
\text { Dez-05 }\end{array}$ & $\begin{array}{c}\text { G. antarcticus P. } \\
\text { Ullmann } \\
\text { Jan-06 }\end{array}$ & $\begin{array}{l}\text { S. polita } 1 \\
\text { EACF } \\
\text { Jan-05 }\end{array}$ & $\begin{array}{c}\text { S. polita } 2 \\
\text { EACF } \\
\text { Jan-05 }\end{array}$ & $\begin{array}{l}\text { S. polita } 3 \\
\text { EACF } \\
\text { Dez-05 }\end{array}$ & $\begin{array}{l}\text { B. gigantea } \\
\text { EACF } \\
\text { Dez-05 }\end{array}$ & $\begin{array}{l}\text { E. superba } \\
\text { EACF } \\
\text { Dez-04 }\end{array}$ & $\begin{array}{l}\text { E. superba } \\
\text { E. Martel } \\
\text { Dez-06 }\end{array}$ & LDM \\
\hline Naftaleno & 25.7 & 31.7 & 26.5 & 15.6 & 144.4 & 25.0 & 100.4 & n.d. & 4.10 \\
\hline Bifenil & n.d. & n.d. & 4.28 & 4.31 & 4.30 & 3.96 & 29.6 & n.d. & 3.80 \\
\hline Acenaftileno & n.d. & 3.99 & 4.81 & 3.97 & 10.8 & 3.41 & 15.0 & n.d. & 3.30 \\
\hline Acenafteno & 0.87 & 2.36 & 3.41 & 4.16 & 3.26 & 2.45 & n.d. & n.d. & 0.80 \\
\hline$\sum$ Alquilnaftalenos & 64.5 & n.d. & 172.4 & 159.1 & 403.2 & 149.7 & 366.0 & 30.5 & 3.80 \\
\hline Fluoreno & 2.28 & n.d. & n.d. & 4.14 & 4.00 & 3.83 & n.d. & n.d. & 1.00 \\
\hline$\sum$ Alquilfluorenos & n.d. & n.d. & 7.2 & 8.8 & n.d. & 4.43 & n.d. & 10.1 & 1.00 \\
\hline Dibenzotiofeno & 2.41 & 16.8 & 1.44 & $\begin{array}{l}\text { o.o } \\
\text { n.d. }\end{array}$ & 3.53 & $\begin{array}{l}4.40 \\
3.12\end{array}$ & 1.00 & 1.53 & 1.00 \\
\hline Fenantreno & 3.48 & 12.8 & 9.4 & 9.6 & 20.8 & 11.0 & n.d. & 7.0 & 2.20 \\
\hline Antraceno & n.d. & n.d. & n.d. & n.d. & n.d. & n.d. & n.d. & n.d. & 1.40 \\
\hline$\sum$ Alquilfenantreno & 7.84 & 2.17 & 28.4 & 25.5 & 13.8 & 17.0 & 2.71 & 35.8 & 1.40 \\
\hline Fluoranteno & n.d. & n.d. & n.d. & n.d. & n.d. & n.d. & n.d. & n.d. & 2.40 \\
\hline Pireno & n.d. & n.d. & 10.5 & 11.4 & 5.64 & 6.22 & 9.17 & 17.4 & 3.80 \\
\hline ¿Alquilfluoranteno & n.d. & n.d. & n.d. & n.d. & n.d. & n.d. & n.d. & n.d. & 3.80 \\
\hline Reteno & n.d. & n.d. & n.d. & n.d. & n.d. & n.d. & n.d. & n.d. & 3.80 \\
\hline ¿Alquilpireno & n.d. & n.d. & n.d. & n.d. & n.d. & n.d. & n.d. & n.d. & 3.80 \\
\hline Benzo(c)fenantreno & n.d. & $\begin{array}{l}\text { n.d. } \\
\text { n.d. }\end{array}$ & n.d. & $\begin{array}{l}\text { n.d. } \\
\text { n.d. }\end{array}$ & $\begin{array}{l}\text { n.d. } \\
\text { n.d. }\end{array}$ & $\begin{array}{l}\text { n.d. } \\
\text { n.d. }\end{array}$ & n.d. & n.d. & $\begin{array}{l}.00 \\
3.80\end{array}$ \\
\hline Benzo(a)fenantreno & n.d. & n.d. & n.d. & n.d. & n.d. & n.d. & n.d. & n.d. & 3.90 \\
\hline 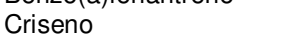 & n.d. & n.d. & n.d. & n.d. & n.d. & n.d. & n.d. & n.d. & 0.60 \\
\hline ¿Alquilcriseno & n.d. & n.d. & n.d. & n.d. & n.d. & n.d. & n.d. & n.d. & 0.60 \\
\hline Benzo(b)fluoranteno & n.d. & n.d. & n.d. & n.d. & n.d. & n.d. & n.d. & n.d. & 0.60 \\
\hline Benzo(k)fluoranteno & n.d. & n.d. & n.d. & n.d. & n.d. & n.d. & n.d. & n.d. & 1.70 \\
\hline $\begin{array}{l}\text { Benzo(e)pireno } \\
\text { Ben }\end{array}$ & n.d. & n.d. & n.d. & n.d. & n.d. & n.d. & n.d. & n.d. & 1.70 \\
\hline Benzo(a)pireno & n.d. & n.d. & n.d. & n.d. & n.d. & n.d. & n.d. & n.d. & 2.90 \\
\hline Perileno & n.d. & n.d. & n.d. & n.d. & n.d. & n.d. & n.d. & n.d. & 2.90 \\
\hline Indeno $(1,2,3-\mathrm{c}, \mathrm{d})$ pireno & $\begin{array}{l}\text { n.d. } \\
\text { n.d. }\end{array}$ & n.d. & $\begin{array}{l}\text { n.d. } \\
\text { n.d. }\end{array}$ & $\begin{array}{l}\text { n.d. } \\
\text { n.d. }\end{array}$ & $\begin{array}{l}\text { n.d. } \\
\text { n.d. }\end{array}$ & $\begin{array}{l}\text { n.d. } \\
\text { n.d. }\end{array}$ & n.d. & n.d. & 3.80 \\
\hline Dibenzo(a,h)antraceno & n.d. & n.d. & n.d. & n.d. & n.d. & n.d. & n.d. & n.d. & 2.50 \\
\hline Benzo(b)criseno & n.d. & n.d. & n.d. & n.d. & n.d. & n.d. & n.d. & n.d. & 2.50 \\
\hline Benzo(g,h,i)perileno & n.d. & n.d. & n.d. & n.d. & n.d. & n.d. & n.d. & n.d. & 1.20 \\
\hline$\sum$ HPAs & 107.1 & 69.8 & 268.3 & 246.5 & 613.7 & 230.0 & 523.8 & 102.4 & \\
\hline$\sum \operatorname{HPAs}(2-3)$ & 107.1 & 69.8 & 274.4 & 293.9 & 608.1 & 223.8 & 514.6 & 84.9 & \\
\hline$\sum$ HPAs(4-6) & 0.0 & 0.0 & 44.5 & 71.4 & 5.6 & 6.22 & 9.17 & 17.42 & \\
\hline$\sum$ PAH-alquil & 72.4 & 2.2 & 212.1 & 244.1 & 417.0 & 171.1 & 368.7 & 76.4 & \\
\hline Lipídio (\%) & 8.84 & 2.03 & 5.11 & 5.35 & 7.61 & 4.29 & 9.44 & 9.03 & \\
\hline Umidade (\%) & 85 & 80 & 76 & 72 & 72 & 78 & 84 & 83 & \\
\hline$\sum$ HPAs peso úmido & 16,4 & 14,0 & 65,6 & 69,0 & 174,4 & 51,1 & 82,2 & 17,4 & \\
\hline
\end{tabular}


HPAs totais em crustáceos

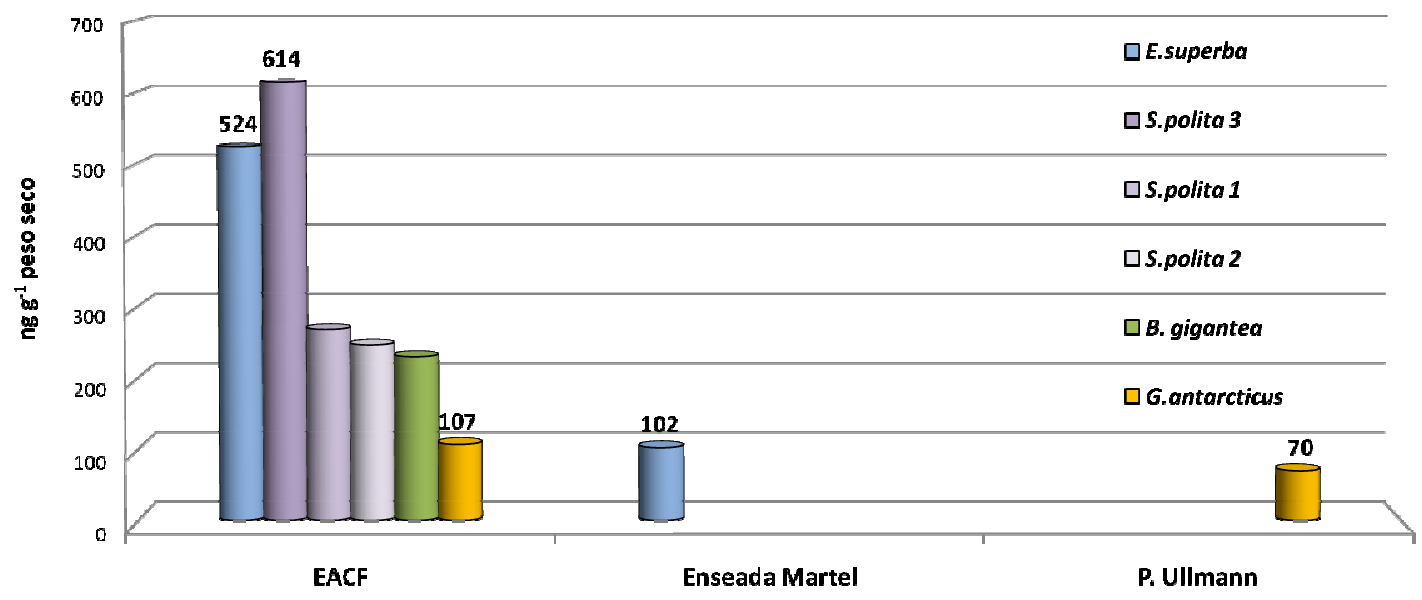

Figura 34. Concentrações de HPAs totais, em ng g ${ }^{-1}$ peso seco, obtidas em $G$. antarcticus, S. polita, B. gigantea e E. superba.

Da mesma forma, como foi observado nos outros grupos de invertebrados, nos crustáceos também predominaram os HPAs leves e alquilados apresentados nas Figuras 35 e 36 .

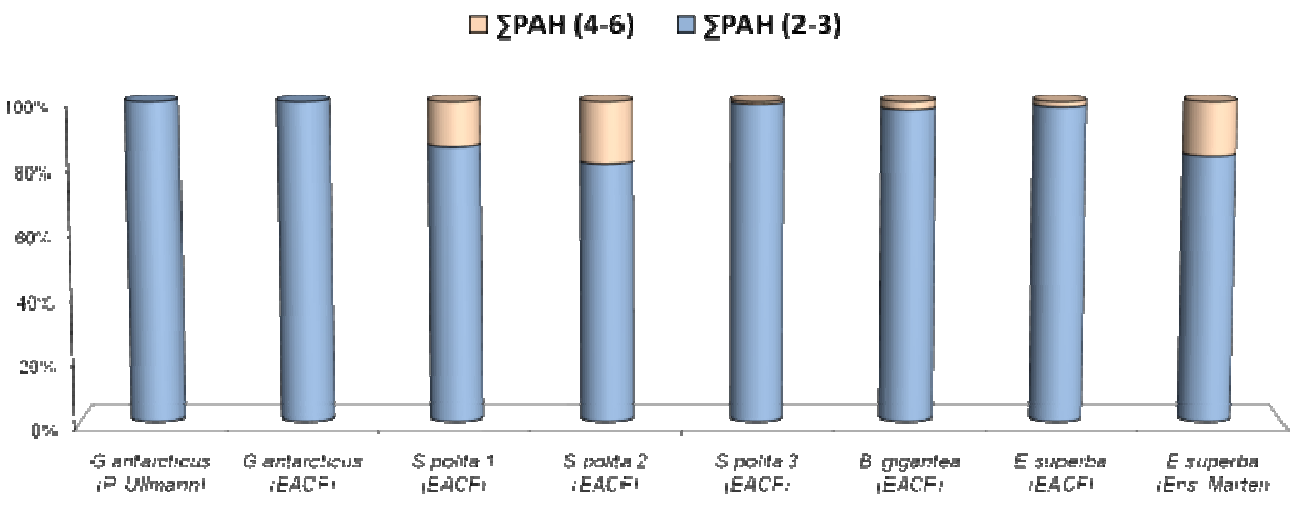

Figura 35. Composição dos parâmetros da $\Sigma$ HPAs (2-3 anéis) e $\Sigma$ HPAs (2-3 anéis) (\%) obtidos em G. antarcticus, S. polita, B. gigantes e E. superb 


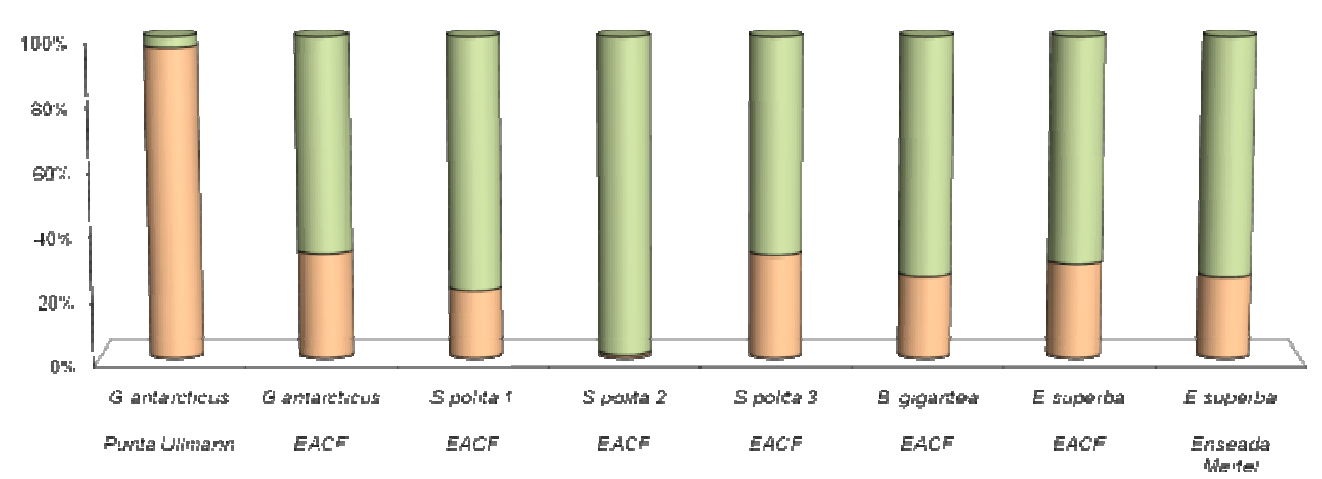

Figura 36. Composição dos parâmetros da $\Sigma$ HPAs alquilado e $\Sigma$ HPAs não alquilados (\%) obtidos em G. antarcticus, S. polita, B. gigantes e E. superba.

Os HPAs individuais predominantes em crustáceos foram o naftaleno, o fenantreno e os grupos dos alquilnaftalenos e alquilfenantrenos. A distribuição dos HPAs individuais para os crustáceos também foi similar a distribuição dos HPAs individuais do DFA. Porém, em algumas amostras mais afastadas da EACF, ocorreram modificações na distribuição dos HPAs individuais, como apresentado na Figura 37. Em E. superba, coletada na Enseada Martel, verificou-se uma semelhança nas concentrações de alquilnaftalenos e alquilfenantreno, enquanto que a amostra de G. antarcticus, coletada em P.Ullmann, apresentou predominância de naftaleno sobre os grupos dos alquilnaftalenos e alquilfenantrenos. Essa diferença pode ser atribuída a processos de degradação química e/ou biológica dos HPAs alquilados. 


\section{HPAs individuais em crustáceo}

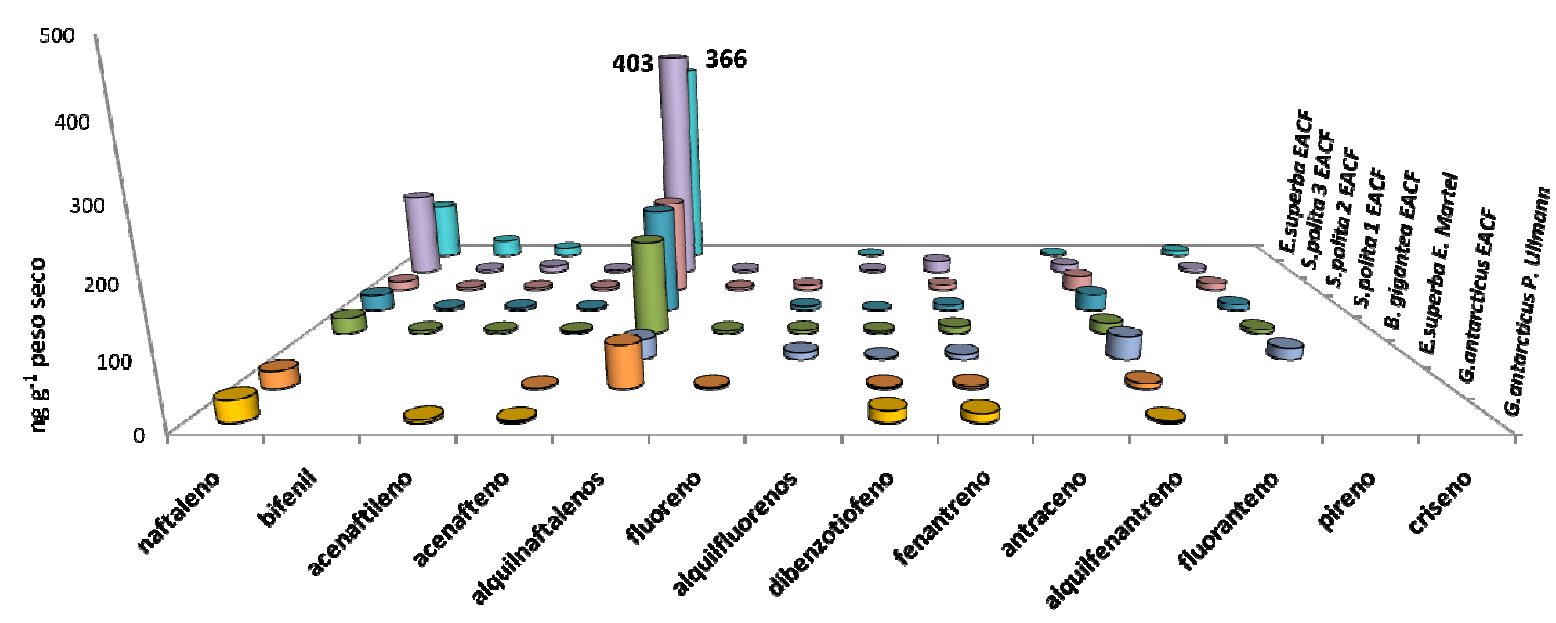

Figura 37. Concentrações de HPAs individuais, em $\mathrm{ng} \mathrm{g}^{-1}$ peso seco, obtidas em G. antarcticus, E. superba, B. gigantea e S. polita.

As concentrações obtidas para o isópode G. antarcticus $(69,8$ a 107,1 ng $\mathrm{g}^{-1}$ ps ou 14 a $16,4 \mathrm{ng} \mathrm{g}^{-1} \mathrm{pu}$ ) foram as menores do grupo dos equinodermos. G. antarcticus é um o isópode predador/necrófago igualmente como S. polita, porém a amostra de G. antarcticus, que também foi coletada nas proximidades da EACF, apresentou concentrações duas a seis vezes menores que as das amostras de S. polita.

Estas concentrações podem ser explicadas por outros fatores, além do hábito alimentar, como por exemplo, a época reprodutiva da espécie. O fato das amostras de $S$. polita conterem indivíduos que estavam carregando ovos pode ter influenciado na maior absorção dos HAPs, pois segundo Perugini et al., 2007), os organismos eliminam poluentes muito lentamente durante a gametogênese e mais rapidamente durante a fase final, por meio dos ovos.

Mesmo a espécie $S$. polita tendo hábito alimentar (predador/necrófago) semelhante a outras espécies apresentadas anteriormente (equinodermos), 
apresentou diferente perfil de absorção de HPAs individuais, comportamento similar às espécies depositívoras e suspensívoras, que acumularam maiores concentrações de alquilados e apresentaram similaridade com o perfil do DFA. A Figura 38 apresenta a distribuição dos HPAs individuais para as amostras de S. polita, a qual foi similar a do DFA.

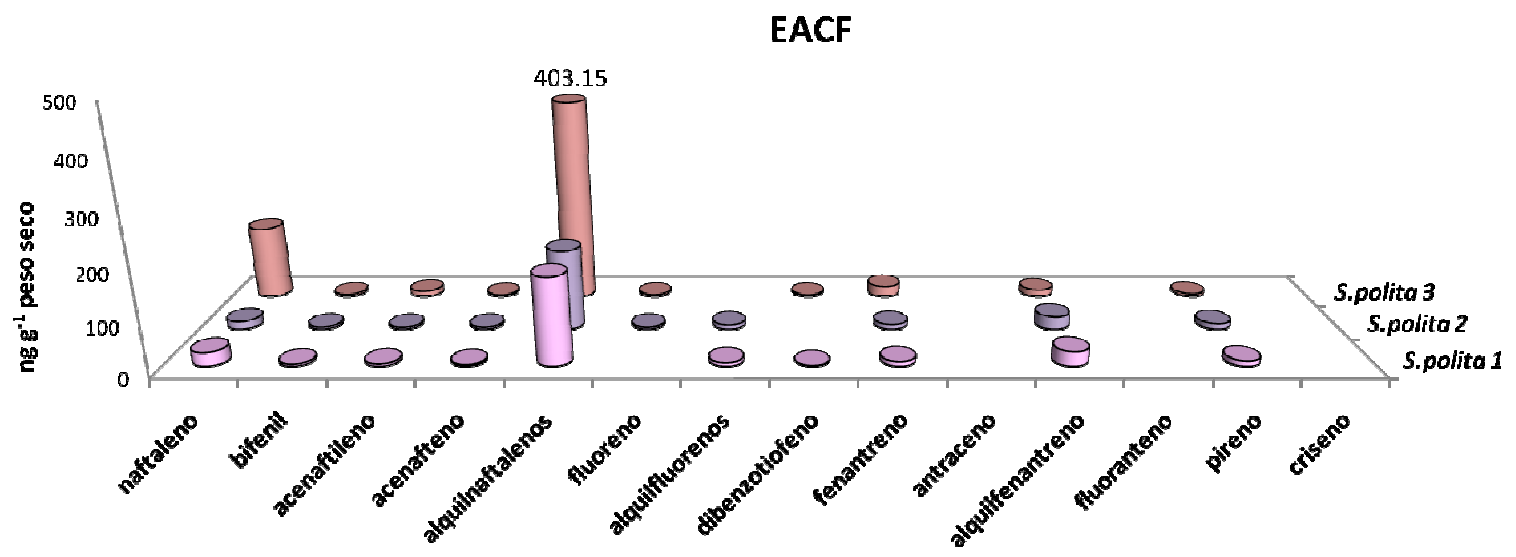

Figura 38. Concentrações de HPAs individuais, em $\mathrm{ng} \mathrm{g}^{-1}$ peso seco, obtidas $S$. polita.

Todas as amostras de $S$. polita foram coletadas na EACF e apresentaram concentrações de HPAs totais de 246,5 a $613,7 \mathrm{ng} \mathrm{g}^{-1}$ ps $(69,0$ $174,4 \mathrm{ng} \mathrm{g}^{-1} \mathrm{pu}$ ). Essas concentrações foram maiores que as obtidas por Clark \& Law (1981) ao analisarem Serolis cornuta (14 - $23 \mathrm{ng} \mathrm{g}^{-1} \mathrm{pu}$ ) em local considerado não contaminado (llha Signy, llha Orkney do Sul) e foram próximas às concentrações obtidas pelos mesmos autores ao analisarem Serolis pagenstecheri (40 - $\left.118 \mathrm{ng} \mathrm{g}^{-1} \mathrm{pu}\right)$ em local com influência antrópica (King Edward Cove, Georgia do Sul). 
As concentrações de HPAs totais para as amostras de E. superba coletadas próximo a EACF $\left(523,8 \mathrm{ng} \mathrm{g}^{-1}\right.$ ps ou $\left.82.2 \mathrm{ng} \mathrm{g}^{-1} \mathrm{pu}\right)$ e na Enseada Martel (102,4 $\mathrm{ng} \mathrm{g}^{-1}$ ps ou $\left.17,4 \mathrm{ng} \mathrm{g}^{-1} \mathrm{pu}\right)$ foram maiores que as obtidas por Cripps $(1989,1990)$ ao analisarem E. superba coletadas em Georgia do Sul (5,75 $\left.\mathrm{ng} \mathrm{g}^{-1} \mathrm{pu}\right)$ e no Estreito de Bransfield (5,90 $\left.\mathrm{ng} \mathrm{g}^{-1} \mathrm{pu}\right)$.

Entre os crustáceos, E. superba teve concentração menor apenas que a amostra S. polita 3, na qual os indivíduos estavam em época reprodutiva. $E$. superba é um suspensívoro, herbívoro e onívoro, que pode absorver HPAs através da água ou pelo material particulado em suspensão. E. superba vive na coluna d'água, espécie pelágica, e acumula reservas de lipídios durante o verão austral (Hagen et al., 1996). Portanto, as características físico-químicas dos HPAs, o habitat e a fisiologia desta espécie, são fatores que podem interferir no processo de absorção dos HPAs individuais (Figura 39).

\section{E. superba}

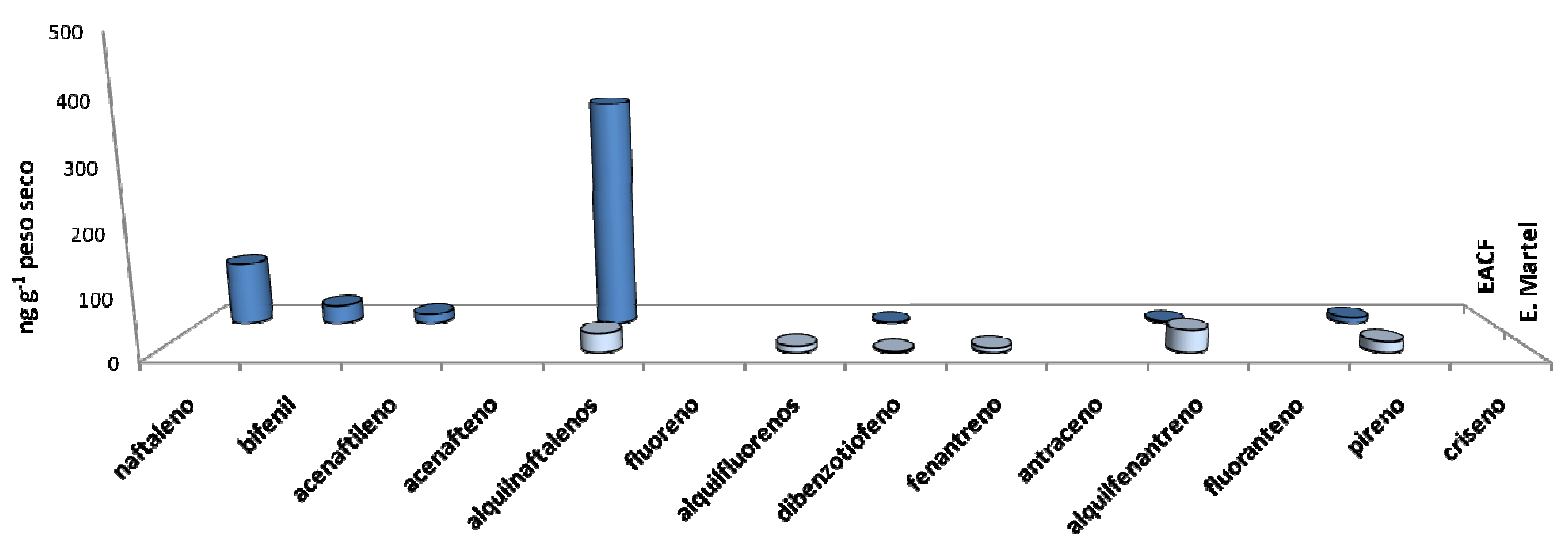

Figura 39. Concentrações de HPAs individuais, em $\mathrm{ng} \mathrm{g}^{-1}$ peso seco, obtidas em E. superba. 
A concentração de HPAs totais obtida na amostra do anfípode $B$. gigantea foi de $230 \mathrm{ng} \mathrm{g}^{-1}$ ps $\left(51,1 \mathrm{ng} \mathrm{g}^{-1} \mathrm{pu}\right)$. Esta espécie absorveu uma variedade de HPAs individuais, onde predominaram o naftaleno e os grupos dos alquilnaftalenos e alquilfenantrenos, apresentando também similaridade ao perfil de distribuição do DFA (Figura 40).

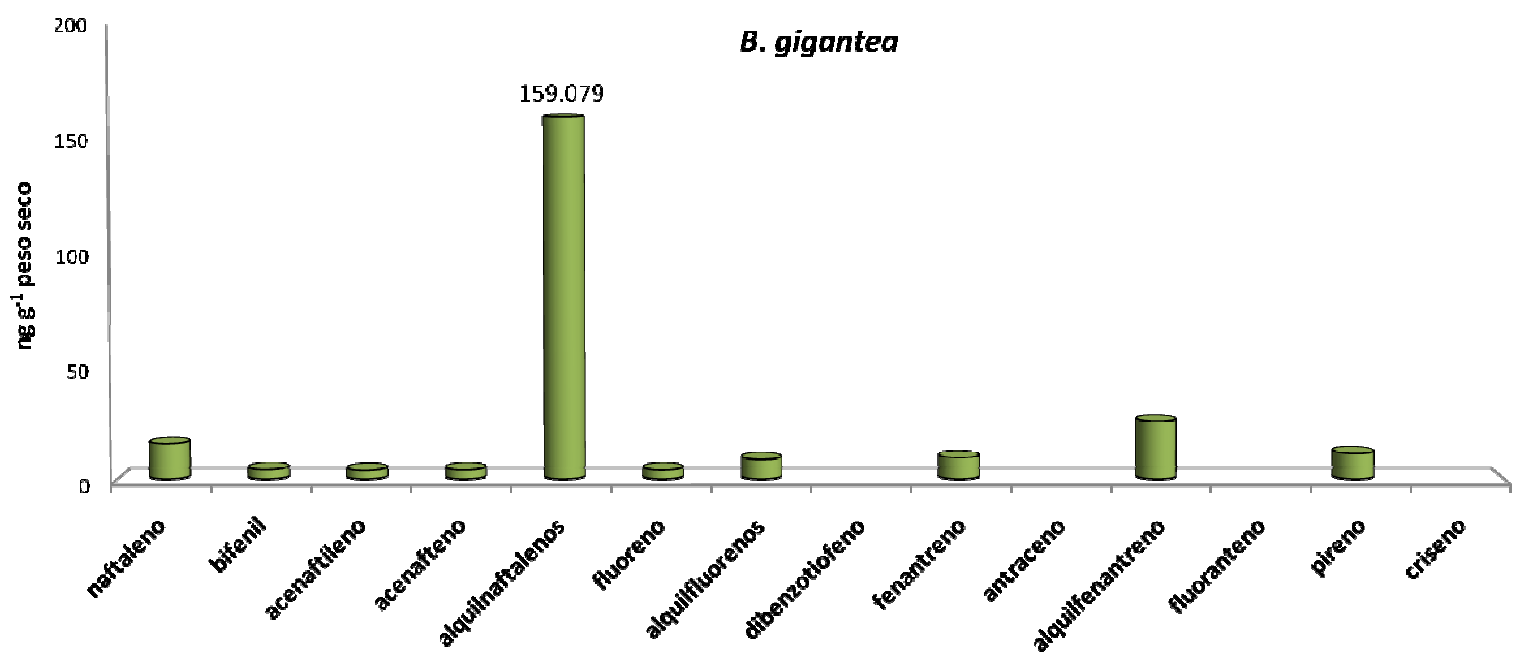

Figura 40. Concentrações de HPAs individuais, em $\mathrm{ng} \mathrm{g}^{-1}$ peso seco, obtidas em B. gigantea coletada na EACF. 


\subsubsection{Comparação entre as espécies de invertebrados}

As concentrações obtidas para os invertebrados variaram de $11,4 \mathrm{ng} \mathrm{g}^{-}$ ${ }^{1}$ a $613,7 \mathrm{ng} \mathrm{g}^{-1}$ ps (3,09 a 174,4 $\left.\mathrm{ng} \mathrm{g}^{-1} \mathrm{pu}\right)$, conforme apresentado na Tabela 16. A maior concentração foi a obtida para a amostra do crustáceo S. polita coletada próximo da EACF, local onde ocorrem atividades de embarcações, utilização de motores a diesel para gerar energia elétrica e armazenamento de combustível, principalmente durante o verão, quando ocorre um aumento do número de pessoas trabalhando, o que, consequentemente, provoca um aumento na utilização de combustível.

Para a amostra do gastrópode $N$. concinna coletada em Blue Dick, próximo à saída da Baía do Almirantado, e dentro da Área de Interesse Científico Especial $N$ ․ 8 (AICE N.ㅇ), protegida para pesquisa e região de maior circulação de água, obteve-se a menor concentração $\left(3,09 \mathrm{ng} \mathrm{g}^{-1} \mathrm{pu}\right)$ nos invertebrados. Concentração esta, que ainda ficou abaixo dos valores encontrados por Clarke \& Law (1981) que, a fim de estabelecer uma linha de base para os HPAs, analisaram amostras de organismos na região Antártica e encontraram a concentração de $10,1 \mathrm{ng} \mathrm{g}^{-1}$ pu para moluscos, $10,9 \mathrm{ng} \mathrm{g}^{-1} \mathrm{pu}$ para equinodermos e de 14,2 - 22,8 $\mathrm{ng} \mathrm{g}^{-1}$ pu para crustáceos.

De forma geral, comparando-se os resultados com os da literatura, temos que as menores concentrações obtidas foram similares àquelas encontradas em locais considerados não contaminados por Platt \& Mackie (1981), Cripps (1990); Cripps \& Priddle (1995) e McDonald et al., (1994). Da mesma forma, as maiores concentrações são comparáveis às obtidas por Clark \& Law (1981), Cripps \& Shears (1997), McDonald et al. (1994) em áreas próximas às estações de pesquisas. 
Tabela 19. Concentrações de HPAs totais (LHPAs) em ng g ${ }^{-1}$ peso seco e peso úmido obtidos em invertebrados.

\begin{tabular}{|c|c|c|c|c|c|}
\hline $\begin{array}{c}\text { Amostras } \\
\text { Moluscos } \\
\text { Local }\end{array}$ & $\begin{array}{c}\sum \text { HPAs } \\
\text { peso seco } \\
\text { (peso úmido) }\end{array}$ & $\begin{array}{c}\text { Amostras } \\
\text { Equinodermos } \\
\text { Local }\end{array}$ & $\begin{array}{c}\sum \text { HPAs } \\
\text { peso seco } \\
\text { (peso úmido) }\end{array}$ & $\begin{array}{c}\text { Amostras } \\
\text { Crustáceos } \\
\text { Local }\end{array}$ & $\begin{array}{c}\sum \text { HPAs } \\
\text { peso seco } \\
\text { (peso úmido) }\end{array}$ \\
\hline N. concinna & 149.4 & O. validus & 99.8 & E. superba & 523.8 \\
\hline EACF(tanques) & (50.2) & EACF heliponto & (23.0) & EACF & $(82,2)$ \\
\hline L. elliptica & 91.3 & S. neumayeri & 179.1 & G. antarcticus & 107.1 \\
\hline EACF & (8.98) & EACF heliponto & (62.7) & EACF & (16.4) \\
\hline N. concinna & 112.3 & S. neumayeri & 118.8 & S. polita 1 & 268.3 \\
\hline EACF & (32.1) & EACF tanques & (41.1) & EACF & $(65,6)$ \\
\hline N. concinna & 112.8 & S. neumayeri & 102.2 & S. polita 2 & 246.5 \\
\hline P.Plazza & (33.2) & P. Ullmann & (36.0) & EACF & $(69,0)$ \\
\hline N. concinna & 31.8 & O. victoria & 78.2 & S. polita 3 & 613.7 \\
\hline P. Ullmann & (10.2) & P. Ullmann & (25.8) & EACF & $(174,4)$ \\
\hline Y. eightsi & 85.6 & S. neumayeri & 76.1 & B. gigantea & 230.0 \\
\hline P. Ullmann & (29.7) & Refúgio I & (26.6) & EACF & $(51,1)$ \\
\hline N. concinna & 38.4 & S. neumayeri & 60.8 & G. antarcticus & 69.8 \\
\hline P. Demay & $(12,7)$ & P. Yellow & (17.3) & P. Ullmann & $(14,0)$ \\
\hline N. concinna & 11.4 & O. validus & 42.1 & E. superba & 102.4 \\
\hline B. Dick & (3.09) & Hennequin & (12.5) & E. Martel & $(17,4)$ \\
\hline
\end{tabular}

Independente da espécie, as concentrações das doze amostras coletadas nas proximidades da EACF variaram de 91,3 a $613,7 \mathrm{ng} \mathrm{g}^{-1}$ os; para as oito amostras coletadas nos demais pontos (P. Yellow, P.Ullmann, Refúgio I, P. Plaza) dentro da Enseada Martel, as concentrações variaram de 31,8 a $112,8 \mathrm{ng} \mathrm{g}^{-1}$ ps e para as três amostras coletadas fora da enseada Martel (Hennequin, P. Demay e B. Dick) as concentrações variaram de 11,4 a 42,1 ng $\mathrm{g}^{-1}$ ps. Os valores obtidos próximo e distante da estação sugerem que a contribuição de HPAs disponibilizados para os invertebrados, dentro da 
Enseada Martel, seja proveniente da EACF, assim como os HPAs presentes nas amostras coletadas em Hennequin e P. Demay podem ser provenientes dos Refúgios Equatoriano e Polonês, em função da utilização de derivados de petróleo no verão.

A presença dos HPAs leves e alquilados geralmente é atribuída a fontes petrogênicas, enquanto que os HPAs pesados e não alquilados, sugerem a combustão de matéria orgânica. Dessa forma, a ocorrência dos grupos de HPAs leves e pesados e o grau de alquilação desses compostos, contribuem para a identificação das principais fontes destes compostos no ambiente.

A predominância dos HPAs leves e alquilados, com dois e três anéis aromáticos e a similaridade da distribuição dos HPAs individuais com o DFA sugerem que os HPAs encontrados nos organismos tenham como origem o DFA (diesel fuel arctic) introduzido na enseada Martel pelas atividades na EACF.

Tanto para as amostras de S. neumayeri quanto para as de N.concinna coletadas nas proximidades da EACF, a distribuição de HPAs individuais foi similar à do DFA. Porém, para amostras das mesmas espécies coletadas em P. Ullmann, local mais afastado da EACF, houve diferença na distribuição de HPAs individuais. Em N.concinna ocorreu a diminuição da concentração do grupo dos alquilnaftalenos, resultando em um perfil diferente do DFA, enquanto que em S. neumayeri a distribuição de HPAs individuais manteve-se similar ao DFA. Uma possível explicação para esta diferença é que a espécie N.concinna possa ter maior capacidade de metabolização, pois a concentração de 
alquilnaftalenos para S. neumayeri foi cinco vezes maior que o seu homólogo, enquanto que em N.concinna foi somente o dobro.

Com exceção do ouriço-do-mar, os HPAs leves e alquilados também predominaram nas amostras de equinodermos, sendo observada em relação aos moluscos uma maior frequência de HPAs com quatro anéis, A presença de HPAs mais pesados pode estar relacionada às diferenças dos hábitos alimentares dos grupos em questão, pois enquanto os moluscos analisados são suspensívoros, depositívoros e herbívoros, os equinodermos, além destas três formas, também são necrófagos e predadores (Dearborne, 1977), absorvendo HPAs de forma indireta.

Foi observado que em todas as amostras de espécies predadoras necrófagas, G. antarcticus, S. polita, O. validus e Ophionotus victoriae predominaram os HPAs alquilados, porém, com exceção das amostras de $S$. polita, todas apresentaram perfil diferente do DFA, o que também provavelmente pode ser atribuído ao habito alimentar destas espécies.

E. superba apresentou o dobro do conteúdo lipídico da L. elliptica, o que pode justificar o fato desta espécie suspensívora e pelágica ter apresentado maior concentração de HPAs totais e uma maior variedade de HPAs individuais que o bivalve, espécie suspensívora e bentônica. Assim, além do hábito alimentar, outros fatores como a característica lipofílica dos HPAs e o conteúdo lipídico das espécies também podem interferir no processo de absorção desses contaminantes.

As concentrações de HPAs totais dos grupos de invertebrados não apresentaram distribuição normal quando aplicado o teste de KolmogorovSmirnov com $95 \%$ de significância. Desta forma, para verificar se havia 
diferença significativa entre as concentrações de HPAs totais entre os grupos de invertebrados foi aplicado o teste não paramétrico de Kruskal Wallis, obtendo-se nível de significância $p>0.1116$, ou seja, não houve diferença significativa.

Por isso, os resultados encontrados para os grupos dos invertebrados, foram tratados como uma amostra composta, a fim de comparar com os resultados dos vertebrados. O intervalo das concentrações para os invertebrados foi de 3,09 a $174,4 \mathrm{ng} \mathrm{g}^{-1}$ pu e a mediana foi $26,2 \mathrm{ng} \mathrm{g}^{-1}$ peso úmido.

\subsection{Hidrocarbonetos policíclicos aromáticos em vertebrados}

Os HPAs podem ser absorvidos por organismos marinhos através do contato com o sedimento, com a água ou através da alimentação, podendo, acumular esses contaminantes em seus tecidos. Aves e peixes possuem um eficiente sistema de enzimas metabolizadoras de xenobióticos capaz de transformar compostos, como os HPAs, em substâncias mais solúveis em água, facilitando sua eliminação (Walker, 2001). A metabolização destes compostos pode transformá-los em potenciais carcinogênicos e mutagênicos, como por exemplo, o 7,8-diol-9,10-óxido de benzo(a)pireno, um metabolito que pode interagir com o DNA (Walker, 2001).

Muitos estudos realizaram medidas de HPAs em vertebrados (Wan et al., 2007; Perugini et al., 2007;Baumard et al.,1998), inclusive, alguns em espécies Antárticas (Curtosi et al., 2009). Neste trabalho, foram analisadas 47 amostras de vertebrados, onde 26 foram de peixes e 21 de aves. Em peixes 0 tecido analisado foi o músculo e em aves a gordura. 


\subsubsection{Hidrocarbonetos policíclicos aromáticos em peixe (Notothenia} rossii)

Na região Antártica, as atividades humanas são restritas a pesca, turismo e pesquisa. Assim, a presença de contaminantes antropogênicos é relativamente baixa em comparação com regiões urbanas. No entanto, estudos mostraram que os peixes provenientes de vários locais da Antártica, apresentaram hidrocarbonetos aromáticos em seus tecidos. A Tabela 20 apresenta dados de estudos onde foram realizadas medidas das concentrações de HPAs, em peso úmido, para peixes Antárticos, e a Tabela 21 apresenta outros estudos onde foram realizadas medidas das concentrações de HPAs em peso seco.

Tabela 20. Concentrações ( $\mu \mathrm{g} \mathrm{kg}^{-1}$ peso úmido) de HPAs em peixes provenientes de diferentes regiões da Antártica.

\begin{tabular}{lccl}
\hline Espécie & Tecido & HPA total & \multicolumn{1}{c}{ Referência e Local } \\
\hline N. rossii & Músculo & $0,97-58,9$ & Este estudo, Baia do Almirantado, \\
N. rossii & Músculo & $1,3^{*}$ & Platt \& Mackie (1980), King Edward \\
& Fígado & 0,6 & Cove, South Georgia. \\
C. gunnari & Músculo & $2,2^{*}$ & Platt \& Mackie (1980), King Edward \\
& Fígado & $4,3^{*}$ & Cove, South Georgia. \\
P. georgianus & Músculo & $1,0^{*}$ & Platt \& Mackie (1980), King Edward \\
& Fígado & $0,5^{*}$ & Cove, South Georgia. \\
E. Antarctica & Músculo & $3,2^{*}$ & Cripps (1990), Bransfield Strait. \\
& Fígado & $9,4^{*}$ & \\
T. bernacchii & Vísceras & $656 \pm 319$ & Kennicutt II et al (1995), Winter \\
& & & Quarters Bay \\
T. bernacchii & Vísceras & $200 \pm 72$ & Kennicutt Il et al (1995), Cinder Cones. \\
& (cont.) & & \\
\hline${ }^{*}$ Dados retirados de Cripps \& Priddle (1991). &
\end{tabular}


Tabela 21. Concentrações ( $\mathrm{ng} \mathrm{g}^{-1}$ peso seco) de HPAs em peixes provenientes de diferentes regiões da Antártica.

\begin{tabular}{lccl}
\hline Espécie & Tecido & HPA total & \multicolumn{1}{c}{ Referência } \\
\hline N. rossii & Músculo & $1,26-76,5$ & Este trabalho, Baia do Almirantado. \\
N. coriiceps & Fígado & $257 \pm 84$ & Curtosi et al. (2009), Potter Cove, \\
& Gônada & $80,4 \pm 31,25$ & South Shetlands Island, Antarctica. \\
N. coriiceps & Músculo & $81-154$ & McDonald et al, (1992), Bahia \\
neglecta & Fígado & $50-1884$ & Paraíso, Arthur Harbor, Antarctica. \\
N. coriiceps & Músculo & $44-75$ & McDonald et al, (1992), Palmer \\
neglecta & Fígado & $145-325$ & Station. \\
N. gibberifrons & Músculo & $38-90$ & McDonald et al, (1992), Low Island \\
& Fígado & $13-145$ & and Dallmann Bay. \\
N. coriiceps & Músculo & "nd" & Kennicutt Il et al, (1991), Bahia \\
neglecta & Cont. & $6259-25854$ & Paraíso, Arthur Harbor, Antarctica. \\
& estomacal & & \\
\hline
\end{tabular}

Notothenia rossii é uma das espécies mais abundantes na Baía do Almirantado e está amplamente distribuída em toda Península Antártica. No geral, esta espécie é costeira e está associada às macroalgas. Seu comportamento é demersal bentônico e no inverno, época reprodutiva, migra para maiores profundidades (cerca de $500 \mathrm{~m}$ ) (Duhamel et al., 1995). Sua alimentação é baseada principalmente em anfípodes e em uma variedade de invertebrados bentônicos associados às macroalgas (Barrera-Oro \& Winter, 2008).

Neste estudo foram realizadas medidas de HPAs em 26 amostras de músculo de $N$. rossii, sendo que 10 amostras foram coletadas em P. Plaza (NRPP), à aproximadamente $1 \mathrm{~km}$ da estação brasileira; 9 foram coletadas nas proximidades da estação de pesquisa polonesa Arctowski (NRArc) 
$\left(62^{\circ} 09^{\prime} 45.0^{\prime \prime} \mathrm{S}, 5^{\circ} 28^{\prime} 00.0^{\prime \prime W}\right)$ e 7 coletadas em Copacabana (NRC) (62 ${ }^{\circ} 10^{\prime} \mathrm{S}$; $58^{\circ} 28^{\prime} \mathrm{W}$ ), área localizada entre a estação polonesa e a saída da Baía do Almirantado (Figura 9).

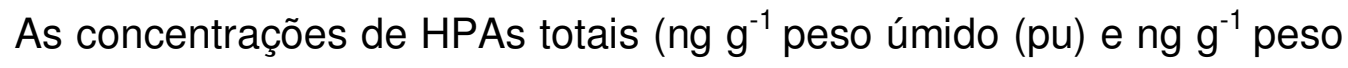
seco (ps)), HPAs individuais ( $\mathrm{ng} \mathrm{g}^{-1} \mathrm{pu}$ ) e o teor lipídico das amostras de $N$. rossii, estão apresentadas nas Tabelas 22, 23 e 24, para P.Plaza, Copacabana e Arctowisk, respectivamente.

Em geral, as concentrações obtidas para $N$. rossii variaram de 0,97 a $58,9 \mathrm{ng} \mathrm{g}^{-1} \mathrm{pu}\left(1,26-76,49 \mathrm{ng} \mathrm{g}^{-1} \mathrm{ps}\right)$, sendo que duas amostras (NRPP1 e NRAr7) apresentaram valores abaixo do limite de detecção (LD). Nas amostras coletadas em P. Plaza $(n=7)$, Copacabana $(n=9)$ e Arctowski $(n=10)$, as concentrações variaram respectivamente de 1,27 a $42,6 \mathrm{ng} \mathrm{g}^{-1} \mathrm{ps}$, de 0,97 a $24,8 \mathrm{ng} \mathrm{g}^{-1}$ ps e de 1,45 a $58,9 \mathrm{ng} \mathrm{g}^{-1}$ ps. 
Tabela 22. Concentrações de HPAs individuais, HPAs totais ( HPAs), soma de HPAs com 2 e 3 anéis aromáticos ( $\Sigma$ HPAs 2 3), soma de HPAs com 4 a 6 anéis aromáticos ( $\Sigma$ HPAs 4-6), soma de HPAs alquilados ( $\Sigma$ HPAs-alquil) em ng g ${ }^{-1}$ peso úmido; porcentagem de lipídios (\%); obtidos em músculo do peixe Notothenia rossii coletado em Punta Plaza. Os valores abaixo do Limite de detecção do método (LDM) estão indicados como "n.d.".

\begin{tabular}{|c|c|c|c|c|c|c|c|c|}
\hline \multirow[b]{2}{*}{ Composto } & \multicolumn{6}{|c|}{ N.rossii de Punta Plaza } & \multirow[b]{2}{*}{ NRPP7 } & \multirow[b]{2}{*}{ LDM } \\
\hline & NRPP1 & NRPP2 & NRPP3 & NRPP4 & NRPP5 & NRPP6 & & \\
\hline Naftaleno & n.d. & 6.50 & n.d. & n.d. & 4.37 & n.d. & 7.67 & 4.10 \\
\hline Bifenil & n.d. & n.d. & n.d. & n.d. & n.d. & n.d. & n.d. & 3.80 \\
\hline Acenaftileno & n.d. & n.d. & n.d. & n.d. & n.d. & n.d. & n.d. & 3.30 \\
\hline Acenafteno & n.d. & n.d. & n.d. & n.d. & n.d. & n.d. & n.d. & 0.80 \\
\hline$\sum$ Alquilnaftalenos & n.d. & 1.14 & 6.32 & 1.27 & n.d. & 1.41 & 35.0 & 3.80 \\
\hline Fluoreno & n.d. & n.d. & n.d. & n.d. & n.d. & n.d. & n.d. & 1.00 \\
\hline$\sum$ Alquilfluorenos & n.d. & 2.00 & n.d. & n.d. & 1.98 & n.d. & n.d. & 1.00 \\
\hline Dibenzotiofeno & n.d. & n.d. & n.d. & n.d. & n.d. & n.d. & n.d. & 1.00 \\
\hline Fenantreno & n.d. & n.d. & n.d. & n.d. & n.d. & n.d. & n.d. & 2.20 \\
\hline Antraceno & n.d. & n.d. & n.d. & n.d. & n.d. & n.d. & n.d. & 1.40 \\
\hline$\sum$ Alquilfenantreno & n.d. & n.d. & n.d. & n.d. & n.d. & n.d. & n.d. & 1.40 \\
\hline Fluoranteno & n.d. & n.d. & n.d. & n.d. & n.d. & n.d. & n.d. & 2.40 \\
\hline Pireno & n.d. & n.d. & n.d. & n.d. & n.d. & n.d. & n.d. & 3.80 \\
\hline Metilfluoranteno & n.d. & n.d. & n.d. & n.d. & n.d. & n.d. & n.d. & 3.80 \\
\hline Reteno & n.d. & n.d. & n.d. & n.d. & n.d. & n.d. & n.d. & 3.80 \\
\hline Metilpireno & n.d. & n.d. & n.d. & n.d. & n.d. & n.d. & n.d. & 3.80 \\
\hline Benzo(c)fenantreno & n.d. & n.d. & n.d. & n.d. & n.d. & n.d. & n.d. & 3.80 \\
\hline Benzo(a)fenantreno & n.d. & n.d. & n.d. & n.d. & n.d. & n.d. & n.d. & 3.90 \\
\hline Criseno & n.d. & n.d. & n.d. & n.d. & n.d. & n.d. & n.d. & 0.60 \\
\hline$\sum$ Alquilcriseno & n.d. & n.d. & n.d. & n.d. & n.d. & n.d. & n.d. & 0.60 \\
\hline Benzo(b)fluoranteno & n.d. & n.d. & n.d. & n.d. & n.d. & n.d. & n.d. & 0.60 \\
\hline Benzo(k)fluoranteno & n.d. & n.d. & n.d. & n.d. & n.d. & n.d. & n.d. & 1.70 \\
\hline Benzo(e)pireno & n.d. & n.d. & n.d. & n.d. & n.d. & n.d. & n.d. & 1.70 \\
\hline Benzo(a)pireno & n.d. & n.d. & n.d. & n.d. & n.d. & n.d. & n.d. & 2.90 \\
\hline Perileno & n.d. & n.d. & n.d. & n.d. & n.d. & n.d. & n.d. & 2.90 \\
\hline Indeno(1,2,3-c,d)pireno & n.d. & n.d. & n.d. & n.d. & n.d. & n.d. & n.d. & 3.80 \\
\hline Dibenzo(a,h)antraceno & n.d. & n.d. & n.d. & n.d. & n.d. & n.d. & n.d. & 2.50 \\
\hline Benzo(b)criseno & n.d. & n.d. & n.d. & n.d. & n.d. & n.d. & n.d. & 2.50 \\
\hline Benzo $(\mathrm{g}, \mathrm{h}, \mathrm{i})$ perileno & n.d. & n.d. & n.d. & n.d. & n.d. & n.d. & n.d. & 1.20 \\
\hline$\sum$ HPAs & n.d. & 9.64 & 6.32 & 1.27 & 6.35 & 1.41 & 42.6 & \\
\hline$\sum \operatorname{HPAs}(2-3)$ & n.d. & 9.64 & 6.32 & 1.27 & 6.35 & 1.41 & 42.6 & \\
\hline$\sum \operatorname{HPAs}(4-6)$ & n.d. & n.d. & n.d. & n.d. & n.d. & n.d. & n.d. & \\
\hline$\sum$ HPAs-alquil & n.d. & 3.14 & 6.32 & 1.27 & 1.98 & 1.41 & 35.0 & \\
\hline Lipídio (\%) & 0,66 & 0,63 & 0,76 & 0,96 & 0,63 & 0,97 & 1,36 & \\
\hline
\end{tabular}


Tabela 23. Concentrações de HPAs individuais, HPAs totais ( HPAs), soma de HPAs com 2 e 3 anéis aromáticos ( $\Sigma$ HPAs 2 3), soma de HPAs com 4 a 6 anéis aromáticos ( $\Sigma$ HPAs 4-6), soma de HPAs alquilados ( $\Sigma$ HPAs-alquil) em ng g ${ }^{-1}$ peso úmido; porcentagem de lipídios (\%); obtidos em músculo do peixe Notothenia rossii coletado em Copacabana. Os valores abaixo do Limite de detecção do método (LDM) estão indicados como "n.d.".

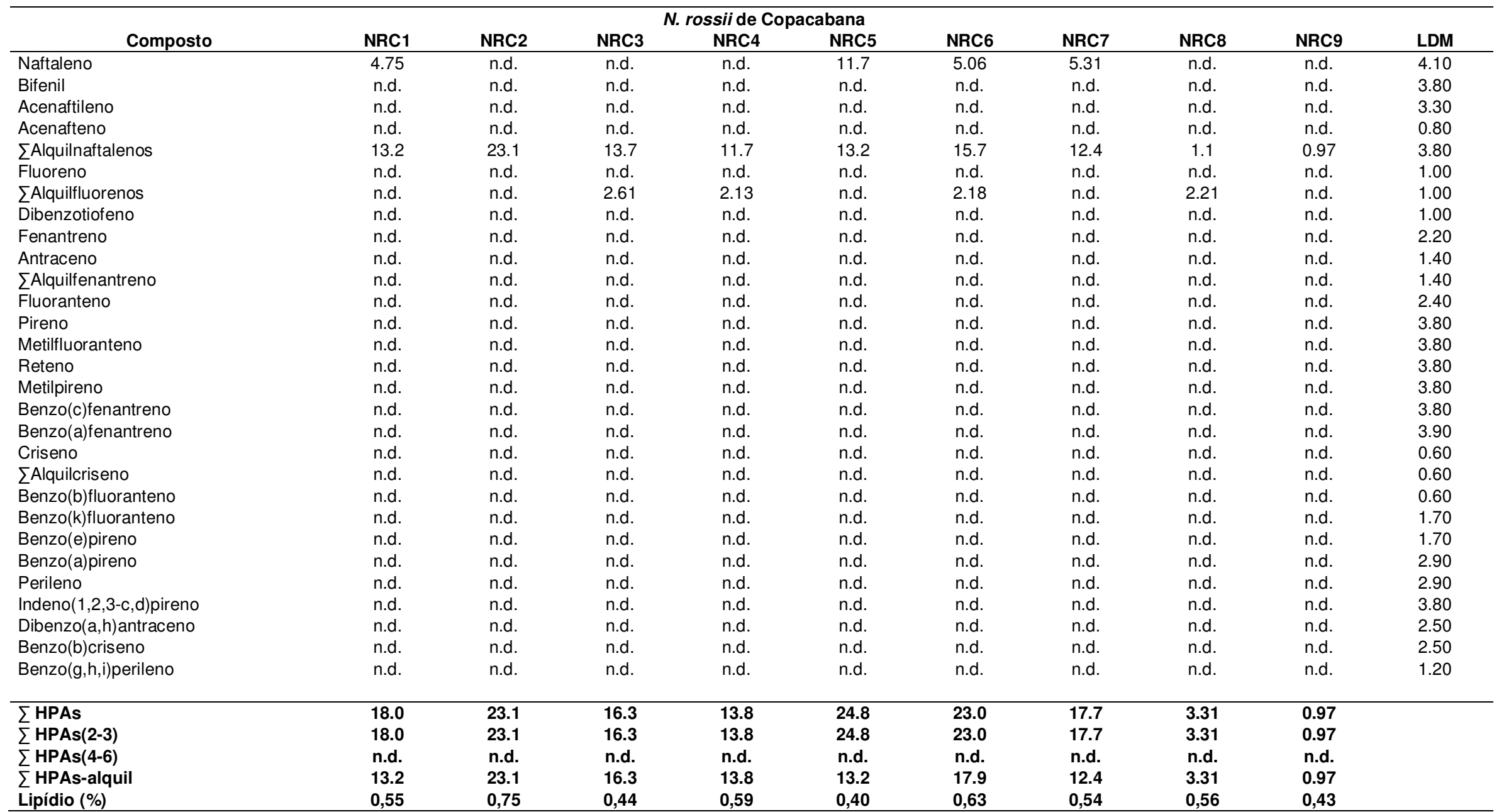




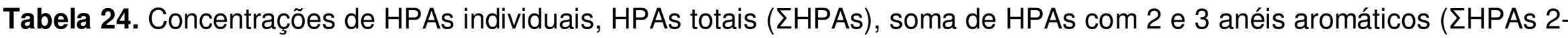

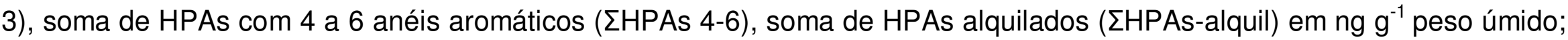
porcentagem de lipídios (\%); obtidos em músculo do peixe Notothenia rossii coletado próxima a estação polonesa Arctowisk. Os valores abaixo do Limite de detecção do método (LDM) estão indicados como "n.d.".

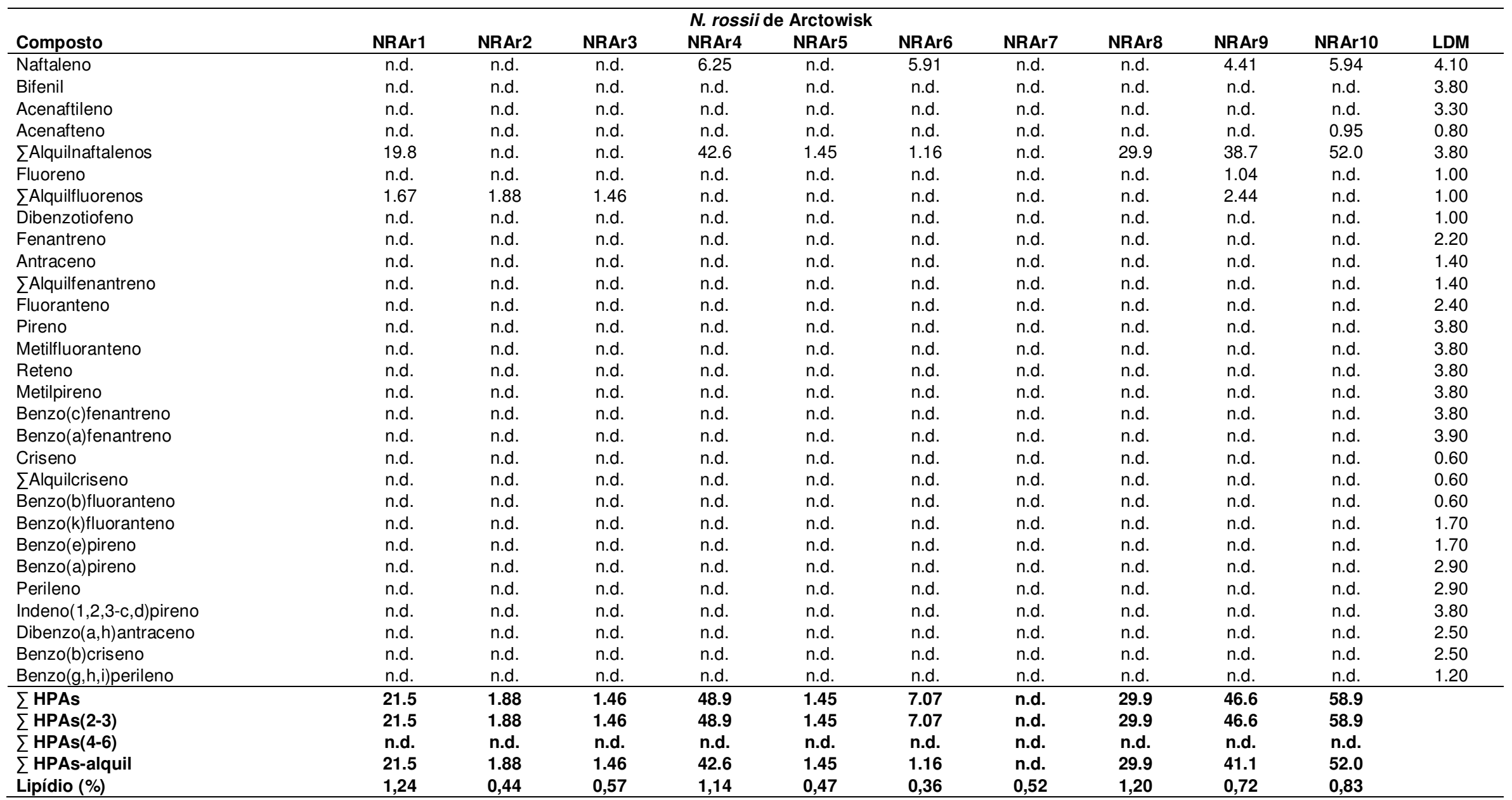


Em $80 \%$ das amostras, as concentrações variaram de 0,97 a $24,8 \mathrm{ng} \mathrm{g}^{-}$ ${ }^{1}$ pu e no restante variaram de 30 a $59 \mathrm{ng} \mathrm{g}^{-1} \mathrm{pu}$. Os valores foram similares às concentrações obtidas por vários autores revisados por Cripps \& Priddle (1991), para músculo de peixes antárticos, inclusive N. rossii. As concentrações também foram comparáveis aos valores obtidos por McDonald et al. (1992) para as espécies de Notothenia neglecta (44-75 $\mathrm{ng} \mathrm{g}^{-1} \mathrm{pu}$ ), coletada próximo à estação Palmer e aos valores obtidos por este mesmo autor para Notothenia gibberifrons (38-90 $\mathrm{ng} \mathrm{g}^{-1} \mathrm{ps}$ ) da ilha Low e Baía Dallman, locais distantes de atividades humanas (Tabela 18).

Os peixes apresentaram predominância de HPAs leves, principalmente dos grupos de alquilnaftalenos, alquilfluorenos e o naftaleno. A distribuição dos compostos individuais, para a maioria das amostras, apresentou similaridade com o perfil do DFA. Esses compostos são os mais solúveis em água e assim mais disponíveis para os peixes, que assimilam esses contaminantes através da ingestão de água e de partículas com hidrocarbonetos adsorvidos (Kennish, 1996).

Para verificar estatisticamente se havia diferença nas concentrações de HPAs totais entre os diferentes locais de amostragem, os dados foram avaliados quanto à normalidade usando um teste de Kolmogorov-Smirnov com 95\% de significância. Como estes não apresentaram distribuição normal optouse pelo teste não paramétrico de Kruskal Wallis. Aplicando esse teste obtivemos o nível de significância $p=0,2958$, indicando que as concentrações de HPAs totais em Copacabana, P. Plaza e Arctowski, na Baía do Almirantado, não apresentam diferenças significativas. 
A falta de diferenças entre os locais de coleta pode ser devida à mobilidade dos peixes, fazendo com que as concentrações encontradas para a espécie $N$. Rossii não sejam associadas exatamente aos pontos de coleta. Como a espécie estudada permanece na baia, as concentrações de HPAs dos peixes podem ser associadas ao local de estudo (Baia do Almirantado) como um todo.

Assim, os resultados encontrados foram tratados como uma amostra de uma mesma região, a fim de obter uma concentração que caracterize a Baía do Almirantado; o intervalo das concentrações dos peixes foi de 0,97 a $58,9 \mathrm{ng}$ $\mathrm{g}^{-1}$ pu e com mediana de $11,7 \mathrm{ng} \mathrm{g}^{-1} \mathrm{pu}$.

\subsubsection{Hidrocarbonetos policíclicos aromáticos em aves}

Foram analisadas 21 amostras de gordura de aves, sendo 14 amostras de pinguins e 7 amostras de outras aves (skua, petrel gigante, pomba-do-cabo e gaivotão).

As Tabelas 25, 26 e 27 apresentam as concentrações de HPAs totais (peso úmido e lipídico), HPAs individuais e o teor lipídico. As concentrações de HPAs totais do pinguim adélia (Pygoscelis adeliae) $(n=7)$, pinguim papua (Pygoscelis papua) $(\mathrm{n}=2)$ e do pinguim antártico (Pygoscelis antarticus) $(\mathrm{n}=5)$ variaram, respectivamente de 84,0 a $202,3 \mathrm{ng} \mathrm{g}^{-1} \mathrm{pu}$, com mediana de $121,5 \mathrm{ng}$ $\mathrm{g}^{-1} \mathrm{pu}$, de 198,4 a $238,7 \mathrm{ng} \mathrm{g}^{-1} \mathrm{pu}$, com mediana de $218,5 \mathrm{ng} \mathrm{g}^{-1}$ pu e de 60,1 a 258,2 $\mathrm{ng} \mathrm{g}^{-1} \mathrm{pu}$, com mediana de 90,3 $\mathrm{ng} \mathrm{g}^{-1} \mathrm{pu}$. As concentrações das amostras de skua (Catharacta $s p$.) $(n=3)$ e das amostras de petrel gigante (Macronectes giganteus) ( $n=2$ ) variaram respectivamente, de 97,0 a $3164,7 \mathrm{ng}$ $\mathrm{g}^{-1} \mathrm{pu}$, com mediana de $157,6 \mathrm{ng} \mathrm{g}^{-1}$ pu e de 210,0 a $6861,0 \mathrm{ng} \mathrm{g}^{-1} \mathrm{pu}$, com 
mediana de 3535,6 $\mathrm{ng} \mathrm{g}^{-1} \mathrm{pu}$. A concentração obtida para o gaivotão (Larus dominicanus) ( $\mathrm{n}=1$ ) foi $249,3 \mathrm{ng} \mathrm{g}^{-1}$ pu e para a pomba do cabo (Daption capensis) ( $\mathrm{n}=1), 1274,7 \mathrm{ng} \mathrm{g}^{-1} \mathrm{pu}$.

Tabela 25. Concentrações de HPAs individuais e os parâmetros: HPAs totais

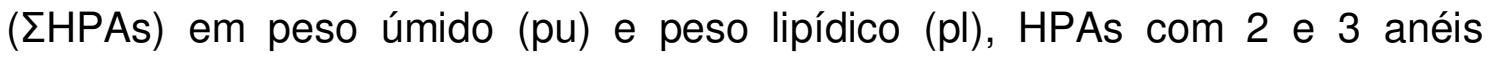

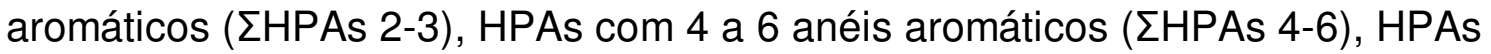
alquilados ( $\Sigma$ HPAs-alquil), em $\mathrm{ng} \mathrm{g}^{-1}$ peso úmido de gordura do Pinguim adeliae $(n=7)$ e a porcentagem de lipídios (\%). Os valores abaixo do Limite de deteç̧ão do método (LDM) estão indicados como "n.d."

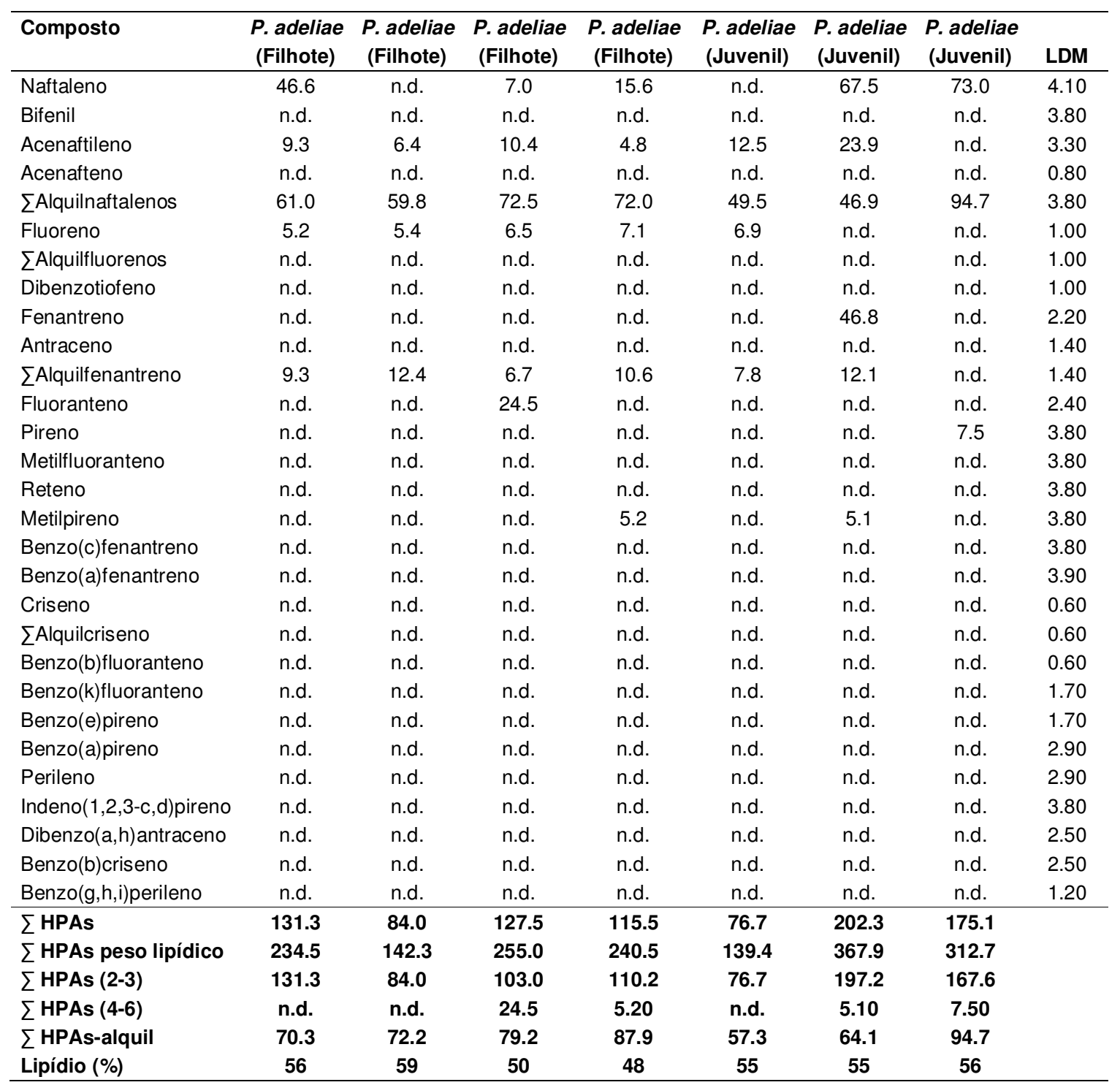


Tabela 26. Concentrações de HPAs individuais e os parâmetros: HPAs totais ( HPAs) em peso úmido (pu) e peso lipídico

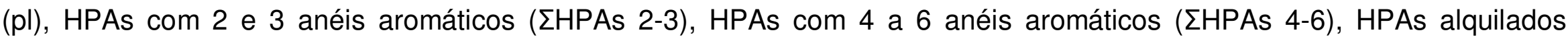
( $\Sigma$ HPAs-alquil), em ng g ${ }^{-1}$ peso úmido de gordura do Pygoscelis papua $(n=2)$ e Pygoscelis antarcticus $(n=5)$ e a porcentagem de lipídios (\%). Os valores abaixo do Limite de detecção do método (LDM) estão indicados como "n.d.".

\begin{tabular}{|c|c|c|c|c|c|c|c|c|}
\hline Composto & $\begin{array}{l}\text { P. papua } \\
\text { (Filhote) }\end{array}$ & $\begin{array}{l}\text { P. papua } \\
\text { (Filhote) }\end{array}$ & $\begin{array}{c}\text { P.antarcticus } \\
\text { (Filhote) }\end{array}$ & $\begin{array}{l}\text { P.antarcticus } \\
\text { (Filhote) }\end{array}$ & $\begin{array}{c}\text { P.antarcticus } \\
\text { (filhote) }\end{array}$ & $\begin{array}{c}\text { P.antarcticus } \\
\text { (adulto) }\end{array}$ & $\begin{array}{c}\text { P.antarcticus } \\
\text { (adulto) }\end{array}$ & LDM \\
\hline Naftaleno & 141.5 & 147.0 & n.d. & n.d. & n.d. & 18.8 & 72.1 & 4.10 \\
\hline Bifenil & n.d. & n.d. & n.d. & n.d. & n.d. & n.d. & n.d. & 3.80 \\
\hline Acenaftileno & 27.2 & 32.0 & n.d. & n.d. & n.d. & 11.5 & n.d. & 3.30 \\
\hline Acenafteno & n.d. & n.d. & n.d. & n.d. & n.d. & n.d. & n.d. & 0.80 \\
\hline$\sum$ Alquilnaftalenos & 61.2 & 12.7 & 47.2 & 78.7 & 43.27 & 47.1 & 186.14 & 3.80 \\
\hline Fluoreno & n.d. & n.d. & 5.5 & n.d. & n.d. & 4.9 & n.d. & 1.00 \\
\hline$\sum$ Alquilfluorenos & n.d. & n.d. & n.d. & 4.0 & n.d. & 4.2 & n.d. & 1.00 \\
\hline Dibenzotiofeno & n.d. & n.d. & n.d. & n.d. & n.d. & n.d. & n.d. & 1.00 \\
\hline Fenantreno & n.d. & n.d. & n.d. & n.d. & n.d. & n.d. & n.d. & 2.20 \\
\hline Antraceno & n.d. & n.d. & n.d. & n.d. & n.d. & n.d. & n.d. & 1.40 \\
\hline$\sum$ Alquilfenantreno & 8.8 & 6.8 & 7.4 & 7.6 & 2.5 & 7.7 & n.d. & 1.40 \\
\hline Fluoranteno & n.d. & n.d. & n.d. & n.d. & n.d. & n.d. & n.d. & 2.40 \\
\hline Pireno & n.d. & n.d. & n.d. & n.d. & n.d. & n.d. & n.d. & 3.80 \\
\hline Metilfluoranteno & n.d. & n.d. & n.d. & n.d. & n.d. & n.d. & n.d. & 3.80 \\
\hline Reteno & n.d. & n.d. & n.d. & n.d. & n.d. & n.d. & n.d. & 3.80 \\
\hline Metilpireno & n.d. & n.d. & n.d. & n.d. & n.d. & n.d. & n.d. & 3.80 \\
\hline Benzo(c)fenantreno & n.d. & n.d. & n.d. & n.d. & n.d. & n.d. & n.d. & 3.80 \\
\hline Benzo(a)fenantreno & n.d. & n.d. & n.d. & n.d. & n.d. & n.d. & n.d. & 3.90 \\
\hline Criseno & n.d. & n.d. & n.d. & n.d. & n.d. & n.d. & n.d. & 0.60 \\
\hline$\sum$ Alquilcriseno & n.d. & n.d. & n.d. & n.d. & n.d. & n.d. & n.d. & 0.60 \\
\hline Benzo(b)fluoranteno & n.d. & n.d. & n.d. & n.d. & n.d. & n.d. & n.d. & 0.60 \\
\hline Benzo $(\mathrm{k})$ fluoranteno & n.d. & n.d. & n.d. & n.d. & n.d. & n.d. & n.d. & 1.70 \\
\hline Benzo(e)pireno & n.d. & n.d. & n.d. & n.d. & n.d. & n.d. & n.d. & 1.70 \\
\hline Benzo(a)pireno & n.d. & n.d. & n.d. & n.d. & n.d. & n.d. & n.d. & 2.90 \\
\hline Perileno & n.d. & n.d. & n.d. & n.d. & n.d. & n.d. & n.d. & 2.90 \\
\hline Indeno $(1,2,3-c, d)$ pireno & n.d. & n.d. & n.d. & n.d. & n.d. & n.d. & n.d. & 3.80 \\
\hline Dibenzo(a,h)antraceno & n.d. & n.d. & n.d. & n.d. & n.d. & n.d. & n.d. & 2.50 \\
\hline Benzo(b)criseno & n.d. & n.d. & n.d. & n.d. & n.d. & n.d. & n.d. & 2.50 \\
\hline Benzo(g,h,i)perileno & n.d. & n.d. & n.d. & n.d. & n.d. & n.d. & n.d. & 1.20 \\
\hline$\sum$ HPAs & 238.7 & 198.4 & 60.1 & 90.3 & 70.7 & 94.2 & 258.2 & \\
\hline$\sum$ HPAs peso lipídico & 426.2 & 348.0 & 109.2 & 164.1 & 104.0 & 229.6 & 263.5 & \\
\hline$\sum$ HPAs $(2-3)$ & 238.7 & 198.4 & 60.1 & 90.3 & 45.8 & 94.2 & 258.2 & \\
\hline$\sum$ HPAs (4-6) & n.d. & n.d. & n.d. & n.d. & 25,0 & n.d. & n.d. & \\
\hline$\sum$ HPAs-alquil & 70.0 & 19.4 & 54.6 & 90.3 & 45.8 & 59.0 & 186.1 & \\
\hline Lipídio (\%) & 56 & 57 & 55 & 55 & 68 & 41 & 98 & \\
\hline
\end{tabular}


Tabela 27. Concentrações de HPAs individuais e os parâmetros: HPAs totais ( $\Sigma$ HPAs) em peso úmido (pu) e peso lipídico

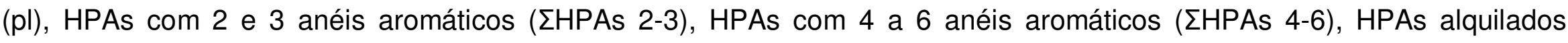

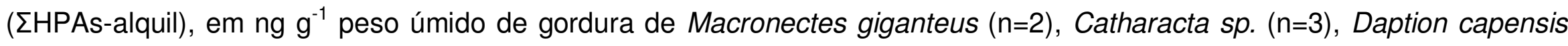
( $n=1$ ) e Larus dominicanus $(n=1)$ e a porcentagem de lipídios (\%). Os valores abaixo do Limite de detecção do método (LDM) estão indicados como "n.d.".

\begin{tabular}{|c|c|c|c|c|c|c|c|c|}
\hline Composto & $\begin{array}{c}\text { Catharacta sp. } \\
\text { (filhote) }\end{array}$ & Catharacta sp. & $\begin{array}{l}\text { Catharacta sp. } \\
\text { (adulto) }\end{array}$ & $\begin{array}{c}\text { Larus } \\
\text { dominicanus } \\
-\end{array}$ & $\begin{array}{c}\text { Macronectes } \\
\text { giganteus } \\
-\end{array}$ & $\begin{array}{c}\text { Macronectes } \\
\text { giganteus } \\
\text { (Jovem) }\end{array}$ & $\begin{array}{l}\text { Daption } \\
\text { capensis } \\
-\end{array}$ & LDM \\
\hline Naftaleno & 127.0 & 25.7 & 2122.5 & 145.7 & 159.8 & 5325.9 & 1047.7 & 4.10 \\
\hline Bifenil & n.d. & n.d. & 124.2 & n.d. & n.d. & 352.1 & 49.3 & 3.80 \\
\hline Acenaftileno & 4.9 & n.d. & 289.6 & 5.3 & n.d. & 502.5 & 66.9 & 3.30 \\
\hline Acenafteno & n.d. & n.d. & n.d. & n.d. & n.d. & n.d. & n.d. & 0.80 \\
\hline ¿Alquilnaftalenos & 25.7 & 69.2 & 628.5 & 98.3 & 50.4 & 680.5 & 110.9 & 3.80 \\
\hline Fluoreno & n.d. & n.d. & n.d. & n.d. & n.d. & n.d. & n.d. & 1.00 \\
\hline$\sum$ Alquilfluorenos & n.d. & n.d. & n.d. & n.d. & n.d. & n.d. & n.d. & 1.00 \\
\hline Dibenzotiofeno & n.d. & n.d. & n.d. & n.d. & n.d. & n.d. & n.d. & 1.00 \\
\hline Fenantreno & n.d. & n.d. & n.d. & n.d. & n.d. & n.d. & n.d. & 2.20 \\
\hline Antraceno & n.d. & n.d. & n.d. & n.d. & n.d. & n.d. & n.d. & 1.40 \\
\hline ¿Alquilfenantreno & n.d. & 2.1 & n.d. & n.d. & n.d. & n.d. & n.d. & 1.40 \\
\hline Fluoranteno & n.d. & n.d. & n.d. & n.d. & n.d. & n.d. & n.d. & 2.40 \\
\hline Pireno & n.d. & n.d. & n.d. & n.d. & n.d. & n.d. & n.d. & 3.80 \\
\hline Metilfluoranteno & n.d. & n.d. & n.d. & n.d. & n.d. & n.d. & n.d. & 3.80 \\
\hline Reteno & n.d. & n.d. & n.d. & n.d. & n.d. & n.d. & n.d. & 3.80 \\
\hline Metilpireno & n.d. & n.d. & n.d. & n.d. & n.d. & n.d. & n.d. & 3.80 \\
\hline Benzo(c)fenantreno & n.d. & n.d. & n.d. & n.d. & n.d. & n.d. & n.d. & 3.80 \\
\hline Benzo(a)fenantreno & n.d. & n.d. & n.d. & n.d. & n.d. & n.d. & n.d. & 3.90 \\
\hline Criseno & n.d. & n.d. & n.d. & n.d. & n.d. & n.d. & n.d. & 0.60 \\
\hline ¿Alquilcriseno & n.d. & n.d. & n.d. & n.d. & n.d. & n.d. & n.d. & 0.60 \\
\hline Benzo(b)fluoranteno & n.d. & n.d. & n.d. & n.d. & n.d. & n.d. & n.d. & 0.60 \\
\hline Benzo(k)fluoranteno & n.d. & n.d. & n.d. & n.d. & n.d. & n.d. & n.d. & 1.70 \\
\hline Benzo(e)pireno & n.d. & n.d. & n.d. & n.d. & n.d. & n.d. & n.d. & 1.70 \\
\hline Benzo(a)pireno & n.d. & n.d. & n.d. & n.d. & n.d. & n.d. & n.d. & 2.90 \\
\hline Perileno & n.d. & n.d. & n.d. & n.d. & n.d. & n.d. & n.d. & 2.90 \\
\hline Indeno $(1,2,3-c, d)$ pireno & n.d. & n.d. & n.d. & n.d. & n.d. & n.d. & n.d. & 3.80 \\
\hline Dibenzo(a,h)antraceno & n.d. & n.d. & n.d. & n.d. & n.d. & n.d. & n.d. & 2.50 \\
\hline Benzo(b)criseno & n.d. & n.d. & n.d. & n.d. & n.d. & n.d. & n.d. & 2.50 \\
\hline Benzo $(\mathrm{g}, \mathrm{h}, \mathrm{i})$ perileno & n.d. & n.d. & n.d. & n.d. & n.d. & n.d. & n.d. & 1.20 \\
\hline$\sum$ HPAs & 157.6 & 97.0 & 3164.7 & 249.3 & 210.2 & 6861.0 & 1274.7 & \\
\hline$\sum$ HPAs peso lipídico & 286.5 & 107.8 & 7032.7 & 470.4 & 724,1 & 7709,0 & 2317,6 & \\
\hline$\sum \operatorname{HPAs}(2-3)$ & 157.6 & 97.0 & 3164.7 & 249.3 & 210.2 & 6861.0 & 1274.7 & \\
\hline$\sum \operatorname{HPAs}(4-6)$ & n.d. & n.d. & n.d. & n.d. & n.d. & n.d. & n.d. & \\
\hline$\sum$ HPAs-alquil & 25.7 & 71.3 & 628.5 & 98.3 & 50.4 & 680.5 & 110.9 & \\
\hline Lipídio (\%) & 55 & 90 & 45 & 53 & 29 & 89 & 55 & \\
\hline
\end{tabular}


As maiores concentrações foram obtidas para as espécies de petrel gigante (jovem) (6861,0 $\mathrm{ng} \mathrm{g}^{-1} \mathrm{pu}$ ), skua (adulto) (3164,7 $\mathrm{ng} \mathrm{g}^{-1} \mathrm{pu}$ ) e pombado-cabo (maturidade não identificada) (1274,7 $\mathrm{ng} \mathrm{g}^{-1} \mathrm{pu}$ ). Estas concentrações podem estar relacionadas com seus hábitos alimentares e migratórios, ao deslocarem-se para outras regiões com maior biodisponibilidade de HPAs. A menor concentração foi obtida para um filhote de skua $\left(157,6 \mathrm{ng} \mathrm{g}^{-1} \mathrm{pu}\right)$.

Entre as amostras de skua, a concentração de HPAs totais para o indivíduo adulto $\left(3164,7 \mathrm{ng} \mathrm{g}^{-1} \mathrm{pu}\right)$ foi relativamente maior que para o filhote (157,6 $\mathrm{ng} \mathrm{g}^{-1} \mathrm{pu}$ ). Como os filhotes de skua ainda não migram, os HPAs absorvidos por eles podem ser somente aqueles disponíveis na região onde se encontram.

As concentrações de HPAs totais para os pinguins foram menores (60,1- 258,2 $\mathrm{ng} \mathrm{g}^{-1}$ pu e mediana de $\left.121,5 \mathrm{ng} \mathrm{g}^{-1} \mathrm{pu}\right)$ quando comparadas às outras aves (jovem e adulta) (3164,7 - 6861,0 $\mathrm{ng} \mathrm{g}^{-1} \mathrm{pu}$ ). $\mathrm{O}$ fato dos pinguins serem aves mais restritas à região Antártica e se alimentarem basicamente de krill e peixes (McGonigal, 2009), os expõem apenas a contaminantes biodisponíveis na região.

Para verificar se havia diferença significativa entre as concentrações de HPAs totais entre as espécies de pinguins foi aplicado o teste não paramétrico de Kruskal Wallis, obtendo-se nível de significância $p=0,1875$ que mostra a ausência de diferença estatística nas concentrações obtidas entre as espécies. Também foi observado que não há diferença significativa $(p=0,2316)$ entre as concentrações de HPAs totais encontradas nas aves, em relação à maturidade.

Taniguchi et al (2009), em trabalho feito na mesma região de estudo, obtiveram concentrações de HPAs totais para Catharacta antarctica, 
Phalacrocorax Atriceps, Chionis Alba, Sterna vittata e para os pinguins respectivamente de $3375 \pm 1588 \mathrm{ng} \mathrm{g}^{-1}$ peso lipídico (pl), $3961 \mathrm{ng} \mathrm{g}^{-1} \mathrm{pl}, 4090$ $\mathrm{ng} \mathrm{g}^{-1} \mathrm{pl}, 5744 \pm 2546 \mathrm{ng} \mathrm{g}^{-1} \mathrm{pl} \mathrm{e}$ de $1588,0 \pm 654 \mathrm{ng} \mathrm{g}^{-1} \mathrm{pl}$

Transformando os resultados obtidos do presente estudo, para peso lipídico (pl), as maiores concentrações de HPAs totais $\left(2317,7\right.$ a $7709,0 \mathrm{ng} \mathrm{g}^{-1}$ pl) encontradas na Baía do Almirantado para aves, com exceção dos pinguins, foram similares às obtidas por Taniguchi et al. (2009). Por outro lado, as concentrações para os pinguins obtidas neste trabalho $\left(104,0-426,2 \mathrm{ng} \mathrm{g}^{-1} \mathrm{pl}\right)$ foram menores que os valores $\left(1588,0 \pm 654 \mathrm{ng} \mathrm{g}^{-1} \mathrm{pl}\right)$ obtidos por aqueles autores.

De forma geral, os HPAs leves predominaram em todas as amostras de aves. Os principais compostos individuais encontrados nas aves analisadas foram o naftaleno, fenantreno e os grupos de alquilnaftalenos e alquilfenantrenos. A distribuição dos compostos individuais nas amostras de pinguins mostrou a similaridade com a distribuição dos HPAs no DFA (Figura 41).

O predomínio de compostos alquilados sobre os seus homólogos não alquilados indicam a contaminação por derivados de petróleo (Sericano et al., 2001). As possíveis fontes petrogênicas de HPAs para a área de estudo são os navios de pesquisa e turismo que navegam na região (principalmente durante 0 verão) e as estações antárticas instaladas, que utilizam o DFA como principal fonte de energia. Como no DFA ocorre o predomínio de alquilnaftalenos sobre o naftaleno, e a distribuição dos HPAs individuais nas amostras de pinguins, aves restritas ao ambiente Antártico, foi similar à do DFA, sugerimos que a utilização deste combustível é a principal fonte de HPAs na Baía do 
Almirantado também para as aves.

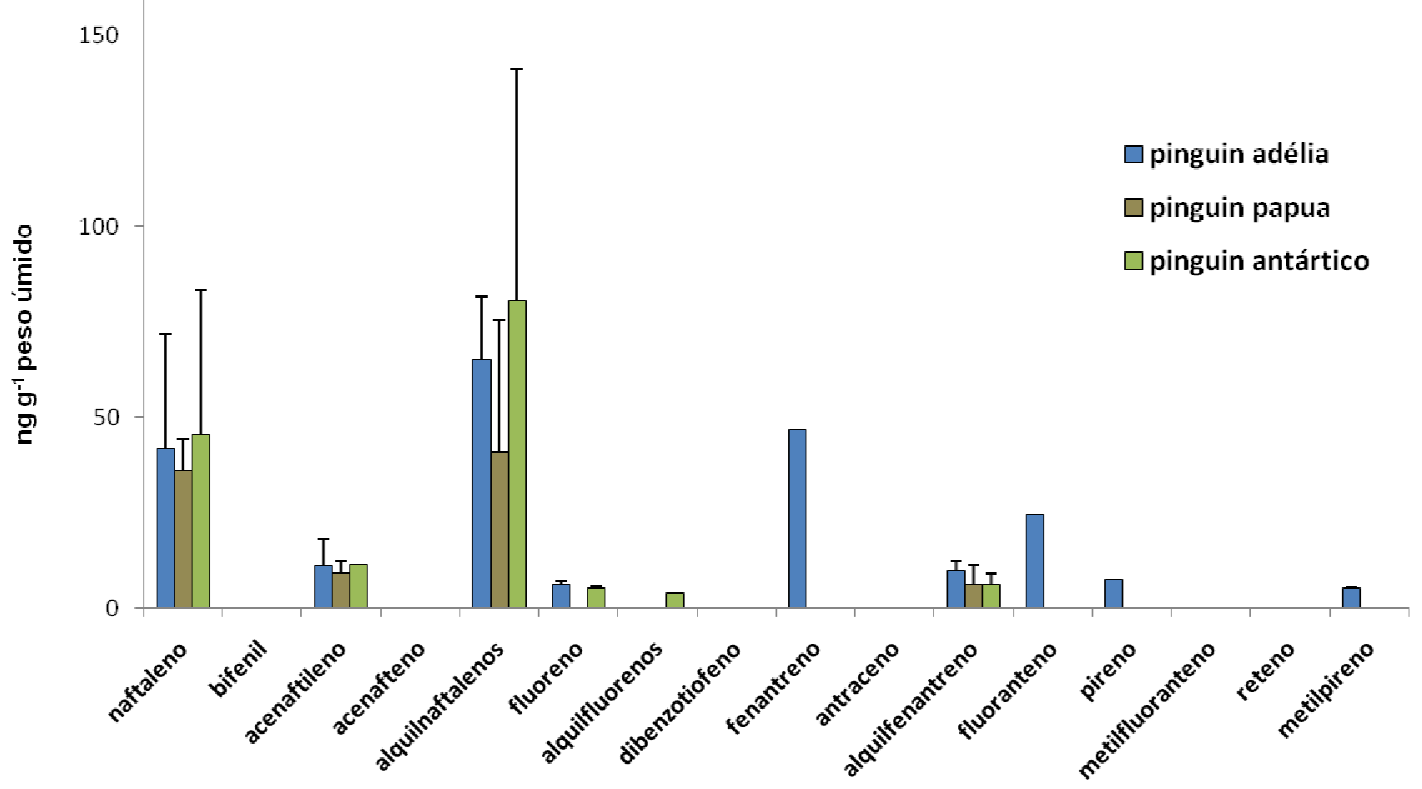

Figura 41. Médias das concentrações de HPAs individuais em pinguins adélia, papua e antártico.

Nas aves voadoras, a distribuição de HPAs individuais (Figuras 42) foi diferente da observada nos pinguins, havendo predomínio dos compostos não alquilados. Este comportamento, mais uma vez, pode ser atribuido ao fato destas aves não serem restritas a região Antártica, podendo assim entrar em contato com outras fontes de HPAs durante o período migratório.

Os resultados obtidos mostram que os HPAs introduzidos na Baía do Almirantado, originários da utilização do DFA, estão biodisponíveis para as espécies de aves analisadas, principalmente para os pinguins. 


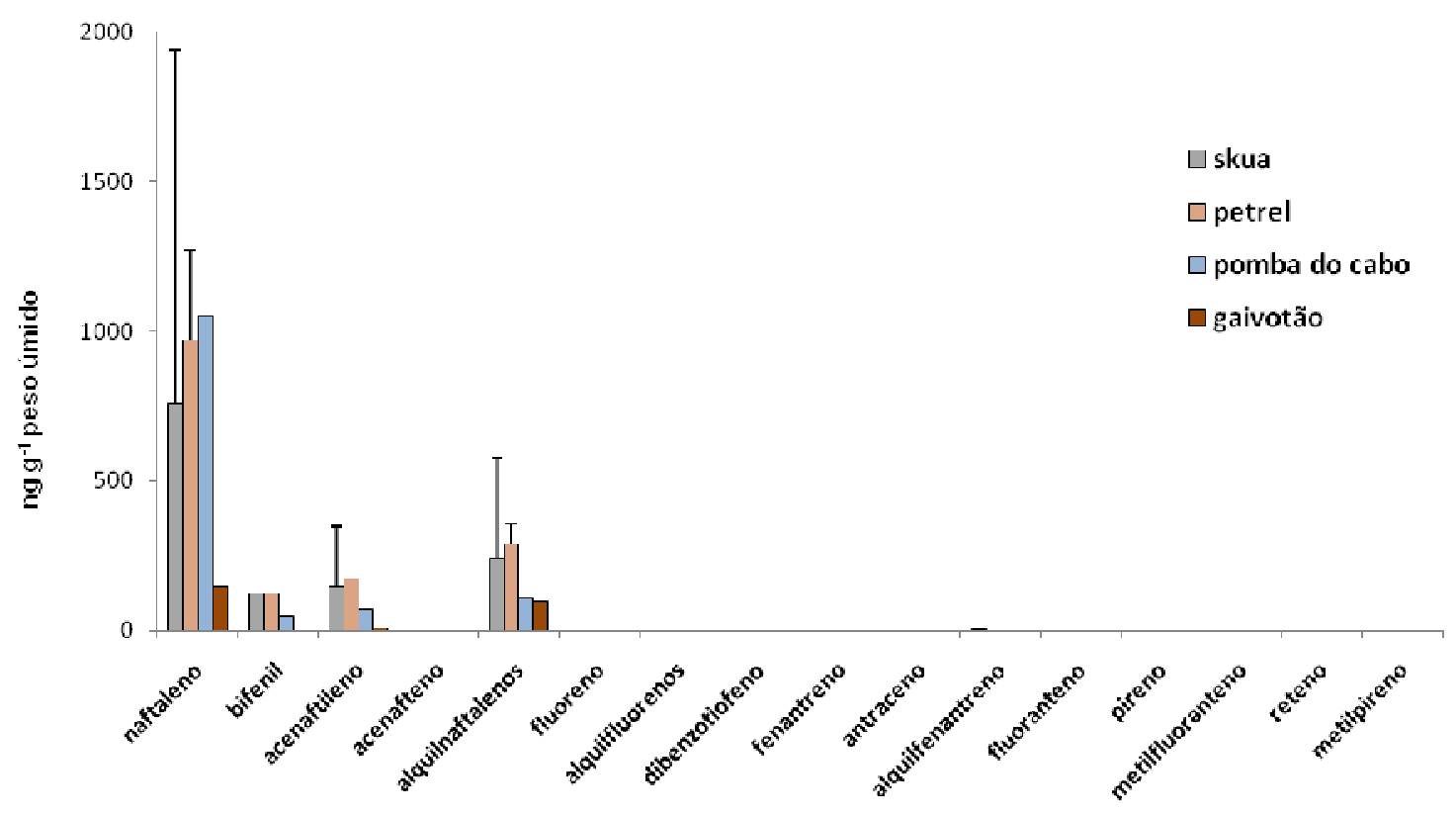

Figura 42. Médias das concentrações de HPAs em skua, petrel gigante e a concentração obtida para amostra de pomba-do-cabo e gaivotão.

\subsection{Comparação entre os invertebrados, peixes e aves}

Como a comparação estatística entre os dados de moluscos, equinodermos e crustáceos não apresentaram diferença significativa, este grupo de invertebrados foi considerado como uma amostra composta. Da mesma forma a comparação estatística entre os dados dos peixes não apresentou diferença entre as amostras coletadas em locais diferentes, o que também ocorreu com os pinguins quando se comparou as espécies entre si.

Em relação às aves voadoras, não foi possível fazer análise estatística devido ao pequeno número de amostra. Além disso, visto que o interesse foi de avaliar a distribuição de HPAs apenas na região de estudo, e estas aves são migratórias, o grupo das aves foi representado apenas pelos pinguins, espécies mais restritas a região Antártica. 
As concentrações de HPAs totais da amostra composta dos invertebrados, peixes e pinguins foram comparadas estatisticamente entre si, com a finalidade de verificar se ocorrem diferenças significativas. Foi aplicado o teste não paramétrico de Kruskal Wallis para comparar os invertebrados com os peixes, os invertebrados com os pinguins e os peixes com os pinguins, obtendo-se respectivamente nível de significância $p=0,0130, p=0,0001, p=$ 0,0001 , ou seja, as concentrações entre invertebrados, peixes e pinguins foram estatisticamente diferentes entre si.

Considerando que os peixes e invertebrados entram em contato com contaminantes no meio aquático, a menor concentração de HPAs totais ocorreu para os peixes (de 0,97 a 58,9 $\mathrm{ng} \mathrm{g}^{-1} \mathrm{pu}$, mediana $=11,7 \mathrm{ng} \mathrm{g}^{-1} \mathrm{pu}$ ), pois estes organismos têm um eficiente sistema de metabolização, diferentemente dos invertebrados, onde as concentrações de HPAs totais foram maiores (de 3,09 a 174,4 $\mathrm{ng} \mathrm{g}^{-1} \mathrm{pu}$, mediana $=26,2 \mathrm{ng} \mathrm{g}^{-1} \mathrm{pu}$ ). Já as maiores concentração de HPAs totais (de 60,10 a 258,2 $\mathrm{ng} \mathrm{g}^{-1} \mathrm{pu}$, mediana = $121,5 \mathrm{ng} \mathrm{g}^{-1} \mathrm{pu}$ ) ocorreram nos pinguins, pois podem absorver HPAs de forma direta, seja por meio da ingestão de água ou da limpeza das penas, ou de forma indireta, alimentando-se de peixes e invertebrados (principalmente krill) contaminados.

Embora não exista nenhum trabalho que contenha dados sobre HPAs em organismos de diferentes níveis tróficos na Antártica, estudos realizados em outras regiões do mundo podem ser comparados com os resultados deste trabalho. Perugini et al. (2007) determinaram os níveis de concentrações de HPAs em bivalves, cefalópodes, crustáceos e peixes do mar Adriático, Itália para compreender seu status de contaminação e concluíram que para os níveis 
HPAs totais, os organismos invertebrados diferem significativamente dos vertebrados, não havendo relação entre o aumento da concentração de HPAs dos organismos com o aumento do nível trófico. Wan et al. (2007) analisaram fitoplâncton, invertebrados, peixes e aves a fim de estudar a diluição trófica de HPAs na cadeia alimentar marinha da baía de Bohai, norte de China. Concluíram que as concentrações de HPAs totais diminuíram significativamente com o aumento do nível trófico, pois a diminuição da concentração de HPAs na cadeia trófica marinha deve-se provavelmente à sua baixa eficiência de assimilação e à eficiente transformação metabólica em animais de níveis mais elevados, na cadeia alimentar.

Neste trabalho, da mesma forma que em Perugini et al. (2007) as concentrações entre invertebrados e peixes também foram diferentes entre si, e as concentrações de HPAs totais diminuíram significativamente com o aumento do nível trófico como em Wan et al. (2007), se considerarmos apenas os resultados para os invertebrados e peixes. Neste estudo realizado na região Antártica, os resultados obtidos para as aves foram maiores que as concentrações obtidas para peixes, o que difere dos resultados obtidos por Wan et al. (2007), provavelmente devido ao fato de as aves deste estudo serem pinguins, que tem hábitos alimentares e capacidade de metabolização diferentes das espécies estudadas por aquele autor.

Neste estudo, de forma geral, os HPAs que predominaram em quase todas as amostras, independentemente da espécie, foram o naftaleno, fenantreno, fluoranteno e seus homólogos alquilados. Tendência semelhante também foi relatada por Perugini et al. (2007). A elevada presença de HPAs leves e alquilados, indica os derivados de petróleo como a principal fonte de 
contaminação de HPAs (Sericano et al., 2001). Na Baía do Almirantado o principal derivado de petróleo utilizado é o DFA, portanto esta foi a principal fonte de HPAs para os organismos analisados. 


\section{CONCLUSÕES}

A ocorrência de hidrocarbonetos policíclicos aromáticos (HPAs) foi observada em todas as espécies de moluscos, equinodermos, crustáceos, peixes e aves, mostrando a biodisponibilidade desses compostos na Baía do Almirantado, Ilha Rei George, Península Antártica. Entretanto, os níveis de concentrações de HPAs obtidos nos organismos analisados neste trabalho foram comparáveis às concentrações obtidas por outros autores em organismos de locais considerados com pouca ou nenhuma contaminação.

Os HPAs predominantes foram os compostos com menor peso molecular e os alquilsubstituídos, principalmente os alquilnaftalenos, estiveram presentes em quase todas as amostras indicando que a principal fonte de HPAs para esses organismos foi petrogênica.

As maiores concentrações de HPAs totais foram obtidas para as amostras coletadas nas proximidades da estação brasileira Comandante Ferraz (EACF), sendo que a distribuição dos HPAs individuais foi similar ao perfil destes compostos no DFA (diesel fuel arctic). Assim, a principal fonte petrogênica para os organismos analisados foi a utilização deste combustível nas atividades da estação.

As concentrações de HPAs totais entre os moluscos, equinodermos e crustáceos foram estatisticamente similares. Entre os grupos de peixes $(N$. rossii) coletados em Copacabana, Arctowski e Ponta Plaza não houve diferença significativa entre as concentrações de HPAs totais. Da mesma forma as comparações entre as espécies de pinguins Pygoscelis adélia, P. papua e P. antarcticus, também foram estatisticamente similares. As aves voadoras apresentaram concentrações maiores que os pingüins, devido ao seu hábito 
migratório.

A maioria das espécies predadoras necrófagas apresentou distribuição de HPAs individuais diferentes das espécies suspensívoras e depositívoras, devido a influência do hábito alimentar das espécies na absorção de HPAs.

A comparação entre os níveis de HPAs totais dos invertebrados, peixes e aves, apresentou diferença significativa, mostrando que as menores concentrações ocorreram para os peixes, as concentrações intermediárias foram para os invertebrados e as maiores concentrações, para os pinguins, não ocorrendo uma relação entre o aumento da concentração de HPAs e o nível trófico dos grupos. Vários fatores como o metabolismo dos contaminantes absorvidos, as características fisiológicas, os hábitos alimentares dos organismos e o teor de lipídios contidos nas amostras de tecidos analisados, tiveram influencia na absorção de HPAs por esses organismos.

Existem poucos dados sobre HPAs em organismos antárticos e este estudo pode contribuir para o entendimento dos processos antrópicos que ocorreram na região. Mesmo sendo observadas baixas concentrações, os resultados indicam a necessidade da ampliação desses estudos, uma vez que pouco se sabe sobre os efeitos desses compostos na área. 


\section{BIBLIOGRAFIA}

AHN, L.Y. Enhanced particle flux through the biodeposition by the Antarctic suspension-feeding bivalve Laternula elliptica in Marian Cove, King George Island. Journal of Experimental Marine Biology and Ecol., v. 171, p. $75-90,1993$.

ALBERS, P. H. Petroleum and individual polycyclic aromatic hydrocarbons. In: Hoffman, D. J.; Rattner, B. A.; Burton Jr. G. A.; Cairms Jr., J. (Eds.), Handbook of Ecotoxicology. Lewis Publishers, Boca Raton. p. 1-330, 1994.

ALBERS, P. H. Petroleum and individual policycyclic aromatic hydrocarbons. In: Hoffman, D. J.; Rattner, B. A.; Burton, G. A.; Cairns, J (Eds.). Handbook of ecotoxicology. Boca Raton : Lewis publishers, p. 330-355,1995.

ASOC - The Antarctic and Southern Ocean Coalition. O Krill conta: conservando a integridade do ecossistema antártico. / The Antarctic and Southern Ocean Coalition - Porto Alegre: Núcleo Amigos da Terra/Brasil / ASOC, 2007. 25 p.

ATCPS. Protocol on Environmental Protection to the Antarctic Treaty, with Annexes, Polar Record 29 (170): 256-275; SCAR Bulletin 110, julho, 1993.

ATCPS. A proposal prepared by Brazil and Poland, in co-ordination with Ecuador end Peru, that Admiralty Bay, King George Island (South Shetland Island) be designated as an Antarctic Specially Managed Area (ASMA). Twentieth Antarctic Treaty Consultative Meeting, Utrecht, Netherlands, 29 April -10 May, 1996. 
AU, D.W.T., WU, R.S.S., ZHOU, B.S., LAM, P.K.S. Relationship between ultrastructural changes and EROD activities in liver of fish exposed to benzo[a]pyrene. Environ. Pollution. v.104, p. 235-247, 1999.

BARGAGLI, R. Environmental contamination in Antarctic ecosystems. Science of the total environment, v. 400, p. 212-226, 2008.

BARRERA-ORO, E.R., WINTER, D.J.. Age composition and feeding ecology of early juvenile Notothenia rossii (Pisces, Nototheniidae) at Potter Cove, South Shetland Islands, Antarctica. Antarctic Science, v. 20, p. 339$341,2008$.

BATTAGLIA, B.; VALENCIA, J.; WALTON, D. W. H. Antarctic communities. International Council of Scientific Unions. Scientific Committee on Antarctic Research. 1997. 464 p.

BELLAS, J; ÁLVAREZ, L.S.; NIETO, Ó.; BEIRAS, R. Ecotoxicological evaluation of polycyclic aromatic hydrocarbons using marine invertebrate embryo-larval bioassays. Marine Pollution Bulletin, v. 57, p. 493-502, 2008.

BOULOUBASSI, I.; SALIOT, A. Investigation of anthropogenic and natural organic inputs in estuarine sediments using hydrocarbon markers (NAH, LAB, PAH). Oceanol. Acta, v. 16, p. 145-161, 1993.

BÍCEGO, M. C.; WEBER, R. R.; ITO, R. G. Aromatic Hydrocarbons on Surface Waters of Admiralty Bay, King George Island, Antarctica. Marine Pollution Bulletin, v. 32, p. 549-553, 1996.

BíCEGO, M. C.; ZANARDI, E.; ITO, R. G.; WEBER, R. R. Hydrocarbons in surface sediments of Admiralty Bay, King George Island, Antarctica, Peninsula. Pesquisa Antártica Brasileira, v. 3, p. 15-21, 1998. 
BíCEGO, M. C.; ZANARDI, E.; TANIGUCHI, S.; WEBER, R. R. Natural levels of dissolved/dispersed petroleum hydrocarbons in the South West Atlantic. Marine Pollution Bulletin, v. 44, p. 1152-1169, 2002.

BíCEGO, M.C., ZANARDI-LAMARDO, E.; WEBER, R.R. Four-year survey of dissolved/dispersed petroleum hydrocarbons on surface waters of Admiralty Bay, King George Island, Antarctica. Brazilian Journal of Oceanography, v. 51, p. 33-38, 2003.

BÍCEGO, M. C.; ZANARDI, E.; TANIGUCHI, S.; MARTINS,C. C.; SASAKI, S. T.; SILVA, D. A.M.; ALBERGARIA-BARBOSA, A. C. R.; PAOLO, F. S.; WEBER, R. R.; MONTONE, R. C. Results from a 15-year study on hydrocarbon concentrations in water and sediment from Admiralty Bay, King George Island, Antarctica. Antarctic Science, v. 21, p. 209-220, 2009.

CARDOSO, W. E. Morfologia e Ultraestrutura do Intestino do peixe Antártico Notothenia rossii Richardson 1844 e sua relação com o hábito alimentar. 2005. 115 p. Dissertação de mestrado. Universidade Federal do Paraná.

CETESB. Companhia de Tecnologia de Saneamento Ambiental. Sistema estuarino de Santos e São Vicente. (Relatório técnico CETESB). São Paulo:CETESB, 2001.

COMNAP (Council of Managers of National Antarctic Programs). 2008. Main Antarctic facilities operated by National Programs in the Antarctic Treaty area (south of 608S). Disponível em http://www.comnap. aq/facilities.

CONNEY, A.H. Introduction of microssomal enzymes by foreign chemicals and carcinogenesis by polycyclic aromatic hydrocarbons: G. H. A. Clowes 
memorial lecture. Cancer Research, v. 42, 4875-4917, 1982.

CORBISIER, T. N.; PETTI, M. A. V.; SKOWRONSKI, R. S. P.; BRITO, T. A. B.; Trophic relationships in the nearshore zone of Martel Inlet (King George Island, Antarctica): $d^{13} \mathrm{C}$ stable-isotope analysis. Pola Biology, v. 27, p. 75-82, 2004.

CULLEN, W. R.; LI, X. F.; REIMER, K. J. Degradation of phenanthrene and pyrene by microorganisms isolated from marine sediment and seawater. The Science of the Total Environ. v. 156, p. 27-37, 1994.

CLARKE, A.; LAW, R. Aliphatic and aromatic hydrocarbons in benthic invertebrates from two sites in Antarctica. Marine Pollution Bulletin, v. 12, p. 10-14, 1981.

CRIPPS, G. C. Problems in the identification of anthropogenic hydrocarbons against natural background levels in the Antarctic. Antarctic Science, v. 1, p. 307-312, 1989.

CRIPPS, G. C. Hydrocarbons in the seawater and pelagic organisms of the southern ocean. Polar Biol., v. 10, p. 393-402, 1990.

CRIPPS, G.C; J. PRIDDLE Review Hydrocarbons in the Antarctic marine environment. Antarctic Science, v. 3, p. 233-250, 1991.

CRIPPS, G. C.; PRIDDLE J., Hydrocarbon content of an Antarctic infaunal bivalve - historical record or life cycle changes? Antarctic Science, v. 7, p. 127-136, 1995.

CRIPPS, G. C.; SHEARS, J. The fate in marine environment of a minor diesel fuel spill from an Antarctic research station. Environ. Monit. And Asses., v. 46, p. 221-232, 1997.

COUILLARD, C.M.; LEE, K.; LEGARE, B.; KING, T.L. Effect of dispersant on 
the composition of the water-accommodated fraction of crude oil and its toxicity to larval marine fish. Environ. Toxicol. Chem., v. 24, p. 14961504, 2005.

CUCCI, T.L., EPIFANIO, C.E. Long-term effects ofwater-soluble fractions of Kuwait crude-oil on the larval and juvenile development of the mud crab Eurypanopeus depressus. Mar. Biol., v.55, p. 215-220, 1979.

CURTOSI, A.; E.P.; VODOPIVEZ, C. L.; CORMACK, W.P.M. Distribution of PAHs in the water column, sediments and biota of Potter Cove, South Shetland Islands, Antarctica. Antarctic Science, v. 21, p. 329-339, 2009.

DAVENPORT, J. Feeding, oxygen uptake, ventilation rate and shell growth in the Antarctic protobranch bivalve mollusc Yoldia eightsi (Couthouy). In HEYWOOD, R. B. ed. Proceedings of British Antarctic Survey Antarctic special topic award scheme symposium, 9-10 November 1988. Cambridge: British Antarctic Survey, p. 57-64.

DAVIS, P.H.; SCHULTZ, T.W.; SPIES, R.B. Toxicity of Santa Barbara seep oil to starfish embryos. Part 2. The growth bioassay. Mar. Environ. Res., v. 5, p. 287-294, 1981.

DAYTON, P. K., ROBILLIARD, G. A., PAINE, R.T., DAYTON, L. B. Biological accomodation in the benthic community at McMurdo Sound, Antarctica. Ecol. Monogr, v. 44, p. 105-128, 1974.

DAYTON, P. K.; WATSON, D.; PALMISANO, A.; BARRY, J. P.; OLIVER, J. S.; RIVERA, D. Distribution patterns of benthic microalgal standing stock at McMurdo Sound, Antarctica. Polar Biology, v. 6, p. 207-213, 1986.

DEARBORN, J.H. Foods and Feeding Characteristic of Antarctic Asteroids and 
Ophiunotus. The Proceedings of the Third SCAR Symposium on Antarctic Biology, 1977.

DEARBORN, J.H. Food and reproduction of Glyptonotus antarcticus (Crustacea: Isopoda) at McMurdo, Sound, Antarctica. Trans. R. Soc. N.Z. Zool., v. 8:15, p. 163-168, 1967.

DENOUX, G. J., GARDINALI, P. \& WADE, T. L. Quantitative determination of polynuclear aromatic hydrocarbons by gas chromatography/mass spectrometry - selected ion monitoring (SIM) mode. NOAA Technical Memorando NOS ORCA, v. 130, p. 129-139, 1998.

DUNTON, K. H. $\delta^{15} \mathrm{~N}$ and $\delta^{13} \mathrm{C}$ measurements of Antarctica Peninsula Fauna: Trophic relationships and assimilation of benthic seaweeds. American Zoologist, v. 41, p. 99-112, 2001.

ECA (Action Group on Environmental Contamination in Antarctica). POPs in the Antarctic Environment: A Review of Findings, by the SCAR, 2009.

EISLER, R. Polycyclic aromatic hydrocarbon hazards to fish, wildlife, and invertebretes: a synoptic review. U.S. Fish and Wildlife Service, U.S. Department of the Interior. Biological report, v. 85, p. 1-11, 1983.

EHRHARDT, BURNS; K. A.; BÍCEGO, M. C. Sunlight-induced compositional alterations in the seawater-soluble fraction of a crude oil. Marine Chemistry, v. 37, p. 53-64, 1992.

FRATT, D. B.; DEARBORN, J. H. Feeding Biology of the Antarctic Brittle Star Ophionotus victoriae (Echinodermata: Ophiuroidea). Polar Biol 3: 127139, 1984.

FUOCO, R.; CAPODAGLIO, G.; MUSCATELLO, B.; RADAELLI, M. Persistent Organic Pollutants (POPs) in the Antarctic environment: A Review of 
Findings. The SCAR Action Group on Environmental Contamination in Antarctica (ECA), 2009. 98 p.

GOKSOYR, A., HUSOY, A.M., LARSEN, H.E., KLUNGSOYR, J., WILHELMSEN, S., MAAGE, A., BREVIK, E.M., ANDERSSON, T., CELANDER, M., PESONEN, M. AND FORLIN, L., Environmental contaminants and biochemical responses in flatfish from the Hvaler Archipelago in Norway. Arch. Environ. Toxicol., v. 21, p. 486, 1991.

GON, O. \& P. C. HEEMSTRA. Fishes of the Southern Ocean. J.L.B. Smith Institute of

Ichthyology, Grahamstown, 462 p.1990.

GREBMEIER J. M.; BARRY J. P. The influence of oceanographic processes on pelagic-benthic coupling in polar regions: a benthic perspective. Journal of Marine Systems, v. 2, p. 495-518, 1991.

HARRISON A.P., RAABE V.E. Factors influencing photodynamic action of benzo[a]pyrene on Escherichia coli; J. Bacteriol., v. 93, p. 618-626, 1967.

HARRISON, P. 1985. Seabirds, an identification guide. Revised edition, 1985. Houghton Mifflin Company.

HARITASH, A. K.; KAUSHIK, C. P. Biodegradation aspects of Polycyclic Aromatic Hydrocarbons (PAHs): A review. Journal of Hazardous Materials, v. 169, p. 1-15, 2009.

Harvey, R.G. Polycyclic Aromatic Hydrocarbons. Wiley-VCH, New York, Chichester, Weinheim, Brisbane, Singapore, Toronto. 1997.

HIGGINS, P.J. \& DAVIES, S.J.J.F. (Eds) Handbook of Australian, New Zealand 
\& Antarctic birds, v.3 Snipe to Pigeons. Melbourne: Oxford University Press. 1996.

HUMPHREY, P.S., BRIDGE, D., REYNOLDS, P.W.; PETERSON, R. 1970. Birds of Isla Grande (Tierra del Fuego). Washington, D.C.: Smithsonian Institution.

IARC (International Agency for Research on Cancer), Polynuclear aromatic hydrocarbons, Part I, environmental and experimental data. Manographs on the evaluation of the carcinogenic risk of chemicals to humans, v.32, 1983.

IARC Monographs on the Evaluation of the Carcinogenic Risk of Chemicals to Humans, v. 38. Tobacco Smoking. International Agency for Research on Cancer, Lyon. p. 12-20; 86, 87, 101, 111, 116, 387- 394, 1986.

INCT - Instituto nacional de tecnologia antártico de pesquisas ambientais, 2009.

Disponível em (http://www.inct-antartico.com.br/?p=124).

JAFFÉ, R. Fate of hidrophobic organic pollutants in the aquatic environment: A review. Environmental Pollution, v. 69, p. 237-257, 1991.

JERINA, D.M.; THAKKER, D.R.; YAGI, H. Carcinogenicity of benzo(a)pyrene derivates: the bay region theory. Pure and Applied Chemistry, v. 50, p. 1033-1044, 1978.

JOHNS, D.M., PECHENIK, J.A. Influence of the water-accommodated fraction of No. 2 fuel oil on energetics of Cancer irroratus larvae. Mar. Biol., v. 55, p. 247-254, 1980.

JOHNSTONE, G.W., LUGG, D.J. \& BROWN, D.A. 1973. The biology of the Vestfold Hills, Antarctica. ANARE Scientific Reports. Series B(1). Zoology. Publication No. 123. 
JOVANOVICH, M.C., MARION, K.R. Seasonal variation in uptake and depuration of antracene by the brackish water clam Rangia cuneata. Mar. Biol., v. 95, p. 395-403,1987.

KAEHLER, S.; PAKHOMOV, E. A.; MCQUAID, C. D. Trophic structure of the marine food web at the Prince Edward Islands (Southern Ocean) determined by $\delta^{13} \mathrm{C}$ and $\delta^{15} \mathrm{~N}$ analysis. Marine Ecology Progress Series, v. 208, p. 13-20, 2000.

KENNICUTT II, M. C.; SWEET, S. T.; FRASER, W. R.; STOCKTON, E. L.; CULVER, M., Grounding of the Bahia Paraiso at Arthur Harbor, Antarctica. 1. Distribution and fate of oil spill Environ. Sci. Technol., v. 25, p. 509-518, 1991.

KENNICUTT II M. C.; SWEET, S. T. Hydrocarbons contamination on the Antarctic Peninsula. The Bahia Paraíso - two years after the spill. Marine Pollution Bulletin, v. 25, p. 303-306, 1992.

KENNICUTT II, M.C., McDONALD, T.J; DENOUX; G. J.; McDONALD, S. J. Hydrocarbon Contamination on the Antarctic Peninsula II. Arthur Harbor Inter and Subtidal Limpets (Nacella concinna). Marine Pollution Bulletin, v. 24, p. 506-511, 1992.

KENNICUTT II, M. C.; MCDONALD, S. J.; SERICANO, J. L.; BOOTHE, P.; OLIVER, J.; SAFE, S.; PRESLEY, B. J.; LIU, H.; WOLFE, D.; WADE, T. L.; CROCKETT, A.; BOCKUS, D. Human contamination of the marine environment - Arthur Harbor and McMurdo Sound, Antarctica. Environment and Science and Technology, v. 29, p. 1279-1287, 1995. KENNISH, M.J. Practical Handbook of Estuarine and Marine Pollution. CRC Press, Boca Raton, Florida, USA. 544 p, 1996. 
KOCK, K. H. Antartic Fish and Fisheries. Cambridge: University Press, 1992. $359 \mathrm{p}$.

KUSSAKIN, O.G.. Isopoda and Tanaidacea from the coast zones of the Antarctic and Subantarctic. Biological Results of the Soviet Antarctic Expedition (1955-1958), 3. Issledovaniya Fauny Morei, v. 4:12, p. 220$380,1967$.

LATIMER, J.S. \& ZHENG, J. The sources, transport, and fate of PAHs in the marine environment. In: PAHs: An ecotoxicological perspective. John Wiley \& Sons, Ltd. ISBN: 0-471-56024-3, p. 9-33: 389, 2003.

LAW, R. J.; BISCAYA, J. L. Polycyclic Aromatic Hydrocarbons (PAH)-Problems and Progress in Sampling Analysis and Interpretation. Marine Pollution Bulletin, v. 29, p. 235-241, 1994.

LEMKE, M.A., KENNEDY, C.J. The uptake, distribution and metabolism of benzo(a)pyrene in coho salmon (Oncorhynchus kisutch) during the parrsmolt transformation. Environ. Toxicol. Chem., v. 16, p. 1384-1388, 1997.

LEWIS, C.; Pook, C.; Galloway, T. Reproductive toxicity of the water accommodated fraction (WAF) of crude oil in the polychaetes Arenicola marina (L.) and Nereis virens (Sars). Aquatic Toxicology, v. 90, p. 7381, 2008.

LOCATELLI, M. A. F. Investigação sobre a emissão e caracterização dos hidrocarbonetos policíclicos aromáticos (HPA) na bacia do rio Atibaia. 2006. 70 p. Dissertação de mestrado, UNIVERSIDADE ESTADUAL DE CAMPINAS, SP.

LUXMOORE, R.A. Moulting and growth in serolid isopods. J. e.up. mar. Biol. 
Ecol., v. 56, p. 63-85, 1982.

LUXMOORE, R. A. The energy budget of a population of the antarctic isopod Serolis polita. In Antarctic Nutrient Cycles and Food Webs (Siegfried, W. R., Condy, P. R. \& Laws, R. M., eds). Springer-Verlag, Berlin, p. 389396, 1985.

MAZUROVÁ, E.; HILSCHEROVÁ, K.; JÁLOVÁ, V.; KÖHLER, H.-R.; TRIEBSKORN, R. ; GIESY, J.P.; BLÁHA, L. Endocrine effects of contaminated sediments on the freshwater snail Potamopyrgus antipodarum in vivo and in the cell bioassays in vitro. Aquatic Toxicology, v. 89: 3, 17, p. 172-179, 2008.

MCDONALD, S. J.; KENNICUTT II, M. C.; BROOKS, J. M. Evidence of Polycyclic Aromatic Hydrocarbon (PAH) Exposure in Fish from the Antarctic Peninsula, Mar. Pollut. Bull., v. 25, p. 313-317, 1992.

MCDONALD, S. J.; KENNICUTT II, M. C.; SERICANO, J.; WADE, T. L.; LIU, H.; SAF, S. H. Correlation between bioassay-derived P4501Al induction activity and chemical analysis of clam (Laternula elllptica) extracts from McMurdo Sound, Antarctica. Chemosphere, v. 28, p. 2237-2248, 1994.

MACKAY, D. \& FRASER, A. Bioaccumulation of persistent organic chemicals: mechanisms and models. Env. Pollution. v. 110, p. 375-391. 2000.

MADSEN, F. J. Ophiuroidea. B.A.N.Z. Antarctic Research Expedition (19291931) under the Command of Sir Douglas Mawson. Rep Ser B, v. 9, p. 123-145, 1967.

MACLEOD, W.D.; BROWN, D.W.; FRIEDMAN, A.J.; BURROWS, D.G.; MAYNES, O.; PEARCE, R.W.; WIGREN, C.A.; BOGAR, R.G. Standard Analytical Procedures of the NOAA National Analytical Facility, 1985- 
1986. In: Extractable Toxic Organic Compounds (2nd Edn. ed.), NOAA Tech. Memorandum NMFS F/NWC-92, US Department of Commerce, 1986.

MÄENPÄÄ, K.; LEPPÄNEN, M.T.; KUKKONEN, J.V.K. Sublethal toxicity and biotransformation of pyrene in Lumbriculus variegatus (Oligochaeta). Science of the Total Environment, v. 407, p. 2666-2672, 2009.

MARTINS, C. C.; BÍCEGO, M. C.; TANIGUCHI, S.; MONTONE, R. C., Aliphatic (Ahs) and Aromatic Hydrocarbons (PAHs) in surface sediments in Admiralty Bay, King George Island, Antarctica: A regional survey of organic contaminants resulting from human activity. Antarctic Science, v. 16, p. 117-122, 2004.

MARTINS, C. C., M.C.B.; ROSE, N. L.; TANIGUCHI, S.; LOURENÇO, R. A.; FIGUEIRA, R.C.L., MAHIQUES, M. M., MONTONE, R. C. Historical record of polycyclic aromatic hydrocarbons (PAHs) and spheroidal carbonaceous particles (SCPs) in marine sediment cores from Admiralty Bay, King George Island, Antarctica. Environmental Pollution, v. 158, p. $192-200,2010$.

MEADOR, J. P.; STEIN, J. E.; REICHERT, W. L.; VARANASI, U. Bioaccumulation of polycyclic aromatic hydrocarbons by marine organisms. Rev. Environ. Contamin. v. 143, p. 79-165, 1995.

MCCLINTOCK, J.B., PEARS, J.S., \& BOSH, I., , Population Structure and Energetics of the Shallow-Water Antarctic Sea Star Odontaster validus in Contrasting Habitats, Mar. Biol., v. 99, p. 235-246. 1988.

MCCLINTOCK, J.B. Trophic biology of antarctic shallow-water echinoderms. Marine Ecology Progress Series, v. 111, p. 191-202, 1994. 
MCGONIGAL. D. Antarctica. 2009. 400 p.

MIDDAUGH, D.P.; WHITING, D.D. Responses of embryonic and larval inland silversides, Menidia beryllina, to No. 2 fuel oil and oil dispersants in seawater. Arch. Environ. Contam. Toxicol., v. 29, p. 535-539, 1995.

MODICA, R.; FIUME, M.; GUAITANI, A. \& BARTOSEK, I. Comparative kinetics of benz(a)anthracene, chrysene and triphenylene in rats after oral administration. I. Study with single compounds. Toxicology Letters, v. 18, p. 103-109, 1983.

MONTONE, R.C.; TANIGUCHI, S.; WEBER, R.R. PCBs in the atmosphere of King George Island, Antarctica, Science of the Total Environ., v. 308, p. 167-173, 2003.

MURPHY, R.C. Oceanic birds of South America. New York: American Museum of Natural History. 1936.

MORIMURA, Y.; KOTIN, P.; FALK, H.L. Photodynamic toxicity of polycyclic aromatic hydrocarbons in tissue culture; Cancer Res., v. 24, p. 12491256, 1964.

NEFF, J. M. Polycyclic aromatic hydrocarbons in aquatic environment: sources, fates and biological effects. Applied Science. Essex, Engrand, 1979.

NETO, J. A. Determinação e interpretação de características glaciológicas e geográficas com sistema de informações geográficas na área Antártica Especialmente Gerenciada Baía do Almirantado, Ilha Rei George, Antática. 2001. 98p. Dissertação de mestrado da Universidade Federal do Rio Grande do Sul.

NYBAKKEN, J.W. Marine Biology: An Ecological Approach (4th edition). Addison-Wesley Educational Publishers Inc., USA, 1997, 
OLIVER, B. G.; NIIMI, A. J. Trophodynamic analysis of polychlorinated biphenyl congeners and other chlorinated hydrocarbons in the Lake Ontario ecosystem. Environmental Science and Technology., v. 22, p. 338$343,1988$.

ORIS, J.T.; GIESY, J.P.J., The photo-induced toxicity of polycyclic aromatic hydrocarbons to larvae of the fathead minnow (Pimepheles promelas). Chemosphere, v. 16, p. 1395-1404, 1987.

PAYNE, J. F.; KICENIUK, J.; FANCEY, L. L.; WILLIAMS, U.; FLETCHER, G. L.; RAHIMTULA, A.; FOWLER, B. What is a safe level of polycyclic aromatic hydrocarbons for fish: Subchronic toxicity study on winter flounder (Pseudopleuronectes americanus). Canadian Journal of Fisheries and Aquatic Science, v. 45, p. 1983-1993, 1988.

PAYNE, J. F.; FANCEY, L.F. Effect of Polycyclic Aromatic Hydrocarbons on ImmuneResponses in Fish: Change in Melanomacrophage Centers in Flounder (Pseudopleuronectes americanus) Exposed to HydrocarbonContaminated Sediments. Marine Environmental Research, v. 28, p. 431-435, 1989.

PAYNE, J.R., CLAYTON, J.R., MCNABB, G.D., KIRSTEIN, B.E., Exxon Valdez oilweathering fate and behaviour: model prediction and field observation. In: Proceeding of 1991 International Oil Spill Conference, American Petroleum Institute,Washington, DC, 1992.

PERUGINI, M.; VISCIANO, P.; GIAMMARINO, A.; MANERA, M.; DI NARDO, W.; AMORENA, M. Polycyclic aromatic hydrocarbons in marine organisms from the Adriatic Sea, Italy. Chemosphere, v. 66, p. 19041910, 2007. 
PLATT, H. M.; MACKIE, P. R. Distribution of aliphatic and aromatic hydrocarbons in Antarctic fauna and environment, Helgoliinder Meeresuntersuchungen, v. 33, p. 236-245, 1980.

PLATT, H.M.; MACKIE, P.R. Sources of Antarctic Hydrocarbons. tlarine Pollution Bulletin, v. 12, p. 407-409, 1981.

POVERO, P.; CHIANTORE, M.; MISIC, C.; BUDILLON, G.; CATTENEOVIETTI, R. Land forcing controls pelagic-benthic coupling in Adelie Cove (Terra Nova Bay, Ross Sea). Polar Biology, v.24, p. 875-882, 2001.

PRESLER, P., 1986, Necrophagous invertebrates of the Admiralty Bay of King George Island (South Shetland Islands, Antarctica). Pol. Polar Res., v. 7, p. 25-61.

RAKUZA-SWAZCZEWSKI, S. Environmental conditions and functioning of Admiralty Bay (South Shetland Islands) as part of the nearshore Antarctic ecosystem. Polish Polar Research, v.1, p.11-27, 1980.

RAKUSA-SUSZCZEWSKI, S. The hydrography of Admiralty Bay and its inlets, coves and lagoons (King George Island, Antarctica). Polish Polar Research, v.16, p.61-70, 1995.

Relatório Rede 2. Gerenciamento Ambiental na Baía do Almirantado, llha Rei George, Antártica. 259 p 2006.

REINHARDT, K., HAHN, S., PETER, H.-U. \& WEMHOFF, H. A review of the diets of Southern Hemisphere skuas. Marine Ornithology 28: 7-19, 2000. ROCHKIND, M.L.; BLACKBURN, J.W., SAYLER, G.S. Microbial decomposition of chlorinated aromatic compounds. United States Environmental Protection Agency, EPA/600/2-86/090, Cincinnati, 1986.

RUSSELL, F. S.; YONGE, M. Advances in marine biology, 559 p., 1972. 
SCHANTZ, M. $\quad$ M.; $\quad$ PARRIS, R. $\quad$ M.; $\quad$ KURZ, J.; $\quad$ BALLSCHMITER, K.; WISE, S.A. Comparison of methods for the gas-chromatographic determination of PCB congeners and chlorinated pesticides in marine reference materials. Fresenius' journal of analytical chemistry, v. 346:6-9, p. 766-778, 1993.

SCAR KGIS The King George Island GIS Project, 2009. Disponível em http://www.kgis.scar.org/index.php?number=29

SERICANO, J.L. Quantitative determination of chlorinated hydrocarbons by gas chromatography/electron capture detection. Geochemical and Environmental Research Group, Standard Operating Procedures (SOP9810), p. 21, 1998.

SERICANO, J.L., BROOKS, J.M., CHAMP, M.A., KENNICUTT, M.C., MAKEYEV, Y.V. Trace contaminant concentrations in the Kara Sea and its adjacent rivers, Russia. Mar. Pollut. Bull, v. 42, p. 1017-1030, 2001.

SERICANO, J.L.; WADE, T.L.; JACKSON, T. J.; BROOKS, J. M.; TRIPP, B. W.; FARRINGTON; J. W.; READMANN, J.W. MEE, L. D., VILLENEUVE, J.P.; GOLDBERG, E. D. Trace Organic Contamination in the Americas: An Overview of the US National Status \& Trends and the International 'Mussel Watch' Programmes. Marine Pollution Bulletin, v. 31, p. 214225, 1995.

SHEPPARD, E. Isopod Crustacea. Part I. The Family Serolidae. Discover, Rep., v.7, p. 253-362, 1933.

SOAVE, G., CORIA, N. R.; MONTALTI, D. Diet of the pintado petrel Daption capense during thelate incubation and chick-rearing periods at Laurie island, South Orkney Island, Antarctica, january-february 1995. Marine 
Ornithology, v. 24, p.35-37, 1996.

SMITH, E.L.; ROWLAND, R.S.; GALLOWAY, T.S.; SCARLETT, A. Potential ecological effects of chemically dispersed and biodegraded oil: evaluation of components and concentrations relevant to policy decisions. Maritime and Coast Guard Agency, UK. Report No. 562, 2006. Disponível em http://www.mcga.gov.uk/c4mca/rp562 final report.pdf.

STEELE, J. H.; THORPE, S. A.; TUREKIAN, K. K. Marine Biology, 630 p., 2009.

SCHREIBER, E. A.; BURGER,.J. Biology of marine birds. 2002. 722 p.

SUMICH, J. L.; MORRISSEY, J. F. Introduction to the biology of marine life. 449 p. 2004.

TANiguCHI, S.; MONTONE, R. C.; BíCEGO, M. C.; COLABUONO, F. I.; WEBER, R. R.; SERICANO, J. L. Chlorinated pesticides, polychlorinated biphenyls and polycyclic aromatic in the fat tissue of seabirds from King George Island, Antarctica. Marine Pollution Bull., v. 58, p. 129-133, 2009.

TARVERDYIEVA, M. I. Daily food consumption and feeding pattern of the South Georgian cod (Notothenia rossii marmorata) and the Patagonian toothfish (Dissostichus eleginoides) in the South Georgia area. J. Ichthyol., Bethesda, v. 12, n. 4, p. 684-692, 1972.

THURSTON, M. H. Notes on the life history of Bovallia gigantea (Pfeffer) (crustacea, amphipoda), Br. Antarct. Surv. Bull., v. 16, p. 57-64, 1968.

UNEP (United Nations Environment Programme). Determinations of petroleum hydrocarbons in sedment. Reference methods for marine pollution studies. n. 20, p. 97, 1991. 
UNEP (United Nations Environment Programme Chemicals). Regionally Based Assessment of Persistent Toxic Substances. Antarctica Regional Report, p. 86, 2002.

VANDERMEULEN, J. H.; FODA, A.; STUTARD, C. Toxicity vs mutagenicity of some crude oils, distillates and their water soluble fractions. Water Res., v.19, p. 1283-1289, 1985.

VARANASI, U.; STEIN, J. E.; NISHIMOTO, M. Biotransformation of PAH in fish. In: Varanasi, U. Metabolism of polycyclic aromatic hydrocarbons in the aquatic environment. Florida: Boca Raton - CRC Press, p. 93-150, 1989.

VERWEIJ, F.; KEES, K.B.; SATUMALAY, K.; MOLEN, N.; VAN DER OOST, R., Assessment of bioavailable PAH, PCB and OCP concentrations in water, using semipermeable membrane devices (SPMDs), sediments and caged carp, Chemosphere, v. 54, p. 1675-1689, 2004.

WADE, T.L.; CANTILLO, A.Y. Use of standards and reference materials in the measurement of chlorinated hydrocarbon residues. Chemistry Workbook. NOAA Technical Memorandum NOS ORCA 77, Silver Spring, Maryland, p. 59, 1994.

WALKER, A. J. M., Introduction to the ecology of the Antarctic limpet Patinigera polaris (Hombron \& Jacquinot) at Signy Island. South Orkney Islands. Br. Antarct. Surv. Bull., v.28, p. 49-71, 1972.

WALKER, C.H. Organic Pollutantes: Polycyclic aromatic hydrocarbons, por Francis \& Taylor Inc, E.U.A. e Canadá. v. 9, p. 274, 2001.

WARHAM, J. 1990. The petrels: their ecology and breeding systems. London: Academic Press. 
WEBER, R. R.; BíCEGO, M. C. Petroleum aromatic hydrocarbons in surface waters around Elephant Island, Antarctic Peninsula. Marine Pollution bulletin, v. 21, p. 448-449, 1990.

WOEHLER, E. J.; PONCET, S. The Distribution and abundance of Antarctic and Subantarctic penguins. International Council of Scientific Unions. Scientific Committee on Antarctic Research. 1995. 76 p.

WAN, X. J.; JIANYING, H.U.; FEN, J.I.N. Trophic Dilution of Polycyclic Aromatic Hydrocarbons (PAHs) in a Marine Food Web from Bohai Bay, North China. Environ. Sci. Technol., v. 41, p. 3109-3114, 2007.

YU, H. Envoronmental Carcinogenic Polycyclic Aromatic Hydrocarbons: Photochemistry and Phototoxicity. Journal of Environmental Science and Health, Part C, v. 20:2, p. 149-183, 2002. 